\title{
Umbilical cord occlusions in fetal sheep
}

Citation for published version (APA):

Keunen, J. E. G. M. (2000). Umbilical cord occlusions in fetal sheep: the effect of asphyxia on fetal heart and brain. [Doctoral Thesis, Maastricht University]. Universiteit Maastricht. https://doi.org/10.26481/dis.20000929jk

Document status and date:

Published: 01/01/2000

DOI:

10.26481/dis.20000929jk

Document Version:

Publisher's PDF, also known as Version of record

\section{Please check the document version of this publication:}

- A submitted manuscript is the version of the article upon submission and before peer-review. There can be important differences between the submitted version and the official published version of record.

People interested in the research are advised to contact the author for the final version of the publication, or visit the DOI to the publisher's website.

- The final author version and the galley proof are versions of the publication after peer review.

- The final published version features the final layout of the paper including the volume, issue and page numbers.

Link to publication

\footnotetext{
General rights rights.

- You may freely distribute the URL identifying the publication in the public portal. please follow below link for the End User Agreement:

www.umlib.nl/taverne-license

Take down policy

If you believe that this document breaches copyright please contact us at:

repository@maastrichtuniversity.nl

providing details and we will investigate your claim.
}

Copyright and moral rights for the publications made accessible in the public portal are retained by the authors and/or other copyright owners and it is a condition of accessing publications that users recognise and abide by the legal requirements associated with these

- Users may download and print one copy of any publication from the public portal for the purpose of private study or research.

- You may not further distribute the material or use it for any profit-making activity or commercial gain

If the publication is distributed under the terms of Article $25 \mathrm{fa}$ of the Dutch Copyright Act, indicated by the "Taverne" license above, 


\section{Umbilical cord occlusions in fetal sheep}

the effect of asphyxia on fetal heart and brain

\section{Proefschrift}

ter verkrijging van de graad van doctor aan de Universiteit Mastricht.

op gezag van de Rector Magnificus.

Prof. dr. A.C. Nieuwenhuijzen Kruseman. volgens het besluit van het College van Decanen, in het openbaar te verdedigen op vrijdag 29 september 2000 om 14.00 uur door

Johannes Elisabeth Gerardus Maria Keunen geboren op 27 december 1965 
Promotor

Prof. dr. J. de Haan

Co-Promotor

dr. T.H.M. Hasaart

Beoordelingscommissie

Prof. dr. J. Troost (voorzitter)

Prof. dr. C.E. Blanco

Prof. dr. M. Borgers

Prof. dr. A. Jensen (Ruhr-Universitaet Bochum)

Prof. dr. H. Vles

Prof. dr. G. Visser (Universiteit Utrecht)

ISBN 90-5681-085-5

De publicatie van dit proefschrift werd mede mogelijk gemaakt door: Astra Zeneca en Ferring. 
De kins het mets neet in het verke loate staeke

Voor Door, Pierre en Lon 


\section{Contents}

Chapter 1 General introduction

page 1

Chapter 2 Umbilical cord occlusion and asphyxia: a review of the literature page II

Chapter 3 Absence of neuronal damage after umbilical cord occlusion of 10,15 and 20 minutes in midgestation fetal sheep

page 51

Chapter 4 Transient umbilical cord occlusion in late gestation fetal sheep results in hippocampal damage but not in cerebral arterio-venous difference for nitrite, a stable end product of NO

page 67

Chapter 5 Fetal arterial pressure and heart rate changes in surviving and non-surviving immature fetal sheep following brief repeated total umbilical cord occlusions

Chapter 6 The effect of repetitive umbilical cord occlusions on neuronal brain activity measured by the Cerebral Function Analysing Monitor and histological outcome in immature fetal sheep page 103

Chapter 7 The PR interval-fetal heart rate relationship during repetitive umbilical cord occlusions in immature fetal sheep page 117

Chapter 8 Summary and discussion page 131

Hoofdstuk 8 Samenvatting en discussie page 139

Curriculum Vitae page 147

Dankwoord 



\section{Chapter 1}

\section{General introduction}

Asphyxia \& Cerebral Palsy: A Confusion of Tongues 


\section{General introduction}

\section{Asphyxia}

Asphyxia, meaning "pulseless", results from the impairment of gaseous exchange and can occur before, during and after the birth process. However, the criteria by which asphyxia is identified vary greatly between observers. The incidence of asphyxia has been reported to be between 0.29 and $0.9 \%$ depending on the inclusion criteria and the population studied (Levene 1985). Which parameters can be used to identify fetal asphyia?

\subsection{Electronic fetal monitoring}

The fetal heart rate pattern can be recorded internally (direct), using a bipolar electrode directly attached to the fetus, or externally (indirect) by placement of an ultrasound doppler probe on the maternal abdomen to record fetal heart motions. Soon after its introduction, fetal heart rate monitoring (or electronic fetal monitoring (EFM)) was used as the primary method of fetal surveillance during labor in a effort to reduce perinatal morbidity and mortality (Hon 1959). Reasuring fetal heart rate patterns with a baseline fetal heart rate between 110 and 150 beats per minute, a variability of more than 10 beats per minute and the presence of accelerations are considered to represent fetal well-being and normoxia (American College of Obstetricians and Gynecologists (ACOG) 1995). Distinct decelerative periodic fetal heart rate changes were described. The most common decelerations encountered during the labor process are variable decelerations. Variable decelerations are elicited during the descent of the fetus and probably the result of compression of the umbilical cord. Release of amniotic fluid, a diminished amniotic fluid volume, loops of the umbilical cord around the fetal neck, very short and long umbilical cords are all associated with a higher incidence of variable decelerations. Variable decelerations are generally considered benign, although significant variable decelerations, decreasing to less than 70 beats per minute and lasting more than 60 seconds may indicate fetal compromise. Late decelerations are uniform in shape and begin 30 seconds or later after the onset of the uterine contraction. Late decelerations are presumed to represent uteroplacental hypoxia. Experimental studies in fetal monkeys and sheep propose that late decelerations are mediated by chemoreceptor vagal activity and myocardial depression during hypoxia (Harris 1982; Myers 1973; de Haan J 1979, 1981; Martin 1979). Late decelerations can be caused by maternal hypotension, uterine hyperactivity or placental 
dysfunction and are considered to reflect fetal compromise. A decrease or absent variability of fetal heart rate ( $<5$ beats per minute) is considered indicative for fetal compromise (Hammacher 1968).

\subsection{Acidemia}

Acidemia can be defined as an increased concentration of hydrogen ions in the blood and is normally expressed as $\mathrm{pH}$ according to the Henderson-Hasselbach equation:

$$
p H=p K+\log \frac{\mathrm{HCO}_{3}}{\mathrm{H}_{2} \mathrm{CO}_{3}}
$$

Normally the $\mathrm{pH}$ in human fetuses is approximately 7.35 in the umbilical artery and 7.38 in the umbilical vein (Longo 1987). During labor an estimate of the fetal acid-base status can be made using fetal scalp blood sampling (Saling 1962). The pH of the capillary blood, sampled after a small incision of the fetal scalp, is usually lower than the $\mathrm{pH}$ in the umbilical vein and approaches the $\mathrm{pH}$ of the umbilical arteries. If placental exchange of blood gases is interrupted as occurs in umbilical cord occlusions, the accumulation of $\mathrm{CO}_{2}$ in the fetal blood will result in a respiratory acidemia as $\mathrm{pH}$ will fall due to metabolizing $\mathrm{CO}_{2}$ into $\mathrm{H}_{2} \mathrm{CO}_{3}$. When hypoxia is sustained organic acids like lactate are produced as the result of anaerobic glycolysis. Consequently, the concentration of $\mathrm{HCO}_{3}$ will decrease as it is used to buffer the produced acids, thus leading to a metabolic acidemia. When both causes of acidemia prevail, an increased concentration of $\mathrm{H}_{2} \mathrm{CO}_{3}$ and decreased concentration of $\mathrm{HCO}_{3}$, it is referred to as a mixed acidemia.

$$
\begin{aligned}
& \downarrow p H=p K+\log \frac{\mathrm{HCO}_{3}}{\uparrow \mathrm{H}_{2} \mathrm{CO}_{3}} \quad=\text { respiratory acidemia } \\
& \downarrow p H=p K+\log \frac{\downarrow \mathrm{HCO}_{3}}{\mathrm{H}_{2} \mathrm{CO}_{3}} \quad=\text { metabolic acidemia } \\
& \downarrow p H=p K+\log \frac{\downarrow \mathrm{HCO}_{3}}{\downarrow_{\mathrm{H}} \mathrm{CO}_{3}} \quad=\text { mixed acidemia }
\end{aligned}
$$




\section{General introduction}

When confronted with an abnormal fetal heart rate tracing, the use of serial sampling of micro-amounts of fetal scalp during labor enables the obstetrician to identify fetuses with or without fetal acidemia. However, the procedure is cumbersome, invasive, and only represents fetal acid-base status at a certain timepoint. Therefore, non-invasive, continuous measurements of fetal acid-base status are under investigation.

\subsection{Meconium stained amniotic fluid}

The presence of meconium stained amniotic fluid and an auscultatory abnormal fetal heart rate were criteria of fetal distress before the advent of electronic fetal monitoring. Vagal stimulation has been associated with the passage of meconium in utero in the term fetus and is as such regarded to be a physiological phenomenon (Matthews 1979). In concordance with this view, meconium staining of the amniotic fluid is reported in 12 to $22 \%$ of human labors (Katz 1992). On the other hand, pathophysiologically the passage of meconium is thought to be triggered by hypoxia and is therefore regarded as a sign of fetal compromise (Walker 1953) or a transient period of umbilical cord occlusion (Hon 1961). A second detrimental role of meconium is attributed to its direct vasoconstrictive effect on the umbilical vessels (Naeye 1995). Recently, a combined hypothesis was proposed regarding meconium aspiration. The presence of meconium stained amniotic fluid is regarded physiological but when supervened by acidemia or asphyxia it may become an environmental hazard with the risk of meconium aspiration (Ramin 1996).

\subsection{Apgar Score}

Virginia Apgar described in 1953 the scoring system and intended it to be used as 1) a tool for the quantification of the neonatal condition and 2) for the comparison of the results of obstetrical practices and the effects of resuscitation (Apgar 1953). The Apgar score is a quick method of assessing the state of the newborn and comprises five components: heart rate, respiratory effort, tone, reflex irritability and color, each of which can be given a score of 0,1 or 2 . 


\begin{tabular}{||cccc|}
\hline & Apgar scoring system (Apgar, 1953) & & \\
\hline & 0 & 1 & 2 \\
\hline Heart Rate & Absent & $<100$ & $>100$ \\
\hline Respiratory Effort & Absent & Slow, irregular & Good crying \\
\hline Muscle Tone & Flaccid & Some flexion & Active motion \\
\hline Reflex Irritability & No response & Grimace & Vigorous cry \\
\hline Color & Blue, pale & Extremities blue & Completely pink \\
\hline
\end{tabular}

The score is normally assessed 1 and 5 minutes after bitth and repeated thereafter every 5 minutes when resuscitation is needed. The 1-minute Apgar score indicates the neonate in need of resuscitation. The 5 minutes score indicates if resuscitation efforts were successful. A score of $\geq 7$ after 5 minutes is considered normal, between 3 and 7 intermediate, and a score of $\leq 3$ abnormal. Beside perinatal asphyxia, the Apgar score can be influenced by numerous factors such as the maturity of the fetus, congenital malformations, and sedation. Particularly, the Apgar score of immature neonates may not reach a value above 7 due to physiologically immature features.

\section{5 Hypoxic-ischemic encephalopathy}

When observation is continued other signs and symptoms may reveal the neurological consequences of a perinatal asphyxic period. In 1976 Samat and Sarnat described the progression of clinical neurological symptoms and coincidental changes in EEG activity in post-asphyxial term neonates (Sarnat 1976).The result was a three-point grading system referring to mild (stage 1), moderate (stage 2) and severe (stage 3) post-asphyxial encephalopathy.

All neonates with mild and $80 \%$ of the neonates demonstrating signs of moderate encephalopathy appeared normal in later infancy. Fetuses who remained in stage 2 for more than 7 days and all fetuses in stage 3 were associated with later neurologic impairment and death. 


\section{General introduction}

\section{Cerebral Palsy (CP)}

Cerebral palsy has been defined as a non-progressive disorder of movement and posture due to a defect or lesion of the immature brain (Bax 1964). The denotion of cerebral palsy as a biological entity is, however, artificial. Cerebral palsy rather constitutes a framework for certain motor-disabled children with special needs (Krageloh 1993). The etiology of cerebral palsy may be diverse. For instance, cerebral malformations, kernicterus, congenital infections, CNS infection and perinatal asphyxia have been described as causes for cerebral palsy. Cerebral palsy may present itself as a spastic, dyskinetic or ataxic movement disorder (Mutch 1992; Michaelis 1982). Among the different types of cerebral palsy, bilateral spastic cerebral palsy is the most common syndrome encountered after perinatal asphyxia. Since 1970 an increasing prevalence up to 2.49 per 1000 live births; 1.56 for term births and 0.93 for preterm births has been reported in Sweden (Hagberg 1993; Krageloh Mann 1994).

An increasing fraction of all CP cases consists of low birth weight infants as $28 \%$ of $\mathrm{CP}$ arose in survivors with a birthweight below $1500 \mathrm{~g}$ (Cummins 1993). The increasing rate of CP was attributed to a decreasing perinatal mortality in parallel with a constant rate of CP among the increasing group of survivors.

The neuropathological features of cerebral palsy after an asphyxic event are predominantly determined by the extent of vascularization of the brain, the responsiveness of the brain vasculature to asphyxia, the maturity of the brain and the particular vulnerability of specific cell types. Brain damage resulting from perinatal asphyxia may affect white or grey matter or both. The white matter, which consists predominantly of glial cells, is commonly involved in immature infants often in conjunction with periventricular hemorrhages (Volpe 1992). On the other hand, neuronal damage in the grey matter is predominantly observed in full-term infants. A typical distribution of grey matter damage in the parasagittal cortex is frequently described in asphyxiated term human infants (Volpe 1977). When pooled together CP cases in term and preterm neonates, brain damage is thought to arise from adverse events at a gestational age of 26-34 weeks (Squier 1991; Bejar 1988; Gaffney 1994), a period when the periventricular region and the germinal matrix in the fetal brain are particularly vulnerable. 


\begin{tabular}{|c|c|c|c|}
\hline औ & \multicolumn{2}{|c|}{ 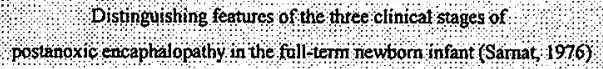 } & क्या \\
\hline & stage 1 & stage 2 & stage 3 \\
\hline Level of consciousness & Hyperalert & Lethargic or obtunded & Stuporous \\
\hline \multicolumn{4}{|l|}{ Neuromuscular control } \\
\hline Muscle Tone & Normal & Mild hypotonia & Flaccid \\
\hline Posture & Mild distal flexion & Strong distal flexion & Intermittent decerebration \\
\hline Stretch reflexes & Overactive & Overactive & Decreased or absent \\
\hline Segmental myoclonus & Present & Present & Absent \\
\hline \multicolumn{4}{|l|}{ Complex Reflexes } \\
\hline Suck & Weak & Weak or absent & Absent \\
\hline Moro & Strong; low threshold & Weak; incomplete; high threshold & Absent \\
\hline Oculovestibular & Normal & Overactive & Weak or absent \\
\hline Tonic neck & Slight & Strong & Absent \\
\hline Autonomic Function & Generalized sympathetic & Generalized parasympathetic & Both sytems depressed \\
\hline Pupils & Mydriasis & Miosis & $\begin{array}{l}\text { Variable; often unequal; poor light } \\
\text { reflex }\end{array}$ \\
\hline Heart rate & Tachycardia & Bradycardia & Variable \\
\hline Bronchial and salivary secretions & Sparse & Profuse & Variable \\
\hline Gastrointestinal motility & Normal or decreased & Increased; diarthea & Variable \\
\hline Seizures & None & Common; focal or multifocal & $\begin{array}{l}\text { Uncommon (excluding } \\
\text { decerebration) }\end{array}$ \\
\hline Electroencephalogram findings & Normal (awake) & $\begin{array}{l}\text { Early: low-voitage continuous } \\
\text { delta and theta. Later: periodic } \\
\text { pattem (awake). Seizures: focal l- } \\
1.5 \mathrm{~Hz} \text { spike-and-wave }\end{array}$ & $\begin{array}{l}\text { Early: periodic pattern with } \\
\text { isopotential phases. Later. totally } \\
\text { isopotential }\end{array}$ \\
\hline Durafion & Less than $24 \mathrm{hr}$ & Two to 14 days & Hours to weeks \\
\hline
\end{tabular}

\section{Asphyxia - Cerebral Palsy}

The purpose of identifying the asphyxiated fetus or neonate is to prevent perinatal mortality and morbidity specifically in terms of neurological impairments. Asphyxia then becomes a synonym for a pathological state which places the newborn at risk for a neurological impairment. Are the aforementioned parameters sufficient enough to describe asphyxia under these restrictions? Electronic monitoring of the fetal heart rate pattern proved to have a high false positive rate as a predictor of fetal asphyxia. A normal fetal heart rate pattern may be 


\section{General introduction}

interpreted as a denominator of fetal well-being but abnormal fetal heart rate traces do not necessarily imply fetal compromise (Beard 1971). Although a reasonable descriptor of fetal stress, electronic fetal monitoring appeared not to be an accurate predictor of the consequences of fetal stress (Young 1995). In a large randomized controlled study (MacDonald 1985), continuous fetal electronic monitoring was compared with intermittent auscultation of fetal heart sounds. Neonatal outcomes were similar in both groups although the number of neonates suffering seizures was lower in the continuous monitored neonates. The latter, however, did not result in differences in neurological impairment at follow-up (Grant 1989). Similarly, no improvement in neurological outcome was observed in lowbirthweight infants when electronic fetal monitoring was compared with intermittent fetal heart rate auscultation (Luthy 1987). Several reports by Vintzileos et al. (1993, 1995,1995a) showed a significant reduction of perinatal deaths due to fetal hypoxia. Reviewing 12 randomized studies Thacker et al (1994) concluded that the benefits of continuous fetal monitoring are primarily in the prevention of neonatal seizures, with less severe long-term implications than anticipated.

A poor correlation was reported between the degree of acidosis and neurological outcome at 12 months of age (Low 1978). Accordingly, the positive predictive value of acidosis, defined by a $\mathrm{pH}<7.16$ and a lactate $>5.4 \mathrm{mmol} / \mathrm{L}$, with respect to neurodevelopmental outcome at 12 months of age was low (Ruth 1988). Acidemia measured by $\mathrm{pH}$ alone appeared to be of poor prognostic value for subsequent neurologic complications (Low 1988; Beeby 1994).

As mentioned before, meconium stained amniotic fluid occurs in 12 to $22 \%$ of all deliveries. Nevertheless, few newborns in this group show signs of asphyxia. Meconium passage appeared to be a weak marker of subsequent neurological impairments as $0.4 \%$ of neonates weighing more than $2500 \mathrm{~g}$ with meconium stained amniotic fluid developed cerebral palsy (Nelson 1986).

The validity of the Apgar-score in the assessment of asphyxia and long-term neurodevelopment is considered poor (Marrin 1988; Marlow 1992). Other factors may influence the Apgar-score, such as the maturity of the fetus (Palme Kilander 1992), the use of narcotic analgesics or preexisting neuromuscular disorders. Recently, the joined committee of the ACOG and American Academy of Pediatrics (AAP) advised that the Apgar-score alone 
should not be used as a criterium of asphyxia (ACOG, AAP 1996).

In conclusion, all of the above parameters individually fail to identify asphyxia succesfully and are of poor predictive value with respect to subsequent neurological impairments. However, when combined they turn into powerful tools to identify the newborn at risk for postasphyxial brain damage. Concordingly, the American College of Obstetricians and Gynecologists advised that asphyxia should be regarded severe enough to cause hypoxic ischemic encephalopathy in case of : 1) umbilical artery or metabolic acidosis $\mathrm{pH}<7.00$.2) a persistent Apgar score of 0 to 3 for more than 5 minutes. 3) neonatal neurological sequelae, such as seizures, coma or hypotonia and 4) multiple organ failure (ACOG 1995). Recently, the significance of a metabolic acidosis was emphasized and a definition of asphyxia suggested as resulting in a metabolic acidosis with a base deficit $>12 \mathrm{mmol} / \mathrm{L}$ (Low 1997, 1994). Asphyxia can cause brain damage severe enough to result in cerebral palsy. However, epidemiological studies reveal that only approximately $8-20 \%$ of all CP cases can be attributed to perinatal asphyxia (Blair 1993; Nelson 1986,1996). The pathogenesis of the majority of the CP cases is unknown although it is anticipated that prenatal factors prevail.

\section{Questions}

Apparently, cerebral palsy is not the endpoint of choice to measure the efficacy of electronic fetal monitoring. Furthermore, fetal asphyxia, fetal distress, fetal stress are ill-defined denominations of fetal conditions during labor. The lack of definitions examplify the paucity of our knowledge of the pathophysiological mechanisms which are encountered in a compromised fetus. The fetal sheep model proved in the past to be a useful experimental model to clarify several aspects of fetal pathophysiology during asphyxia. The following questions arose with emphasis on the immature fetus, at a gestational age perinatal brain damage often occurs:

1) How tolerant is the immature fetus to asphyxia? Is the degree of asphyxia reflected in the degree of brain damage? (Chapter 3)

2) Which neuropathophysiological mechanisms play a role in selective neuronal loss? (Chapter 4) 


\section{Geacral introduction}

3) What is the time course of cardiovascular decompensation in immature fetuses when subjected to repetitive periods of fetal compromise? (Chapter 5)

4) What is the potential use of fetal EEG monitoring for detecting fetal compromise during repetitive umbilical cord occlusions in immature fetuses? Does this type of asphyxia result in brain damage at this gestational age? (Chapter 6)

5) Can the fetal ECG be used as an indicator of fetal compromise in immature fetuses? (Chapter 7) 


\section{Chapter 2}

Umbilical cord occlusion and asphyxia : a review of the literature 
The umbilical cord directs the blood from the fetal circulation to the placenta and back again to the fetus. In the placenta the fetal blood is reoxygenated and supplied with nutrients. When comprehending the effects of transient umbilical cord occlusion(s) on the fetus, the anatomy of the umbilical circulation in the sheep fetus has to be considered.

\section{The umbilical circulation (Dawes, 1962)}

The umbilical vessels of fetal sheep consist of two umbilical arteries and two umbilical veins in contrast to the umbilical vessels in human fetuses which comprise two umbilical arteries and only one umbilical vein. The two umbilical arteries originate from the caudal end of the descending aorta. After passing through the umbilicus they run out to the placenta where they split into multiple ramifications to the various cotelydons. The cotelydons are spread throughout the uterus. In the cotelydons the cotelydonary branches of the umbilical arteries split up to even smaller ramifications until the capillary network of the fetal villi is reached. Thence the cotelydonary venules are gathered together to constitute two umbilical veins which unite shortly after they enter the fetal abdomen. The single abdominal umbilical vein enters the fetal liver where a few branches are subdividing to the left lobe of the liver. The umbilical vein is now joined by the portal vein to form the ductus venosus which traverses the liver to enter directly the thoracic inferior vena cava. Here the well-oxygenated blood from the ductus venosus is mixed with the less well-oxygenated blood from the abdominal inferior vena cava. Nevertheless, the blood directed to the heart from the thoracic inferior vena cava is better oxygenated than the blood from the superior vena cava. When blood from the inferior vena cava enters the right atrium it is deflected by the crista dividens through the foramen ovale into the left atrium. The well oxygenated blood from the inferior vena cava bypasses in this manner the right ventricle and pulmonary circulation and permits delivery of highly oxygenated blood into the left ventricle. With each cardiac cycle, blood flow is then directed into the ascending aorta. The less-well oxygenated blood from the superior vena cava enters the right atrium and is then directed to the right ventricle. The right ventricle ejects the blood into the pulmonary trunk where a small portion of the blood flow is directed to the pulmonary circulation and the larger portion is shunted to the descending aorta through the ductus arteriosus. 
The vessels in the umbilical cord are spiraling and twisting, forming cylindrical helices, and thus are protected against torsion and traction. The extracellular matrix of the umbilical vessels consists of Wharton jelly which protects the umbilical vessels from occlusions. Nevertheless, despite these protective measures the umbilical circulation can be interrupted which may result in asphyxia and even fetal death. Particularly during the process of labor the umbilical cord is subjected to several hazards. For instance, the umbilical cord can be twisted around the fetal neck (nuchal cord), contain a true knot, prolapse through the birth canal, or become entrapped between the fetus and its surrounding anatomical structures. The latter form of umbilical cord occlusion is partly prevented by the cushioning effect of the amniotic fluid. The following discussion will direct its attention to the effect of umbilical cord occlusion(s) on the fetus, specifically the fetal heart and fetal brain, the cardiovascular responses of the fetus that are observed, and the physiological and pathophysiological mechanisms that play a role in these responses.

\section{Reflex pathways of cardiovascular responses to umbilical cord occlusions}

The foundation of our current knowledge about the short term cardiovascular adaptations of the fetus to occlusion of the umbilical cord was most elegantly laid by Sir Joseph Barcroft (Barcroft 1946). Experiments conducted in fetal goats and sheep and in a neonatal preparation in rabbits and kittens demonstrated the pivotal role of the vagal influence in the initiation of fetal bradycardia after ligation of the umbilical cord. Furthermore, a subsequent increasing influence of the sympathetic nervous system was identified during the time course of the occlusion followed by an eventual depression of the myocardium when the occlusion lasted a sufficient period of time. Particularly the vagal response has been subjected to intensive study by many fetal physiologists and the following discussion will direct most of its attention toward the main components of the vagal response, the baro- and the chemoreflex.

\subsection{The baroreceptor}

There are two main groups of baroreceptors, those of the carotid sinus and those of the aortic arch (Hanson 1988; Blanco 1988). Furthermore, the circulatory system contains several sites of mechanoreceptors in the cardiac atria and ventricles, pericardium and the great vessels. 


\section{Review of the literature}

Once stimulated baroreceptors elicit a slowing of the heart rate through their vagal efferents. The mechanoreceptors are stimulated by an increase in systemic arterial blood pressure and/or by an increase in cardiac volume or contractility of the heart (Coleridge 1980). Spontaneous carotid (Biscoe 1969) and aortic (Ponte 1973) baroreceptor activity was recorded in fetal sheep in synchronicy with the arterial pressure pulse. Fetal baroreceptor activity has been described to be active from ca. 85 days of gestation (Blanco 1985). Furthermore, it has been shown that the sensitivity of the baroreceptor afferents decreases with the increase of gestational age (Blanco 1988). In the fetal preparation the baroreflex was studied by increasing the arterial blood pressure by means of 1) injecting phenylepinephrine or angiotensin (Dawes 1980; Ismay 1979) 2) inflation of a balloon in the descending aorta (Shinebourne 1972) and 3) occlusion of the umbilical cord (Siassi 1979), whereby one has to bear in mind that the sensitivity of the eventual induced baroreflex is dependent on the mode of induction (Dawes 1980; de Haan J 1979).

Spontaneous baroreceptor activity might be important for the stability of the arterial pressure and fetal heart rate (Itskovitz 1983). Denervation of the carotid sinus nerve and aortic nerves demonstrated that slowing of the fetal heart rate did not occur after increasing arterial pressure (Itskovitz 1982). However, the results of these studies should be interpreted with caution as it was not possible to denervate the baroreceptors and chemoreceptors independently.

During the first seconds of total umbilical cord occlusion fetal arterial pressure increases due to obstruction of the low-resistant placental circulation (Evers 1981; Künzel 1980). An increase of $20-30 \%$ of the arterial pressure was measured 3 seconds after complete umbilical cord occlusion. The abrupt increase in arterial pressure may beside the carotid and aortic baroreceptors also stimulate the mechanoreceptors in the fetal heart as a result of increase in left ventricular volume following the increase in afterload. However, partial umbilical cord occlusion which reduced umbilical blood flow by $<50 \%$ did not induce a baroreceptor reflex as an increase in fetal arterial pressure and decrease in fetal heart rate was not observed (Itskovitz 1983). 


\subsection{The chemoreceptor}

Two types of chemoreceptors have been described to date, the central (Hohimer 1983, Koos 1985 ) and peripheral chemoreceptors. As data in the fetal sheep preparation almost limits itself to the peripheral chemoreceptors, the following discussion will be confined to the latter. Subsequently, the peripheral chemoreceptors can be divided into arterial and aortic chemoreceptors and a wide variety of receptors localized in the heart, lungs and great vessels, showing chemoreflex-like reactions after administration of various substances like veratridine (Hanson 1988).

Arterial chemoreceptors are predominantly found in the carotid body from were they send their afferent fibers to the carotid sinus nerve. The aortic chemoreceptors lie along the aortic arch and the roots of the great arteries, afferent fibers running in the aortic nerve to the CNS (Itskovitz 1982). Blanco et al.(1984) demonstrated that chemoreceptors were spontaneously active in the latter third of gestation. This activity was mainly attributed to aortic chemoreceptors compared to the low spontaneous activity from the carotid chemoreceptors. Stimulation of the chemoreceptors was accomplished after induction of fetal hypoxia by means of maternal inhalation hypoxia or reduction of uterine blood flow (Yaffe 1987), isolated fetal hypercapnia using an extracorporeal membrane oxygenator (Kuipers 1997) or fetal hypercapnia combined with hypoxia as a result of umbilical cord oclusion (Siassi 1979). Depending on the duration of the hypoxic period, the chemoreflex can result both in bradycardia or tachycardia indicating the parasympathetic (Dalton 1977) and sympathetic (Rudolph 1984) limb of the chemoreceptor efferents respectively. During acute hypoxia fetal heart rate will fall. Vagotomy (Boddy 1974) and muscarinic blockade (Martin 1985) prevented the bradycardia during acute hypoxia, suggesting a parasympathetic reflex mechanism. The sympathetic limb of the chemoreceptor reflex consists of an $\alpha$-adrenergic and a $\beta$-adrenergic effect. The activation of $\alpha$-adrenergic receptors results in vasoconstriction of the peripheral, mesenteric, splachnic, renal and splenic vasculature and in an increase in fetal arterial pressure. Fetal hypertension during hypoxia was prevented with $\alpha$-adrenergic blocking agents (de Haan J 1979; Lewis 1980), cutting the sciatic nerve (Dawes 1968), transection of the spinal cord at L1-L2 (Blanco 1983), carotid sinus denervation and phentolamine chemodenervation of the $\alpha$-adrenergic pathways (de Haan J 1979; Evers 1981; Giussani 


\section{Review of the literature}

1993). The following increase in arterial pressure activates on its turn the baroreceptors, thus contributing to the vagal input and bradycardia. The increased sympathetic activity during prolonged or severe hypoxia stimulates the adrenal medulla in the production of cathecholamines. Furthermore, the adrenal production of catecholamines is directly stimulated by hypoxia. Combined with the activated $\beta$-adrenergic pathway, the release of catecholamines will override the vagal effect and result in an increase in fetal heart rate (Rudolph 1984).

\section{Effect of umbilical cord occlusion on fetal oxygenation and distribution of blood flow}

As stated earlier compression of the umbilical cord will impair the gaseous exchange in the placenta and will eventually lead to fetal hypoxia and hypercapnia. The effect of compression of the umbilical cord on the fetal blood flow distribution and oxygenation was described by Itskovitz et al.(1983a, 1987) The effect was dependent on the degree of the compression. A reduction of $50 \%$ of the umbilical blood flow resulted in a $50 \%$ decrease in oxygen delivery to the fetus and a $20 \%$ reduction in combined ventricular output. However, blood flow to the fetal body was maintained. The percentage of the combined ventricular blood flow increased for the brain, heart and adrenals and decreased for the lungs. Remarkably the proportion of the combined ventricular blood flow increased to the skin, carcass, and kidneys. In contrast, during maternal hypoxemia the proportions of the combined blood flow to the latter organs decreased (Peeters 1979). Furthermore, umbilical blood flow remained unchanged during fetal hypoxia alone. The redistribution of blood flow has been termed centralization as blood flow was directed from peripheral tissues towards centrally localized vital organs like the brain, heart and adrenals (Jensen 1987,1991). Furthermore, oxygenated blood from the inferior vena, specifically blood from the ductus venosus, is preferentially guided through the foramen ovale to the left ventricle, thereby providing the organs in the upper body (heart, brain) with a greater proportion of the oxygenated blood. This preferential streaming is even enhanced during hypoxia (Reuss 1980, Rudolph 1984)

The effect of umbilical cord compression on fetal oxygenation is also dependent on the duration of the compression. When the partial umbilical cord compression is maintained for a sufficient period of time, severe acidosis develops. During 90 minutes of partial occlusion, cardiac blood flow did not increase in contrast to the increase in total cerebral blood flow 
(Ball 1994). Extending the duration of reduction in umbilical blood flow to days or weeks will eventually reduce fetal growth. This could be explained by the decrease in oxygen consumption dependent on the degree of the reduction of blood flow (Itskovitz 1983a; Anderson 1986).

\section{Effect of umbilical cord occlusion on fetal heart rate}

The response of the fetal heart rate on compression of the umbilical cord is, again, dependent on the degree and the duration of the reduction of umbilical blood flow. During partial occlusion of the umbilical cord for a period of 40 seconds no response could be elicited after a reduction of the umbilical blood flow of $<25 \%$. Reduction of the umbilical blood flow of 50 $\%$ resulted in a gradual decrease in fetal heart rate, attributed to chemoreceptor activity. In case of complete umbilical cord occlusion bradycardia is abrupt and arterial pressure is steadily increasing (Itskovitz 1983). The latter bradycardia is attributed to a mixed chemo- and baroreceptor response. Prolonged partial occlusion of the umbilical cord by reduction of the umbilical blood flow of $33 \%$ resulted in no apparent changes in fetal arterial pressure and a gradual modest increase in fetal heart rate. When reduction of the umbilical blood flow is increased to $66 \%$, at first marked bradycardia develops which subsequently dissolves and changes into tachycardia (Itskovitz 1983).

In addition to changes in fetal heart rate, the fetal heart rate variation is considered to be essential in the interpretation of intrapartum fetal heart rate recordings. A progressive loss of variation is thought to reflect fetal hypoxemia and acidemia (Hammacher 1968; Beard 1971; Paul 1975; Skupski 1996). In contrast, experimental studies demonstrated an increase of fetal heart rate variation following maternal inhalation hypoxia (Dalton 1977;Kozuma 1997; Lilja 1984; Field 1991; Parer 1980). However, a number of experimental studies have documented a progressive fall in fetal heart rate variation following the acute rise when inhalation hypoxia was continued and fetal acidemia occurred (Dalton 1977; Lilja 1984; Martin Jr 1979; Stange 1977). Furthermore, acute placental embolization in fetal sheep resulted in severe acidemia and a decrease in fetal heart rate variation (Gagnon 1996). Recently, the effect of repetitive umbilical cord occlusions resulting in acute asphyxia on fetal heart rate variation was described (Westgate 1999). Acute, progressive asphyxia was associated with an immediate, 
transient increase in fetal heart rate variation. Subsequently, fetal heart rate variacion became suppressed in two thirds of fetuses. The mechanisms which underlie the initial rise in fetal heart rate variation are likely to involve a combination of activation of the chemoreflex (Kozuma 1997) and sympathetic stimulation (Segar 1994; Lindecrantz 1993; Rosen 1986; Dalton 1983). The factors involved in the subsequent fall in fetal heart rate variation are unknown. It was speculated that a habituation of autonomic and humoral mechanisms may play a pivotal role in the observed decrease of fetal heart rate variation (Westgate 1999). Changes in parasympathetic and sympathetic neural activity during asphyxia may influence fetal heart rate variation (Dalton 1983; Segar 1994). Furthermore, an increase of humoral factors during asphyxia such as angiotensin II may decrease fetal heart rate variation (Green 1998; Akselrod 1985).

\section{Asphyxia}

Umbilical cord occlusions result in a cardiovascular adaptive response that might be characterized as fetal stress, a prepathological state and therefore a physiological response to the adversaries of the birth process (Cibils 1996). However, when increasing the duration and degree of umbilical cord occlusions or repeating them a sufficient period of time, the fetus eventually will decompensate, as soon as metabolic acidosis develops as a result of prolonged obstruction of the gaseous exchange in the placenta: asphyxia.

\subsection{The effect of asphyxia on the fetal brain}

How does the fetal brain protect itself against the adversaries encountered during asphyxia? As already stated above, redistribution of blood flow is partly directed to the brain to maintain cerebral oxygen delivery. When oxygen delivery falls cerebral oxygen consumption is maintained by an increase in cerebral extraction of oxygen delivered to the brain (Rudolph 1984; Field 1990; Richardson 1993; Ball 1994). Furthermore, blood flow to phylogenetically older brain structures as the brainstem, pons, medulla oblongata is increased compared to cortical flow (Peeters 1979). Next to changes in oxygenation, fluctuations in blood pressure may also endanger the brain during asphyxia. The cerebral vasculature possesses an effective defensive mechanism to dampen periods of hyper- and hypotension by increasing and 
decreasing its vasculature resistance respectively, a process called autoregulation (Paulson 1990). However, the range of this autoregulatory capacity is limited. An abrupt increase of arterial pressure above the upper limit of autoregulation can result in brain edema or even rupture of a cerebral vessel and thus cause intracerebral hemorrhages. When arterial blood pressure falls below the limit of autoregulation, cerebral perfusion may decrease proportionately or even cease completely. It has been shown that cerebral autoregulation is already present in midgestation fetal sheep (Papile 1985). However, the range of autoregulation is smaller compared to mature fetal sheep. Furthermore, mean arterial blood pressure in immature fetuses reaches the lower limit of the autoregulatory range. During or shortly after a period of asphyxia autoregulation may be severely impaired (Lou 1988; Tweed 1986). Deprived of the defensive mechanism of autoregulation, the fetal brain is even more at risk for subsequent asphyxial episodes. Although metabolic parameters may be restored following a period of asphyxia cerebral blood may still be impaired (Fellman 1997). This socalled 'no reflow' phenomenon is probably due to endothelial injury and swelling (Pluta 1994), to granulocyt plugging of microvessels (del Zoppo 1991), or to intravascular clotting (Thomas 1993).

Eventually, the adaptive mechanisms of the fetal brain are incapable to withstand the initiation of a cascade of process leading to neuronal death. Which processes are initiated and at what time point they do occur is not clear and in this respect many questions are still open.

\subsubsection{The time course of neuronal death following a hypoxic-ischemic insult}

Four consecutive phases have been proposed to occur in neuronal death following a hypoxicischemic event: 1) a primary phase of neuronal death, 2) an intermediate phase of neuronal suppression, 3) a second phase of neuronal death and 4) a phase of neuronal repair (Gluckman 1992).

\section{Primary neuronal death}

When the brain is long enough deprived of oxygen, aerobic metabolism will be replaced by anaerobic metabolism resulting in a lesser production of the energy-enriched adenosine triphosphate (ATP) (Palmer 1990). This deprivation of ATP will impede the $\mathrm{Na}^{+} / \mathrm{K}^{+}$-transport across the cellular membrane and thus results in a decrease in the membrane potential. 
Voltage- dependent calcium channels open and transport of $\mathrm{Ca}^{++}$-ions into the cell will increase and transport of $\mathrm{Na}^{+}$-ions out of the cell decreases (Hansen 1985). Accumulation of intracellular $\mathrm{Ca}^{++}$and $\mathrm{Na}^{+}$results in an osmotic influx of water thereby leading to cellular edema (Hossmann 1980; Hansen 1977). This primary edema may further compromise the microcirculation by compression of the microvasculature and if severe leads to cell lysis and immediate cell death. The accumulation of $\mathrm{Ca}^{++}$into the cytosol is aggravated by the release of $\mathrm{Ca}^{++}$out of the mitochondria and endoplasmatic reticulum (Rehncrona 1982). A high intracellular concentration of $\mathrm{Ca}^{++}$triggers several processes. Activation of phospholipases $\mathrm{A}$ and $\mathrm{C}$ results in membrane phospholipid hydrolysis and herewith in a further disruption of the cell membrane integrity, cell edema and neuronal death (Hansen 1985). The activation of excitotoxic amino acids, free oxygen radicals, nitric oxide although they occur in the primary phase, will be discussed in the secondary phase of neuronal death paragraph as they appear to be of more significance at this time point.

\section{The intermediate phase (neuronal suppresion)}

In the phase following the hypoxic-ischemic event, neuronal activity remains suppressed for some hours depending on the severity of the injury. The length of this episode correlates with the degree of neuronal damage described three days after the event. Repetitive events during this period worsen the outcome (Mallard 1993). The sustained suppression of EEG activity is probably due to the release of neuromodulators such as $\gamma$-aminobutyric acid (GABA), adenosine and opiates (Gluckman 1992).

\section{Secondary neuronal death}

Six to twelve hours after the primary insult a secondary phase occurs resulting in neuronal death. As stated above, following the primary insult various processes are induced in the reperfusion phase.

\section{Oxygen free radicals}

Reoxygenation of previous hypoperfused and hypoxic tissue results in metabolizing purines which accumulated during the hypoxic-ischemic event (Thiringer 1982,1987). The purines hypoxanthine and xanthine are metabolized to oxygen free radicals which can direct or indirectly result in cell damage (Del Maestro 1980). Oxygen free radicals in high concentrations induce production of prostanoids by metabolizing arachidonic acid and result 
in the destruction of the cell membrane by the process of lipid peroxidation (Espinoza 1991; Wolfe 1992). Furthermore, oxygen free radicals are held responsible for the endothelial damage shortly after an hypoxic-ischemic event. Combined with the vasoconstrictive potency of prostanoids this may lead to the impairment of reflow following an hypoxic-ischemic event.

\section{Excitotoxic amino acids}

Influx of $\mathrm{Ca}^{++}$triggers the production of excitotoxic amino acids. Excitotoxic amino acids or stimulatory neurotransmitters are normally counterbalanced by inhibitory neurotransmitters like GABA and glycine. However, following a hypoxic-ischemic event production of excitotoxic amino acids may exceed the decreasing concentrations of inhibitatory neurotransmitters (Tan 1996). Various excitotoxic amino acids have been identified, however, primarily attention is directed to glutamate, and specifically its agonist $N$-methyl-D-aspartate (NMDA). Glutamate is the most abundant amino acid in the central nervous system (McDonald 1990). After depolarization of the cell membrane following $\mathrm{Ca}^{++}$influx, glutamate is released from the presynaptic vesicles (Clark GD 1989; Rothman 1987). Glutamate can interact with all the EAA receptor subtypes, which can be divided into NMDA- and nonNMDA receptors (Choi 1988, 1988a). NMDA receptors are linked to a $\mathrm{Na}^{+}$and $\mathrm{Ca}^{++}$ permeable cationic channel which is blocked by a magnesium in a voltage dependent manner. Activation of the NMDA receptor results in a depolarization of the membrane, raises the magnesium blockade thereby permitting the influx of $\mathrm{Ca}^{++}$and $\mathrm{Na}^{+}$. Higher concentrations of extracellular glutamate therefore results in higher concentrations of intracellular $\mathrm{Ca}^{++}$thus creating a postive feedback for glutamate production and initiation of various earlier described neurotoxic processes. Excessive extracellular concentration of glutamate during or after a hypoxic ischemic event has been attributed to an increase in neuronal production and/or decrease in glial uptake (Novelli 1988). Apart from its role as a mediator of neurotoxicity, glutamate also determines the distribution of brain damage after a hypoxic-ischemic event. The selective vulnerability of certain cerebral regions to global cerebral ischemia is thought to be confined to regions with a high glutamatergic input (e.g. the hippocampus) (Silverstein 1991; Benveniste 1989). Prior lesioning of these glutaminergic pathways, by intracerebral or sytemic adminstration of NMDA-antagonists, is proven to be protective to neuronal damage 
following forebrain ischemia.

\section{Nitric Oxide}

A third process that is initiated after cellular influx of $\mathrm{Ca}^{++}$is the production of nitric oxide (NO). Nitric oxide has recently been identified as the endothelium-derived relaxing factor (EDRF), which acts as a vasodilator by the activation of soluble gyanylate cyclase in vascular smooth muscle cells (Palmer 1988; Furchgott1989). Since then, other properties of NO have been discovered as it proved to be a neurotransmitter, platelet aggregation inhibitor, and cytotoxic agent (Moncada 1991). Nitric oxide is a free radical and is synthetized from the substrates L-arginine, an amino acid, and oxygen through an enzymatic reaction with nitric oxide synthase. To date, three isoforms of NOS are known: $\mathrm{Ca}^{++}$dependent endothelial (eNOS) and neuronal NOS (nNOS), and the $\mathrm{Ca}^{++}$independent inducible NOS (iNOS) (Bredt 1990; Marletta 1988). Once activated the $\mathrm{Ca}^{++}$dependent or constitutive isoforms produce NO in small amounts for a short period. In contrast, the iNOS is activated by macrophages and endothelial cells through cytokines resulting in a prolonged production of NO. The role of NO in the pathophysiology of hypoxic-ischemic brain damage is complex and possibly double edged (Beckman 1991). The source, localization and circumstances under which NO is produced may determine whether its effect on brain damage is benificial or detrimental. NO produced by eNOS in the endothelial cells may attenuate the cerebral hypoperfusion during asphyxia by its vasodilatory effect (Faraci 1994). On the other hand, NO production during the reperfusion phase may facilitate reaction of $\mathrm{NO}$ with simultaneously formed oxygen derived free radicals to form the highly toxic substance peroxynitrite (Faraci 1994; Beckman 1991). In concordance with this hypothesis, a surge of citrulline (a by-product of NO synthesis) was measured by microdialysis in the parasagittal cortex after 30 minutes of global cerebral ischemia in the chronic fetal sheep preparation (Tan 1996).

\section{The fourth phase: repair}

Three to four days after the initial hypoxic-ischemic event another phase sets in: repair. Three to eleven days after a hypoxic-ischemic event the induction of several neurotrophic factors can be observed such as insuline-like growth factors (IGF), nerve growth factor (NGF), fibroblast growth factor (FGF) and transformal growth factor (TGF) (Finklestein 1990; Dragunow 1992; Knusel 1990; Yamada 1991; Gluckman 1992a). The action of endogenous neuroprotective 
mechanisms and their induction have been demonstrated in neonatal rats and fetal sheep as well (Johnston 1996). The loss or inadequacy of this trophic support may lead to apoptosis. Apoptosis is a naturally occurring form of cell death during normal brain development where approximately half the the cells generated are eliminated by apoptosis. Histologically, apoptosis can be distinguished from cell necrosis by the intactness of the cell membrane and nucleus combined with a lacking infiltration of neutrophils and macrophages. Death is the default pathway of all cells, therefore the apoptotic machinery is permanent available in the cell genome. Two genes ced- 3 and ced-4, discovered in the nematode, are essential for the execution of the apoptotic programme. Ced-3 encodes a cystine protease. These enzymes cleave specific cellular targets such as the DNA repair enzyme poly(ADP-ribose)polymerase (PARP) (Miura 1993). Ultimately, apoptosis results in degradation of genomic DNA by an endonuclease into DNA fragments which produce characteristic ladders following agarose gel electrophoresis (Whyllie 1980). Regarding the control of the cell cycle oncogenes such as c-Fos, c-Jun and C-Myc can trigger apoptosis (Evan 1996). The activation of apoptosis accounts for at least a part of the delayed neuronal death. In addition to cerebral necrosis, apoptosis has been clearly identified in the neonatal rat pup (Beilharz 1995) and piglet (Mehmet 1994) following a hypoxic-ischemic event. The variations in the frequency of apoptosis and necrosis depend on the type and state of differentation of the cell subjected to the insult and the intensisty of the insult. Mild insults are prone to result in apoptosis whereas severe insults cause necrotic cell death. Necrotic neurons were seen after a hypoxic-ischemic injury in contrast to adjacent glial cells where apoptosis prevailed. Immature neurons undergo preferentially apoptosis, while more differentiated neurons likely suffer necrosis instead (Yue 1997).

In conclusion, neuronal death following a hypoxic-ischemic event is first of all triggered by the depletion of cellular energy, resulting in a failing cellular homeostasis and membrane integrity and when severe enough leading to osmotic swelling and cell death. Accumulation of intracellular $\mathrm{Ca}^{++}$triggers several cytotoxic processes which interreact and eventually may lead to secondary cell death. Next to the described necrotic cell death neuronal demise may also be the result of apoptosis. The latter process may be triggered in the intermediate suppressive phase due to lack of electric activity or in the repair phase three to eleven days 


\section{Review of the literature}

after the insult when the induction of endogenous neurotrophic factors is inadequate.

\subsection{Neuropathological features of hypoxic-ischemic encephalopathy}

The neuropatholocial features of hypoxic-ischemic brain damage may vary considerably. Nevertheless, some basic varieties in brain lesions can be recognized. The distribution and cellular aspects are dependent on the maturity of the fetus and the nature of the insult. Selective neuronal necrosis is the most common variety of hypoxic-ischemic encephalopathy and may coexist with other features of brain damage as well. In the mature brain the order of vulnerability is neuron $>$ oligodendrocyte $>$ astrocyte $>$ microglia (Scholz 1963). However, it is suggested that with increasing immaturity oligodendrocytes may become more vulnerable than neurons (Volpe 1995). The predilection sites of selective neuronal loss are the cerebral cortex, hippocampus and the cerebellum. Regional vascular factors play a dominant role in neuronal necrosis of the neocortex. The neuronal loss here is predominantly localized in the areas of marked vascular border zones in the depth of the sulci. Necrotic cells in the hippocampus consist predominantly of pyramidal cells in the CAl sector. This particular distribution might be attributed to the regional distribution of glutamate receptors (NMDA). Purkinje cells in the cerebellum are particularly vulnerable to hypoxia. With respect to their high metabolic needs the large Purkinje cells in the cerebellum are prone to cellular energy failure when their energy requirements are not met.

Neuronal loss in the basal ganglia and thalamus is frequently observed after repeated episodes of hypoxia-ischemia. Pathogenetically, lesions in the striatum are thought to be the result of regional distribution of glutamate receptors. Furthermore, increased levels of glutamate were measured using microdialysis in the extracellular compartment of the striatum of fetal lambs during hypoxia-ischemia (Hagberg 1987). Moreover, repeated episodes of hypoxia-ischemia may result in a sustained elevation of extracellular glutamate in the striatum thus leading to preferential striatal damage (Lin 1992; Mallard 1992,1995). In human infants, the characteristic feature of neuronal loss of the basal ganglia is the hypermyelination of the affected regions due to aberrant myelination of axons and/or astrocyte processes. Regarding the macroscopic marmer-like appearance this specific lesion is also called status marmoratus. A characteristic feature of neuropathology of hypoxic-ischemic brain damage in mature 
fetuses and term infants is necrosis of the parasagittal cortex. The lesion is characterized by bilateral necrotic areas of the cortex and subcortical white matter, particularly in the parietaloccipital region of the cerebrum. These areas of injury are in the border zones of the end fields of the major cerebral arteries. Therefore, parasagittal necrosis of the cortex is thought to be the result of cerebral hypoperfusion or ischemia. A similar distribution is seen after 30 minutes of cerebral ischemia in mature fetal sheep. In contrast to frequent mild episodes of hypoxiaischemia resulting in predominant striatal injury, a single period of severe cerebral hypoperfusion is more likely to result in this particular distribution of hypoxic-ischemic brain injury.

Periventricular leucomalacia (PVL) consists of focal necrosis of periventricular white matter, predominantly located at the level of the optic radiation adjacent to the trigone of the lateral ventricles and at the level of the frontal cerebral white matter near the foramen of Monro. An early expression of PVL or less severe example of PVL is the perinatal telencephalic leukoencephalopathy (TL). TL is characterized by areas of reactive astrogliosis in areas which undergo active myelination. PVL an TL are characteristic features of hypoxic-ischemic brain injury of the preterm neonate although the lesions has been described in term infants. The occurrence of PVL and TL is probably due to a combination of periventricular vascular factors and the intrinsic vulnerability of the white matter of the premature newborn. The artery border and end zones in the periventricular region render these areas vulnerable to periods of cerebral hypoperfusion or ischemia. Furthermore, it has been shown that these boundary zones are more pronounced in the less mature infants. Moreover, during severe compromise autoregulation is absent and cerebral circulation pressure-passive. Under these circumstances the boundary zones are even more at risk during transient periods of hypotension. Experimental data suggest that the white matter of the premature fetus is particularly vulnerable. First, an insufficient vasodilatory capacity during and after a period of hypoxiaischemia result in a persistent deficit of blood flow to the periventricular white matter region. Secondly, differentiating oligodendrocytes are at risk possibly due to their pronounced metabolic requirements and specific vulnerability to glutamate. 


\subsection{Brain damage in fetal sheep}

To study the pathophysiology of brain damage after perinatal asphyxia experimentally, the human fetus is not at our disposal for obvious ethical reasons. Therefore, several experimental models were developed in primates, sheep, goats, (guinee) pigs and rats (Roohey 1997). The fetal sheep preparation was and is still frequently used based on the following arguments: 1) the pregnant ewe endures fetal surgery well and is not prone to premature delivery, 2) fetal sheep show similarities with human fetuses in several aspects like fetal weight and gross anatomy of the cardiovascular and nervous system, 3) fetal proportions make extensive instrumentation and therefore the acquisition of integrative physiological date possible , 4) a reasonable amount of knowledge about fetal physiology has been gathered in this preparation in the past decades.

However, the comparison between the central nervous system of the fetal sheep and human fetus calls for careful attention. Compared to man, sheep are precocious with respect to brain development (Dobbing 1979). As a result, the brain maturity of a human at term can roughly be compared with a fetal sheep brain at 0.8 of gestation (term approximately 147days) (McIntosh 1979). Likewise, immature fetal sheep at a gestational age of 90 days can be compared to immature fetuses at 24-30 weeks of gestation, before myelination occurs. Several models have been developed to study postasphyxial brain damage in fetal sheep. Roughly these models can be divided into functional and pathophysiological experimental models (de Haan HH 1996).

\section{Functional models}

Functional models consist of experimental preparations which are consistent in the production of fetal cerebral damage, both in degree and localisation. Predominantly the insult is confined to the brain alone. Such an insult has frequently been described after global ischemia of the fetal brain (Williams 1992). Global ischemia was induced following a transient bilateral carotid artery occlusion for 30 minutes. Histological analysis 3 days after the insult predominantly demonstrated laminar necrosis in the parasagittal cortex, a specific distribution also encountered following birth asphyxia in term human fetuses. 


\section{Pathophysiological models}

In contrast, pathophysiological models result in a more divergent cerebral damage, in degree and distribution as well. In these models, the insult is not confined to the cerebrum alone but to the whole fetus. Therefore, pathophysiological models are, as is delineated by the name, more compatible to the actual pathophysiological processes which are thought to occur during human perinatal asphyxia. Moreover, in addition to the cerebral pathophysiology, concomittant disturbances in metabolic and/or cardiovascular homeostasis can be monitored. Several methods of induction of asphyxia in fetal sheep have been described: 1) Inhalation (maternal) hypoxia (Bocking 1988; Penning 1994), 2) Reduction of the uterine perfusion (de Haan 1993) and 3) umbilical cord occlusion (Mallard 1992). The following discussion will be restricted to umbilical cord occlusions.

\section{Single period umbilical cord occlusion}

A single-period transient umbilical cord occlusion has been implemented at various degree and duration of the occlusion. Partial occlusion for 90 minutes in late gestation fetal sheep resulted in severe fetal asphyxia and electrophysiological evidence for seizure activity after the occlusion (Ball 1994). In another study the umbilical cord of near term sheep fetuses was partially occluded until pH decreased to $<6.9$ (Ikeda 1998). Neuropathologic changes in that study ranged from almost total infarction of cortical and subcortical structures to extremely subtle and patchy white matter alterations characterized by slight vacuolization of the white matter or slight to moderate increases in cellularity confined to the junction of cerebral cortex and white matter. Electrocortigraphic parameters, duration of hypotension during asphyxia, and delayed recovery of blood lactate concentrations correlated well with the histologic grading of brain damage. Additional analysis of brain lipid peroxidants and antioxidants in different brain regions suggested an essential role for oxidative stress in the development of brain damage observed in the white matter (Ikeda 1998a). Complete occlusion of the umbilical cord for 10 minutes resulted in preferential hippocampal damage in late gestation fetal sheep, a distribution of damage also reported in fetal rats after umbilical cord occlusion (Mallard 1992). The degree of damage correlated well with the degree of hypotension during the occlusion, thereby stressing the significance of the combination of hypoxia and hypotension for the induction of postasphyxic brain damage. 


\section{Repetitive umbilical cord occlusions}

In clinical practice, the umbilical cord is often compressed repetitively, coincident with uterine contractions. Repeated periods of 5 minutes of total umbilical cord occlusion resulted in a different distribution of cerebral damage compared to a singular occlusion (Mallard 1995). Neuronal damage was mainly confined to the striatum. These results are in concordance with observations in fetal sheep following repetitive periods of global cerebral ischemia (Mallard 1992a). The preferential damage to the striatum could be explained by a more sustained release of excitotoxic agents after repetitive occlusions in the extracellular space of the striatum compared to a brief surge during a singular insult (Lin 1992). Recently, de Haan et al. (de Haan 1997) described the effect of repetitive umbilical cord occlusions on the fetal brain at a rate encountered with uterine contractions during labor. Brief repeated umbilical cord occlusions at a rate of 1 out of every 2.5 minutes or 2 out of every 5 minutes for a maximum period of 4 hours resulted in severe asphyxia with profound acidosis and hypotension. Sustained cytotoxic cortical edema developed during occlusions until several hours after the last occlusion. Furthermore, mild epileptiform activity of the EEG could be registered 5 to 10 hours after the last occlusion. Accordingly, histological analysis demonstrated mild selective neuronal damage throughout the brain.

\section{The effect of asphyxia on the fetal heart}

In addition to the effect of asphyxia on fetal heart rate and cardiac output discussed earlier the fetal electrocardiogram (FECG) has been and still is the subject of extensive study. Shortly after the discovery of the ECG by Einthoven, recordings were made of the fetal ECG by Cremer in the beginning of the 20th century (Cremer 1906). Several decades ago a relationship was proposed between deterioration of the fetal condition and changes in the FECG (Southern 1957; Hon 1963). However, a low signal to noise ratio of the registered FECG made analysis of its several components difficult. With the advent of adequate noise filters and improved signal processing the FECG regained interest (Lilja 1988; Jongsma 1989; Hasaart 1989). Several components of the FECG and their relationship to fetal compromise were studied. 
The T/QRS-ratio was subjected to extensive study as it was demonstrated that hypoxia induced a rise in the T/QRS-ratio due to anaerobic myocardial metabolism and increasing beta-adrenergic stimulation (Greene 1987; Rosen 1984; Widmark 1989). However, this relationship could not be demonstrated by all investigators, especially not in those experimental set ups which resulted in severe asphyxia, i.e. profound hypoxia and acidosis (de Haan 1995). Accordingly, clinical studies on the T/QRS-ratio could not reach a consensus (Westgate 1992,1993; Skillern 1994; Maclachlan 1992; Murphy 1992).

The number of reports on the PR interval and specifically the relationship between the PR interval and fetal heart rate have increased. A lenghtening of the PR interval had been reported after umbilical cord occlusion in the fetal baboon (Yeh 1975). Complete occlusion of the maternal aorta resulted in an initial lengthening of the PR interval proportionately with the lengthening of the RR interval, followed by a shortening of the PR interval (Widmark 1992). The initial lengthening was thought to be due to an increased vagal input, the following shortening was attributed to an increased sympathico-adrenal influence thereby resulting in a positive temporal relationship between the PR interval and fetal heart rate (Murray 1986). The report of a consistent change from predominant negative to a positive PR interval - fetal heart rate relationship with random changes in arterial pressure during prolonged and severe hypoxia suggests a prominent role of oxygen in this transition (van Wijngaarden 1996). Clinical studies demonstrated a positive correlation between a transition to a positive $P R$ interval - fetal heart rate relationship and acidemia at birth (Murray 1986). Recently, the results of a prospective clinical trial were reported and is still underway, using an automated FECG analyzer for on-line measurement of PR interval and fetal heart rate (van Wijngaarden 1996a).

\section{The immature fetus}

As the immature fetus takes a central place in this thesis a separate discussion on its characteristics with special reference to the fetal brain is warranted. Most data concerning the physiology of fetal sheep, and pathophysiology of fetal brain damage in particular, has been compiled in the mature fetus. However, an increasing number of studies in immature sheep fetus were reported and it became clear that data collected in the mature fetus could not be 
automatically transferred to the immature fetus.

Distinctive differences in metabolic and circulatory properties were described in immature sheep fetuses (gestational age 71-93 days). Fetal heart rate in immature fetuses was higher ( \pm 200 beats per minute vs. \pm 150 beats per minute) and mean arterial pressure lower (30-40 $\mathrm{mmHg}$ vs. 50-60 $\mathrm{mmHg}$ ) than in mature fetuses (Bell 1986; Dawes 1962). Umbilical blood flow was twice as high when corrected for fetal weight, oxygen uptake $40 \%$ greater, and placental mass $60 \%$ bigger when compared to mature fetuses. Cerebral blood flow, glucose and oxygen consumption of immature fetuses was lesser compared to their more mature counterparts (Gleason 1989).

When the circulatory and metabolic system of the immature fetus was stressed, striking similarities were reported with mature fetuses although differences still exist. When subjected to acute or prolonged hypoxia immature fetuses demonstrated a similar response compared to mature fetus although the response, particularly the increase in arterial blood pressure, was less pronounced (Matsuda 1992; Iwamoto 1989,1991).

Several experimental set ups has been used to study the relationship between asphyxia and brain damage in the immature fetal sheep. Periventricular white matter damage was observed after prolonged maternal inhalation hypoxia (Penning 1994). Likewise, neuronal death was observed in the neocortex, hippocampus and cerebellum in midgestation fetal sheep following 6 to 12 hours hypoxemia induced by restricting utero-placental blood flow (Rees 1997). Chronic hypoxia in that study resulted in neuronal cell death in the deeper cortical layers, a delayed gyral formation, an attenuation in the growth of neural processes in the hippocampus and a reduction in cerebellar mitosis and number of Purkinje cells. In contrast, neuronal damage was not observed in immature sheep fetuses following a more acute insult induced by total umbilical cord occlusion during 10 minutes (Mallard 1994). In that same study selective cerebral damage in the hippocampus was evident in mature fetuses when subjected to a similar insult. It was suggested that the absence of neuronal damage was due to the observed lesser decrease in mean arterial pressure in the immature fetuses. Increasing the duration of the total umbilical cord occlusion up to 30 minutes in immature fetal sheep resulted in an initial redistribution of blood flow away from the periphery to maintain vital organ function, subsequently partial failure of this redistribution and near terminal cardiovascular collaps, 
with profound hypotension and cerebral and peripheral hypoperfusion (Bennet 1999). A secondary period of significant cerebral hypoperfusion and reduced oxygen delivery occurred 3-5 hours following the insult. Therefore, this study demonstrated the capacity of the immature fetus to survive prolonged periods of asphyxia, paradoxically exposing it to profound hypotension and hypoperfusion.

Regarding the high incidence of intraventricular hemorrhages in immature human newborns, several protocols were used to induce similar lesions with various success. It was suggested that the inadequacy of the cerebral vasculature autoregulation and its impairment during asphyxia rendered the immature brain vulnerable for intracranial hemorrhages to occur (Lou 1988; Helou 1991, 1994; Paulson 1990; Tweed 1986; Papile 1985). Immature sheep fetuses appeared rather resistant when compared to other species and a combination of severe asphyxia and induced fluctuations of arterial pressure were needed to produce intraventricular hemorrhages (Reynolds 1979; Ting 1984).

\section{The effect of age on susceptibility to brain damage}

During development a pronounced shift in the relative vulnerability of various brain regions and a change in the pattern of hypoxic-ischemic lesions occur (Yager 1996). In immature subjects cortical lesions consist of radial columns of dead cells. With increasing age these lesions become more horizontally oriented, resulting in laminar selective neuronal demise of the cortex. The former columnar orientation is probably due to hypoperfusion of long radially penetrating arteries which provide few horizontal collateral arterioles. Measurements of local cerebral blood flow showed differential perfusion deficits which correspond closely to the radially oriented bands of destroyed neurons (Ringel 1991) .

Pyramidal cells of various histologically distinct sectors within the hippocampus show different degrees of vulnerability during development. Vulnerability shifts from the lateral $\mathrm{CA} 3$ and $\mathrm{CA} 4$ sector to the $\mathrm{CA} 1$ and $\mathrm{CA} 2$ sector (Towfighi 1997). Unlike in cerebral cortex, the reductions in cerebral blood flow during hypoxia-ischemia are uniform throughout the pyramidal cell layer and, therefore, cannot account for the known developmental vulnerability of specific regions of this structure to hypoxia-ischemia. 


\section{Review of the literature}

Brain damage may be dependent on mechanisms other than a lower metabolic rate. In vitro studies in hippocampal slices demonstrated lower postischemic inhibition of protein synthesis during ischemic circumstances in slices of immature fetal guinee pigs compared to mature fetuses (Berger 1995). These postischemic disturbances in protein synthesis reflect the ontogenic changes in vulnerability of the brain.

Likewise, ontogenic factors regarding both excitatory and inhibitory neurotransmitters may have a profound effect on the age related susceptibility to hypoxic-ischemic brain injury. In the immature rat, the hippocampus undergoes dramatic maturation with ionotropic glutamate receptors present and increasing profoundly during the first few postnatal weeks. The immature brain of neonatal rats has enhanced vulnerability to overstimulation of NMDA receptors compared with the adult brain (Johnston 1990; Macdonald 1988). Likewise, single intracerebral injections of other excitotoxic amino acids such as $\alpha$-amino-3 hydroxy- 5 methyl4 isoxazol propionic acid (AMPA) and quisqualic acid (QA) have greater toxicity in immature animals than in mature animals (MacDonald 1990, 1992; Thurber 1994). It is possible that these age-related phenomenons relate to differences in the postsynaptic action of glutamate. It is known that the NMDA receptor subunit composition varies with age. For example, early in development subunit GluR2c is expressed in hippocampus. Since GluR2c reduces voltagedependent $\mathrm{Mg}^{2+}$ block of NMDA channels, its expression may render immature hippocampal neurons rather prone to hyperexcitabiliy (Kleckner 1991; Monyer 1994). Each step following eventual $\mathrm{Ca}^{2+}$ entry through NMDA receptors may be age-related too. During development, resistance to hypoxic-ischemic injury parallels the development of calcium binding protein, calbindin D28k, probably resulting in buffering neurotoxic increases of intracellular $\mathrm{Ca}^{2+}$ (Goodman 1993).

Experimental data compiled in sheep fetuses demonstrated a maturational change in the cortical response following cerebral hypoperfusion. The severity of the delayed phase of cortical injury and selective neuronal loss increased in mature fetuses. In contrast, immature fetuses had a more rapidly evolving injury leading to necrosis of the subcortical white matter (Reddy 1998). 


\section{References}

Akselrod s, Gordon D, Madwed JB, Snidman NC, Shannon DC, Cohen RJ 1985

Hemodynamic regulation: investigation by spectral analysis. Am J Physiol 249:H867-H875

American Academy of Pediatrics, and the American College of Obstetricians and

Gynecologists 1996 Use and abuse of the Apgar score. Paediatrics 98:141-142.

American College of Obstetricians and Gynecologists 1994 Committee Opinion: Committee on obstetric practice number 137-April 1994 Fetal distress and birth asphyxia. Int J Gynecol Obstet 45:302.

American College of Obstetricians and Gynecologists 1995 Fetal heart rate patterns. Technical Bulletin No. 207

Anderson DF, Parks CM, Faber JJ 1986 Fetal $\mathrm{O}_{2}$ consumption in sheep during controlled long-term reductions in umbilical blood flow. Am J Physiol 250:H1037-H1042.

Apgar V 1953 A proposal for a new method of evaluation of the newborn infant. Curr Res Anesth Analg 32:260-267.

Ball RH, Parer JT, Caldwell LE, Johnson J 1994 Regional blood flow and metabolism in ovine fetuses during severe cord occlusion. Am J Obstet Gynecol 171:1549-55.

Ball RH, Parer JT 1992 The physiologic mechanisms of variable decelerations [see comments]. [Review]. Am J Obstet Gynecol 166:1683-8; discussion 1688-9

Barcroft J 1947 Researches on prenatal life. Blackwell Scientific Publications, Oxford, pp 260-272.

Bax MCO 1964 Terminology and classification of cerebral palsy. Dev Med Child Neurol 6:295-297.

Beard RW, Filshie GM, Knight CA, Roberts GM 1971 The significance of the changes in the changes in the continuous fetal heart rate in the first stage of labour. J Obstet Gynaecol Br Cmnwlth 78:865-881.

Beckman JS 1991 The double-edged role of nitric oxide in brain function and superoxidemediated injury. J Dev Physiol 15:53-59. 
Beeby PJ, Elliott EJ, Hendersonsmart DJ, Rieger ID 1994 Predictive value of umbilical artery pH in preterm infants. Arch Dis Child 71:F93-F96.

Beilharz E, Williams CE, Dragunow M, Sirimanne E, Gluckman PD 1995 Mechanisms of cell death following hypoxic-ischaemic injury in the immature rat: evidence of apoptosis during selective neuronal loss. Mol Brain Res 29:1-14.

Bejar R, Wozniak P, Allard M, Bernischke K, Vaucher Y, Coen R, Berry C, Schragg P, Villegas I, Resnik R 1988 Antenatal origin of neurologic damage in newborn infants I. Preterm infants. Am J Obstet Gynecol 159:357-63.

Bell AW, Kennaugh JM, Battaglia FC, Makowski EL, Meschia G 1986 Metabolic and circulatory studies of fetal lamb at midgestation. Am J Physiol 250:E538-E544.

Bennet L, Rossenrode S, Gunning MI, Gluckman PD, Gunn AJ 1999 The cardiovascular and cerebrovascular responses of the immature fetal sheep to acute umbilical cord occlusion. J Physiol 517.1:247-257.

Benveniste $\mathrm{H}$, Jorgensen MB, Diemer NH, Hansen A 1988 Calcium accumulation by glutamate receptor activation is involved in hippocampal cell damage after ischemia. Acta Neurol Scand 78:529-536.

Berger R, Djuricic B, Jensen A, Hossmann KA, Paschen W 1995 Ontogenic diffferences in energy metabolism and inhibition of protein synthesis in hippocampal slices during in vitro ischemia and $24 \mathrm{~h}$ of recovery. Dev Brain Res 91: 281-291.

Biscoe TJ, Purves MJ, Sampson SR 1969 Types of nervous activity which may be recorded from the carotid sinus nerve in the sheep fetus. J Physiol 202:1-23.

Blair E, Stanley F 1993 When can cerebral palsy be prevented? The generation of causal hypotheses by multivariate analysis of a case-control study. Pediatr Perinatal Epidemiol 7:272-301.

Blanco CE, Dawes GS, Walker DW 1983 Effect of hypoxia on postsynaptic hindlimb reflexes of unanaesthetized fetal and newborn lambs. J Physiol 339:453-466.

Blanco CE, Dawes GS, Hanson MA, McCooke HB 1984 The response to hypoxia of arterail chemoreceptors in fetal sheep and new-born lambs. J Physiol 351:25-37.

Blanco CE, Dawes GS, Hanson MA, McCooke HB 1985 Studies of carotid baroreceptor afferents in fetal and newborn lambs. In: The physiological development of the fetus and the newborn. (Jones CT \& Nathanielsz PW, eds.) pp 595-598. London, Academic Press. 
Blanco CE, Dawes GS, Hanson MA, McCooke HB 1988 Carotid baroreceptors in fetal and newborn sheep. Pediatr Res 24:342-346.

Boddy K, Dawes GS, Fisher R, Pinter S, Robinson JS 1974 Foetal respiratory movements, electrocortical and cardiovascular responses to hypoxaemia in sheep. J Physiol 243:599-618.

Bocking AD, Gagnon R, White SE, Homan J, Milne KM, Richardson BS 1988 Circulatory responses to prolonged hypoxemia in fetal sheep. Am J Obstet Gynecol 159:14181424

Bredt DS, Hwang PM, Snyder SH 1990 Localization of nitric oxide synthase indicating a neural role for nitric oxide. Nature 347:768-770.

Choi DW 1988 Calcium mediated neurotoxicity: Relationship to specific channel types and role in ischemic damage. Trends Neurosci 11:465-469.

Choi DW 1988 Glutamate neurotoxicity and diseases of the nervous system. Neuron 1:623634

Cibils LA 1996 On intrapartum fetal monitoring. Am J Obstet Gynecol 174:1382-1389.

Clark GD 1989 Role of excitatory amino acids in brain injury caused by hypoxia-ischemia, status epilepticus, and hypoglycemia. Clin Perinatol 16:459-474.

Coleridge HM, Coleridge JCG 1980 Cardiovascular afferents involved in regulation of peripheral vessels. Ann Rev Physiol 42:413-427.

Cremer 1906 Über die direkte Ableitung der Aktionstrome des menschlichen Herzens vom Oesophagus und über das Electrokardiogram des Föten. Münchener Medizinische Wochenschrift 53:811.

Cummins SK, Nelson KB, Grether JK, Velie EM 1993 Cerebral palsy in four northern

California counties, births 1983 through 1985. J Pediatr 123:230-237

Dalton KJ, Dawes GS, Patrick JE 1977 Diurnal, respiratory and other rythms of fetal lambs. Am J Obstet Gynecol 127:414

Dalton KJ, Dawes GS, Patrick JE 1983 The autonomic nervous system and fetal heart rate variability. Am J Obstet Gynecol 146:456-462

Dawes GS 1962 The umbilical circulation. Am J Obstet Gynecol 84:1634-1648

Dawes GS, Johnston BM, Walker DW 1980 Relationship of arterial pressure and heart rate in fetal, newborn and adult sheep. J Physiol (Lond ) 309:405-417 
Dawes GS, Lewis BV, Milligan JE, Raoch MR, Talner NS 1968 Vasomotor responses in the hind limbs of fetal and newborn lambs to asphyxia and aortic chemoreceptor stimulation. J Physiol 195:55-81.

de Haan HH, Ijzermans AC, de Haan J, Hasaart TH 1995 The T/QRS ratio of the electrocardiogram does not reliably reflect well-being in fetal lambs. Am J Obstet Gynecol 172:35-43

de Haan HH, Gunn AJ, Gluckman PD 1996 Experiments in perinatal brain injury: What have we learnt? Prenat Neonat Med 1:16-25

de Haan HH, Van Reempts JLH, Vles JSH, de Haan J, Hasaart THM 1993 Effects of asphyxia on the fetal lamb brain. Am J Obstet Gynecol 169:1493-1501

de Haan HH, Gunn AJ, Gluckman PD 1997 Fetal heart rate changes during brief repeated umbilical cord occlusion do not reflect cardiovascular deterioration in fetal lambs. Am J Obstet Gynecol 176:8-17

de Haan HH, Gunn AJ, Williams CE, Gluckman PD 1997 Brief repeated umbilical cord occlusions cause sustained cytotoxic cerebral edema and focal infarcts in near-term fetal lambs. Pediatr Res 41:96-104

de Haa.1 J, Martin CB, Evers JLH, Jongsma HW 1979 Pathophysiologic mechanisms underlying fetal heart-rate patterns. In: Perinatal Medicine. Sixth European Congress, Vienna 1978. Editors: Thalhammer O, Baumgarten K, Pollak A. Georg Thieme Publishers, Stuttgart, Germany.

de Haan J, Martin CB, Evers JLH, Jongsma HW 1981 Pathophysiology of variable and late decelerations. J Perinatol Med 9:7-16.

del Zoppo GJ, Schmid-Schönbein GW, Mori E, Copeland BR, C-M Chang 1991 Polymorphonuclear leukocytes occlude capillaries following middle cerebral artery occlusion and reperfusion in baboons. Stroke 22:1276-1283.

Del Maestro RF1980 An approach to free radicals in medicine and biology. Acta Physiol Scand (Suppl) 492:153-168.

Dobbing J, Sands J 1979 Comparative aspects of the brain growth spurt. Early Hum Dev 3:7983

Dragunow M, Sirimanne E, Lawlor PA, Williams CE, Leah J, Gluckman PD 1992 Accumulation of calcitonin-gene-related peptide during recovery from hypoxicischaemic brain injury in the infant rat. Brain Res Mol Brain Res 4:267-272. 
Espinoza MI, Parer JT 1991 Mechanisms in asphyxial brain damage, and possible pharmacologic interventions, in the fetus. Am J Obstet Gynecol 164:1582-1591.

Evers JLH, de Haan J, Jongsma HW, Crevels AJ, Arts THM, Martin Jr CB 1981 The preejection period of the fetal cardiac cycle. I. Umbilical cord occlusions. Eur J Obstet Gynecol Reprod Biol 11:401-418.

Evan AD, Harrington E, McCarthy N, Gilbert C, Benedict MA, Nunez G 1996 Intergrated control of cell proliferation and apoptosis by oncogenes. In: Apoptosis and Cell Cycle Control in Cancer. Ed. NSB Thomas. Oxford:BIOS:109-29.

Faraci FM, Brian JE, Jr. 1994 Nitric oxide and the cerebral circulation. [Review] [242 refs]. Stroke 25:692-703

Fellman V, Raivio KO 1997 Reperfusion injury as the mechanism of brain damage after perinatal asphyxia [review]. Pediatr Res 41:599-606

Field DR, Parer JT, Auslender RA, Cheek DB, Baker W, Johnson J 1990 Cerebral oxygen consumption during asphyxia in fetal sheep. J Dev Physiol 14:131-137

Field DR, Parer JT, Auslender RA, Baker BW, Ross BK, Leicht CH 1991 Fetal variability and cerebral oxygen consumption in fetal sheep during asphyxia. Eur $\mathrm{J}$ Obstet Gynecol Reprod 42:145-153

Finklestein SP, Caday CG, Kano M, Berlove DJ, Hsu CY, Moskowitz M, Klagsbrun M 1990 Growth factor expression after stroke. Stroke 21:122-124

Freud S 1890 Infantile cerebral paralysis. Russin LA, trans. Coral Gables 1968, Fla.:University of Miami Press.

Furchgott RF, Vanhoutte PM 1989 Endothelium-derived relaxing and contracting factors. FASEB 3:2007-2018.

Gaffney G, Squier MV, Johnson A, Flavell V, Sellers S 1994 Clinical associations of prenatal ischaemic white matter injury. Archives of Disease in Childhood Fetal \& Neonatal Edition X X 70:F101-6

Gagnon R, Johnston L, Murotsuki J 1996 Fetal placental embolization in the late-gestation ovine fetus: alterations in umbilical blood flow and fetal heart rate patterns. Am J Obstet Gynecol 175:63-72

Giussani DA, Spencer JAD, Moore PJ, Bennet L, Hanson MA 1993 Afferent and efferent components of the cardiovascular reflex responses to acute hypoxia in term fetal sheep. J Physiol 461:431-449. 
Gleason CA, Hamm C, Jones MD, Jr. 1990 Effect of acute hypoxemia on brain blood flow and oxygen metabolism in immature fetal sheep. Am J Physiol 258:H1064-9

Gleason CA, Hamm C, Jones MD, Jr. 1989 Cerebral blood flow, oxygenation, and carbohydrate metabolism in immature fetal sheep in utero. Am J Physiol 256:R12648

Gluckman PD, Williams CE 1992 When and why do brain cells die? Dev Med Child Neurol 34:1010-1014

Gluckman PD, Klempt ND, Guan J, Mallard EC, Sirimanne E, Dragunow M, Klempt M, Singh K, Williams CE, Nikolics K 1992a A role for IGF-1 in the rescue of CNS neurons following hypoxic-ischemic injury. Biochem Biophys Res Commun $182: 593-599$

Goodman JH, Wasterlain CG, Masserweh WF, Dean E, Sollas AL, Sloviter RS 1993 Calbindin-D28k immunoreactivity and selective vulnerability to ischemia in the dentate gyrus of the developing rat. Brain Res 606:309-314.

Grant A, Joy M, O'Brien N, Hennessy E, MacDonald D 1989 Cerebral palsy among children born during the Dublin randomised trial of intrapartum monitoring. Lancet 12331236

Green LR, McGarrigle HH, Bennet L, Hanson MA 1998 Angiotensin II and cardiovascular chemoreflex responses to acute asphyxia in the late gestation fetal sheep. J Physiol 507:857-867

Greene KR, Westgate J 1992 Fetal ECG waveform for intrapartum monitoring. Lancet $340: 1171$

Hagberg H, Andersson P, Kjellmer I, Thiringer K, Thordstein M 1987 Extracellular overflow of glutamate, aspartate, GABA and taurine in the cortex and basal ganglia of fetal lambs during hypoxia-ischemia. Neurosci Lett 78:311-317.

Hagberg B, Hagberg G, Olow I 1993 The changing panorama of cerebral palsy in Sweden. VI. Prevalence and origin during the birth year period 1983-1986. Acta Paediatr 82:387393

Hammacher K, Hueter KA, Bokelmann J, Werners PH 1968 Foetal heart frequency and perinatal condition of the foetus and newbom. Gynaecologia 166:349-360.

Hansen A 1977 Extracellular potassium concentration in juvenile and adult rat brain cortex during anoxia. Acta Physiol Scand 99:412-420 
Hansen A 1985 Effect of anoxia on ion distribution in the brain. Physiological Reviews 65:101-148

Hanson MA 1988 The importance of baro- and chemoreflexes in the control of the cardiovascular system. J Dev Physiol 10:491-511.

Harris JL, Krueger TR, Parer JT 1982 Mechanisms of late decelerations of the fetal heart rate during hypoxia. Am J Obstet Gynecol 144:491-496.

Hasaart TH, Talmon $\mathrm{L} 1989$ Electrocardiogram waveform in fetal sheep: a system for ECG analysis. Clin Phys Physiol Meas 10 Suppl B:41-46

Helou SM, Hudak ML, Jones MD, Jr. 1991 Cerebral blood flow response to hypercapnia in immature fetal sheep. Am J Physiol 261:H1366-70

Helou S, Koehler RC, Gleason CA, Jones MD, Traystman RJ 1994 Cerebrovascular autoregulation during fetal development in sheep. Am J Physiol 266:H1069-H1074.

Hohimer AR, Bissonette JM, Richardson BS, Machida LM 1983Central chemical regulation of breathing movements in fetal lambs. Resp Physiol 52:99-111.

Hon EH 1959 Observations on "pathologic" fetal bradycardia. Am J Obstet Gynecol 77:10841092.

Hon EH, Bradfield AM, Hess OW 1961 The electronic evaluation of the fetal heart rate. Am J Obstet Gynecol 82:291.

Hon EH, Lee ST 1963 The fetal electrocardiogram I. The fetal electrocardiogram of the dying fetus. Am J Obstet Gynecol 87: 804-813.

Hon EH, Quilligan EJ 1967 The classification of fetal heart rate. Conn Med 31:779.

Hossmann KA, Sakaki S, Zimmermann V 1977 Cation activities in reversible ischemia of the cat brain. Stroke 8:77-81

Ikeda T, Murata Y, Quilligan EJ, Choi BH, Parer JT, Doi S, Park S-D 1998 Physiologic and histologic changes in near-term fetal lambs exposed to asphyxia by partial umbilical cord occlusion. Am J Obstet Gynecol 178:24-32.

Ikeda T, Murata Y, Quilligan EJ, Parer JT, Doi S, Park S-D 1998a Brain lipid peroxidation and antioxidant levels in fetal lambs 72 hours after asphyxia by partial umbilical cord occlusion. Am J Obstet Gynecol 178:474-478.

Ismay MJA, Lumbers ER, Stevens AD 1979 The action of angiotensin II on the baroreflex of the conscious ewe and the conscious fetus. J Physiol (Lond) 288:467-479 
Itskovitz J, Rudolph AM 1982 Denervation of arterial chemoreceptors and baroreceptors in fetal lambs in utero. Am J Physiol 242:H916-20

Itskovitz J, LaGamma EF, Rudolph AM 1983 Heart rate and blood pressure responses to umbilical cord compression in fetal lambs with special reference to the mechanism of variable deceleration. Am J Obstet Gynecol 147:451-457

Itskovitz J, LaGamma EF, Rudolph AM 1983a The effect of reducing umbilical blood flow on fetal oxygenation. Am J Obstet Gynecol 145:813-818

Itskovitz J, LaGamma EF, Rudolph AM 1987 Effects of cord compression on fetal blood flow distribution and $\mathrm{O} 2$ delivery. Am J Physiol 252:H100-H109

Iwamoto HS, Stucky E, Roman CM 1991 Effect of graded umbilical cord compression in fetal sheep at 0.6-0.7 gestation. Am J Physiol 261:H1268-H1274

Iwamoto HS, Kaufman T, Keil LC, Rudolph AM 1989 Responses to acute hypoxemia in fetal sheep at 0.6-0.7 gestation. Am J Physiol 256:H613-H620

Jensen A, Berger R 1991 Fetal circulatory responses to oxygen lack. [Review]. J Dev Physiol $16: 181-207$

Jensen A, Hohmann M, Kunzel W 1987 Dynamic changes in organ blood flow and oxygen consumption during acute asphyxia in fetal sheep. J Dev Physiol 9:543-559

Johnston BM, Mallard EC, Williams CE, Gluckman PD 1996 Insulin-like growth factor-1 is a potent neuronal rescue agent following hypoxic-ischemic injury in fetal lambs. J Clin Invest 97:300-308

Johnston MV 1996 Brain development and its relationship to patterns of injury. In: Brain injury and pediatric cardiac surgery. Jonas RA, Newburger and Volpe JJ Eds., Butterworth-Heinemann, Boston, pp 13-27.

Jongsma HW, Crevels AJ, Menssen JJ 1989 Variability of the ECG waveform in fetal and neonatal lambs. Clin Phys Physiol Meas 10 Suppl B:47-50

Katz VL, Bowes WA 1992 Meconium aspiration syndrome:Reflections on a murky subject. Am J Obstet Gynecol 166:652.

Kleckner NW, Dingledine R 1991 Regulation of hippocampal NMDA receptors by magnesium and glycine during development. Mol Brain Res 11:151-59.

Knusel M, Michel PP, Schwaber JS, Hefti F 1990 Selective and non-selective stimulation of central cholinergic and dopaminergic development in vitro by nerve growth factor, insulin and the insulin-like growth factors 1 and 2. J Neurosci 10, 558-570. 
Koos BJ 1985 Central stimulationof breathing movements in fetal lambs by prostaglandin synthetase inhibitors. J Physiol 362:455-466.

Kozuma S, Watanabe T, Bennet L, Green LR, Hanson MA 1997 The effect of carotid sinus denervation on fetal heart rate variation in normoxia, hypoxia and post-hypoxia in fetal sheep. Br J Obstet Gyneacol 104:460-465

Krageloh Mann I, Hagberg G, Meisner C, Haas G, Eeg Olofsson KE, Selbmann HK, Hagberg B, Michaelis R 1994 Bilateral spastic cerebral palsy--a comparative study between southwest Germany and western Sweden. II: Epidemiology. Dev Med Child Neurol $36: 473-483$.

Krageloh Mann I, Hagberg G, Meisner C, Schelp B, Haas G, Eeg Olofsson KE, Selbmann HK, Hagberg B, Michaelis R 1993 Bilateral spastic cerebral palsy--a comparative study between southwest Germany and western Sweden. I: Clinical patterns and disabilities. Dev Med Child Neurol 35:1037-1046.

Kuipers IM, Maertzdorf, de Jong DS, Hanson MA, Blanco CE 1997 The effect of hypercapnia and hypercapnia associated with central cooling on breathing in unanesthetized fetal lambs. Pediatr Res 41:90-95.

Künzel W, Mann LI, Bhakthavathsalan A, Airomlooi J 1980 Cardiovascular, metabolic and fetal brain function observation following total cord occlusion. J Perinat Med 8:7384.

Lee CV 1975 A study of fetal heart rate acceleration patterns. Obstet Gynecol 45:142.

Levene MI, Kornberg J, Williams THC 1985 The incidence and severity of post asphyxial encephalopathy in fullterm infants. Early Hum Dev 11:21-28

Lewis AB, Donovan M, Platzker AC 1980 Cardiovascular responses to autonomic blockade in hypoxemic fetal lambs. Biol Neonate 37:233-242.

Lilja H, Karlsson K, Kjellmer I, Lindekrantz K, Olsson T, Rosen KG 1983 Heart rate variability and electrocardiogram changes in the fetal lamb during hypoxia and betaadrenoceptor stimulation. J Perinat Med 12:115-125.

Lilja H, Arulkumaran S, Lindecrantz K, Ratnam SS, Rosen KG 1988 Fetal ECG during labour: a presentation of a microprocessor system. J Biomed Eng 10:348-350

Lin B, Globus MYT, Dietrich D, Busto R, Martinez E, Ginsberg MD 1992 Differing neurochemical and morphological sequelae of global ischemia: comparison of singleand multiple-insult paradigms. J Neurochem 59:2213-2223. 
Lin BW, Dietrich WD, Ginsberg MD, Globus MYT, Busto R 1993 MK-801 (Dizocilpine) Protects the Brain from Repeated Normothermic Global Ischemic Insults in the Rat. $\mathbf{J}$ Cereb Blood Flow Metab 13:925-932

Lindekrantz K, Cerutti S, Civardi S 1993 Power spectrum analysis of the fetal heart rate during noradrenaline infusion and acute hypoxia in the chronic fetal lamb preparation. Int J Biomed Comp 33:199-207.

Little WJ 1862 On the influence of abnormal parturition, difficult labour, premature birth and asphyxia neonatorum on mental and physical conditions of the child, especially in relation to deformities. Trans Obstet Soc London 3:293-344.

Lou HC 1988 The "lost autoregulation hypothesis" and brain lesions in the newborn--an update. [Review]. Brain \& Development 10:143-146

Low JA, Galbraith RS, Muir D, Killen H, Karchmar J, Campbell D 1978 Intrapartum fetal asphyxia: a preliminary report in regird to long-term morbidity. Am J Obstet Gynecol 130:525-533.

Low JA 1988 The role of blood gas and acid-base assessment in the diagnosis of intrapartum fetal asphyxia. Am J Obstet Gynecol 159:1235-1240.

Low JA, Panagiotopoulos C, Derrick EJ 1994 Newborn complications after intrapartum asphyxia with metabolic acidosis in the term fetus. Am J Obstet Gynecol 172:10811087.

Low JA 1997 Intrapartum fetal asphyxia: Definition, diagnosis, and classification. Am J Obstet Gynecol 176:957-959.

Luthy DA, Shy KK, van Belle G, Larson EB, Hughes JP, Benedetti TJ, Brown ZA, Effer S, King JF, Stenchever MA 1987 A randomized trial of electronic fetal monitoring in preterm labor. Obstet Gynecol 69:687.

MacDonald D 1996 Cerebral palsy and intrapartum fetal monitoring [editorial; comment] $\mathrm{N}$ Engl J Med 334:659-660

MacDonald D, Grant A, Sheridan-Pereira M, Boylan P, Chalmers I 1985 The Dublin randomized controlled trial of intrapartum fetal heart rate monitoring. Am J Obstet Gynecol 152:524.

MacDonald JW, Silverstein FS, Johnston MV 1988 Neurotoxicity of N-methyl-D-aspartate is markedly enhanced in the developing rat central nervous system. Brain Res 459:200203. 
MacDonald JW, Trescher WH, Johnston MV 1990 The selective ionotropic-type quisqualate receptor agonist AMPA is a potent neurotoxin in immature rat brain. Brain Res 526:165-68.

MacDonald JW, Trescher WH, Johnston MV 1992 Susceptibility of brain to AMPA induced excitotoxicity transiently peaks during early postnatal development. Brain Res 583 : 54-70.

Maclachlan NA, Spencer JA, Harding K, Arulkumaran S 1992 Fetal acidaemia, the cardiotocograph and the T/QRS ratio of the fetal ECG in labour. Br J Obstet Gynaecol 99:26-31

Mallard EC, Williams CE, Johnston BM, Gunning MI, Davis SL, Gluckman PD 1995 Repeated episodes of umbilical cord occlusion in fetal sheep lead to preferential damage to the striatum and sensitise the heart to further insults. Pediatr Res 37:707713

Mallard EC, Williams CE, Johnston BM, Gluckman PD 1994 Increased vulnerability to neuronal damage following umbilical cord occlusion in the fetal sheep with advancing gestation. Am J Obstet Gynecol 170:206-214

Mallard EC, Gunn AJ, Williams CE, Johnston BM, Gluckman PD 1992 Transient umbilical cord occlusion causes hippocampal damage in the fetal sheep. Am J Obstet Gynecol $167: 1423-1430$

Mallard EC, Williams CE, Gunn AJ, Gunning MI, Gluckman PD 1993 Frequent episodes of brief ischemia sensitize the fetal sheep brain to neuronal loss and induce striatal injury. Pediatr Res 33:61-65

Marletta MA, Yoon PS, Iyengar R, Leaf CD, Wishnok IS 1988 Macrophage oxidationof Larginine to nitrite and nitrate: nitric oxide is an intermediate. Biochem. 27:87068711.

Marlow N 1992 Do we need an Apgar score? Arch Dis Child 67:765-769.

Marrin M, Paes BA 1988 Birth asphyxia: does the Apgar score have diagnostic value? Obstet Gynecol 72:120-123.

Martin Jr CB, de Haan J, van der Wildt B, Jongsma HW, Dieleman A, Arts THM. 1979 Mechanisms of late decelerations in the fetal heart rate. A study with autonomic blocking agents in fetal lambs. Eur J Obstet Gynecol Reprod Biol 9:361-373.

Mathews TG, Vaquier J, Chavinie J, Sureau C 1979 Relevance of the gestational age distribution of meconium passage in utero. Pediatrics $64: 30$. 
Matsuda Y, Patrick J, Carmichael L, Challis J, Richardson B 1992 Effects of sustained hypoxemia on the sheep fetus at midgestation - endocrine, cardiovascular, and biophysical responses. Am J Obstet Gynecol 167:531-540

McDonald JW, Johnston MV 1990 Physiological and pathophysiological roles of excitatory amino acids during central nervous system development. Brain Res Rev 15:41-70.

McIntosh GH, Baghurst KI, Potter BJ, Hetzel BS 1979 Foetal brain development in the sheep. Neuropathology \& Applied Neurobiology 5:103-114

Mehmet H, Yue X, Squier MV 1994 Increased apoptosis in the cingulate sulcus of newborn piglets following transient hypoxia -ischaemia is related to the degree of high energy phosphate depletion during the insult. Neurosci Lett 181:121-125.

Michaelis R, Hege U 1982 Die infantilen Zerebralparesen. Aktuelle Neurologie 9:35-41.

Miura M, Zhu H, Rotello R, Hartweig EA, Yuan J 1993 Induction of apoptosis in fibroblasts by $\mathrm{IL}-1$ beta converting enzyme, a mammalian homologue of the c-elegans cell death gene ced-9. Cell; 75:653-60.

Moncada S, Palmer RMJ, Higgs EA 1991 Nitric oxide: physiology, pathophysiology, and pharmacology. Pharmacol Rev 43:109-142

Monyer H, Burnashev N, Laurie DJ, Sakman B, Seeburg PH 1994 Developmental and regional expression in the rat brain and functional properties of four NMDA receptors. Neuron 12:520-540.

Murphy KW, Russell V, Johnson P, Valente J 1992 Clinical assessment of fetal electrocardiogram monitoring in labour. Br J Obstet Gynaecol 99:32-37

Murray HG 1986 The fetal electrocardiogram: current clinical developments in Nottingham. J Perinat Med 14:399-404.

Mutch L, Alberman E, Hagberg B, Kodama K, Velickovic Perat M 1992 Cerebral palsy epidemiology: where are we now and were are we going? Dev Med Cild Neurol 34:547-555.

Naeye RL, Peters EC, Bartholomew M, Landis J 1989 Origins of cerebral palsy. Am J Dis Child 143:1154-1161.

Naeye RL 1995 Can meconium in the amniotic fluid injure the fetal brain? Obstet Gynecol 86:720-724.

Nelson KB, Ellenberg JH 1986 Antecedents of cerebral palsy. Multivariate analysis of risk. N Engl J Med 315:81-86 
Nelson KB, Dambrosia JM, Ting TY, Grether JK 1996 Uncertain value of electronic fetal monitoring in predicting cerebral palsy. N Engl J Med 334:613-618

Novelli A, Reilly JA, Lysko PG, Henneberry RC 1988 Glutamate becomes neurotoxic via the $\mathrm{N}$-methyl-D-aspartate receptor when intracellular energy levels are reduced. Brain Res 451:205-212

Palme Kilander C 1992 Methods of Resuscitation in Low-Apgar-Score Newborn Infants - A National Survey. Acta Paediatr 81:739-744

Palmer C, Brucklacher RM, Christensen MA, Vannucci RC 1990 Carbohydrate and energy metabolism during the evolution of hypoxic-ischemic brain damage in the immature rat. J Cereb Blood Flow Metab 10:227-235

Palmer RMJ, Ashton DS, Moncada S 1988 Vascular endothelial cells synthesize nitric oxide from L-arginine. Nature 333:664-666

Papile L, Rudolph AM, Heymann MA 1985 Autoregulation of cerebral blood flow in the preterm fetal lamb. Pediatr Res 19:159-161

Parer JT, Dijkstra HR, Vredebregt PP, Harris JL, Krueger TR, Reuss ML 1980 Increased fetal heart rate variability with acute hypoxia in chronically instrumented sheep. Eur $\mathfrak{J}$ Obstet Gynaecol Reprod 10:-93-399.

Paul RH, Suidan AK, Yeh S, Shifrin BS, Hon EH 1975 Clinical fetal monitoring. VII. The evaluation and significance of intrapartum baseline fetal heart rate variability. Am J Obstet Gynecol 123:206-210.

Paulson OB, Strandgaard S, Edvinsson L 1990 Cerebral autoregulation. Cerebrovasc Brain Metab Rev 2:161-192

Peeters LLH, Sheldon RE, Jones Jr. MD, Makowski EL, Meschia G 1979 Blood flow to fetal organs as a function of arterial oxygen content. Am J Obstet Gynecol 135:637-646.

Penning DH, Grafe MR, Hammond R, Matsuda Y, Patrick J, Richardson B 1994

Neuropathology of the near-term and midgestation ovine fetal brain after sustained in utero hypoxemia. Am J Obstet Gynecol 170:1425-1432

Pluta R, Lossinsky AS, Wisniewski HM, Mossakowski MJ 1994 Early blood-brain barrier changes in the rat following transient complete cerebral ischemia induced by cardiac arrest. Brain Res 633:41-52.

Ponte J, Purves MJ 1973 Types of afferent nervous activity which may be measured in the vagus nerve of the sheep foetus. J Physiol 229:51-76. 
Ramin KD, Leveno KJ, Kelly MS, Carmody TJ 1996 Amnionic fluid meconium: A fetal environmental hazard. Obstet Gynecol 87:181.

Reddy K, Mallard C, Guan J, Marks K, Bennet L, Gunning M, Gunn A, Gluckman P, Williams C 1998 Maturational change in the response to hypoperfusion injury in the fetal sheep. Pediatr Res 43:674-82.

Rees S, Stringer M, Just Y, Hooper SB, Harding R 1997 The vulnerability of the fetal sheep brain to hypoxemia at mid-gestation. Dev Brain Res 103:103-18.

Rehncrona S, Weslerberg F, Akesson B, Siesjö BK 1982 Brain cortical fatty acids and phospholipids during and following complete and severe incomplete ischemia. J Neurochem 38:84-93

Reuss ML, Rudolph AM 1980 Distribution and recirculation of umbilical and systemic venous blood flow in fetal lambs during hypoxia. J Dev Physiol 2:71-84.

Reynolds ML, Evans CA, Reynolds EO, Saunders NR, Durbin GM, Wigglesworth, JS. 1979 Intracranial haemorrhage in the preterm sheep fetus. Early Hum Dev 3:163-186

Richardson BS, Carmichael L, Homan J, Patrick JE 1993 Cerebral Oxidative Metabolism in Fetal Sheep with Prolonged and Graded Hypoxemia. J Dev Physiol 19:77-83

Ringel M, Bryan RM, Vannucci RC 1991 Regional cerebral blood flow during hypoxiaischemia in the immature fetal rat: comparison of iodoantipyrine and iodoamphetamine as radioactive tracers. Dev Brain Res 59:231-235.

Roohey T, Raju TNK, Moustogiannis AN 1997 Animal models for the study of perinatal hypoxic-ischemic encephalopathy - A critical analysis. Early Hum Dev 47:115-146

Rosen KG, Dagbjartsson A, Henriksson BA, Lagercrantz H, Kjellmer I 1984 The relationship between circulating catecolamines and ST waveform in the fetal lamb electrocardiogram during hypoxia. Am J Obstet Gynecol 149:72-77

Rosen KG, Hrbek A, Karlsson K, Kjellmer I 1986 Fetal cerebral, cardiovascular and metabolic reactions to intermittent occlusion of ovine maternal placental blood flow. Acta Physiol Scand 126:209-216.

Rothman SM, Olney JW 1987 Excitotoxicity and the NMDA receptor. Trends Neurosci 10:299-302.

Rudolph AM 1984 The fetal circulation and its response to stress. J Dev Physiol 6:11-19

Ruth VJ, Raivio KO 1988 Perinatal brain damage: predictive value of metabolic acidosis and the Apgar score. BMJ 297:24-27. 
Saling E 1962 Erstmalige Blutgasanalysen und pH Messungen an Feten unter der Geburt und die klinische Bedeutung dieses neuen Verfahrens. Arch Gynaec 198:62.

Sarnat HB, Sarnat MS 1976 Neonatal encephalopathy following fetal distress. Arch Neurol 33:696-705.

Segar JL, Merrill DC, Smith BA, Robillard JE 1994 Role of sympathetic activity in the generation of heart rate and arterial pressure variability in fetal sheep. Pediatr Res $35: 250-254$.

Shinebourne EA, Vapaavuori EK, Williams RL, Heymann MA, Rudolph AM 1972 Development of baroreflex activity in unanaesthetized fetal and neonatal lambs. Circ Res 31:710-713.

Siassi B, Wu PYK, Blanco C, Martin CB 1979 Baroreceptor and chemoreceptor responses to umbilical cord occlusion in fetal lambs. Biol Neonate 35:66-79.

Silverstein FS, Naik B, Simpson J 1991 Hypoxia-ischemia stimulates hippocampal glutamate efflux in perinatal rat brain: an in vivo microdialysis study. Pediatr Res 30:587-590

Skillern L, Cockburn J, Benjamin M, Pearce JM, Sahota D, Reed N, Mohajer M, James D, Symonds M 1994 A comparative study of the fetal electrocardiogram recorded by the STAN and Nottingham systems. Br J Obstet Gynaecol 101:582-586

Skupski DW, Chevernak FA, McCullough LB, Horowitz S 1996 Cesarian delivery for intrapartum fetal heart rate abnormalities: incorperating survey data into clinical judgement. Obstet Gynecol 88:60-64.

Southern EM 1957 Fetal anoxia and its potential relation to changes in the prenatal fetal electrocardiogram. Am J Obstet Gynecol 73:233-247.

Squier M, Keeling JW 1991 The incidence of prenatal brain injury. Neuropathol App1 Neurobiol 17:29-38

Stange L, Rosen KG, Hokegard KH 1977 Quatification of fetal heart rate variability in relation to oxygenation in the sheep fetus. Acta Obstet Gynecol Scand 56:205-209.

Tan WKM, Williams CE, During MJ, Mallard CE, Gunning MI, Gunn AJ, Gluckman PD 1996 Accumulation of cytotoxins during the development of seizures and edema after hypoxic-ischemic injury in late gestation fetal sheep. Pediatr Res 39:791-797

Thacker SB, Stroup DF, Peterson HB 1995 Efficacy and safety of intrapartum electronic fetal monitoring: an update. Obstet Gynecol 86:613. 
Thiringer K, Blomstrand S, Hrbek A, Karlsson K, Kjellmer I 1982 Cerebral arterio-venous difference for hypoxanthine and lactate during graded asphyxia in the fetal lamb. Brain Res 239:107-117

Thiringer K, Hrbek A, Karlsson K, Rosen K, Kjellmer I 1987 Postasphyxial cerebral survival in newborn sheep after treatment with oxygen free radical scavengers and a calcium antagonist. Pediatr Res 221:62-66

Thomas WS, Mori E, Copeland BR, Yu J-Q, Morrissey JH, del Zoppo GJ 1993 Tissue factor contributes to microvascular defects after focal cerebral ischemia. Stroke 24:847-854.

Thurber S, Mikati MA, Stafstrom CE, Jensen FE, Holmes GL 1994 Quisqualic acid-induced seizures during development: a behavioral and EEG study. Epilepsia 35:868-875.

Ting P, Yamaguchi S, Bacher JD, Killens RH, Myers RE 1984 Failure to produce germinal matrix or intraventricular hemorrhage by hypoxia, hypo-, or hypervolemia. Exp Neurol 83:449-460

Towfighi J, Mauger D, Vannucci RC, Vannucci SJ 1997 Influence of age on the cerebral lesions in an immature rat model of cerebral hypoxia-ischemia: a light microspic study. Dev Brain Res 100:149-60.

Tweed A, Cote J, Lou H, Greorgy G, Wade J 1986 Impairment of cerebral blood flow autoregulation in the newborn lamb by hypoxia. Pediatr Res 20:516-519.

van Wijngaarden WJ, Sahota DS, James DK, Farrel T, Mires GJ, Wilcox M, Chang A 1996 Improved intrapartum surveillance with $P R$ interval analysis of the fetal electrocardiogram: a randomized trial showing a reduction in fetal blood sampling. Am J Obstet Gynecol 174:1295-1299.

van Wijngaarden WJ, de Haan HH, Sahota DS, James DK, Symonds EM, Hasaart THM 1996a Changes in the PR time interval-fetal heart rate relationship of the ECG during fetal compromise in chronically instrumented sheep. Am J Obstet Gynecol 175:548554.

Vintzileos AM, Antsaklis A, Varvarigos I, Papas C, Sofatzis I, Montgomery JT 1993 A randomized trial of intrapartum electronic fetal heart rate monitoring versus intermittent auscultation. Obstet Gynecol 81:899-907

Vintzileos AM, Nochimson DJ, Guzman ER, Knuppel RA, Lake M, Schifrin BS 1995 Intrapartum electronic fetal heart rate monitoring versus intermittent auscultation: a meta-analysis [see comments]. Obstet Gynecol 85:149-155 
Vintzileos AM, Nochimson DJ, Antsaklis A, Varvarigos I, Guzman ER, Knuppel RA 1995a Comparison of intrapartum electronic fetal heart rate monitoring versus intermittent auscultation in detecting fetal acidemia at birth. Am J Obstet Gynecol 173:1021-1024

Volpe JJ, Pasternak JF 1977 Parasagittal cerebral injury in neonatal hypoxic-ischemic encephalopathy: clinical and neuroradiologic features. J Paediatrics 91:472-476.

Volpe JJ 1992 Brain injury in the premature infant - Current concepts of pathogenesis and prevention. Biol Neonate 62:231-242

Walker J 1953 Foetal anoxia. J Obstet Gynaecol Br Commonw 61:162.

Weiss E, Hitschold T, Berle P 1991 Umbilical artery blood flow velocity waveforms during variable decelerations of the fetal heart rate. Am J Obstet Gynecol 164:534-540.

Westgate J, Harris M, Curnow JS, Greene KR 1992 Randomised trial of cardiotocography alone or with ST waveform analysis for intrapartum monitoring. Lancet 340:194-198

Westgate J, Harris M, Curnow JSH, Greene KR 1993 Plymouth randomized trial of cardiotocogram only versus ST waveform plus cardiotocogram for intrapartum monitoring in 2400 cases. Am J Obstet Gynecol 169:1151-1160

Whyllie AH 1980 Glucocorticoid-induced thymocyte apoptosis is associated with endogenous endonuclease activation. Nature;284:555-56.

Widmark C, Hokegard KH, Lagercrantz H, Lilja H, Rosen KG 1989 Electrocardiographic waveform changes and catecholamine responses during acute hypoxia in the immature and mature fetal lamb. Am J Obstet Gynecol 160:1245-1250

Widmark C, Lindecrantz K, Murray H, Rosen KG 1992 Changes in the PR, RR intervals and ST waveform of the fetal lamb electrocardiogram with acute hypoxemia. J Dev Physiol 18:99-103

Williams Obstetrics (Cunningham et al. eds.) 20 $0^{\text {th }}$ edition 1997 Chapter 14 Intrapartum assessment, pg 359 .

Williams CE, Gunn AJ, Mallard EC, Gluckman PD 1992 Outcome after ischemia in the developing sheep brain: An electroencephalographic and histological study. Ann Neurol 31:14-21

Wolfe LS 1982 Eicosanoids: prostaglandins, thromboxanes, leukotrienes, and other derivates of carbon-20 unsaturated fatty acids. J Neurochem 38:1-14.

Yaffe H, Parer JT, Block BS, Llanos AJ 1987 Cardiorespiratory responses to graded reductions of uterine blood flow in the sheep fetus. J Dev Physiol 9:325-336 
Yager JY, Shuaib A, Thornhill J 1996 The effect of age on susceptibility to brain damage in a model ofglobal hemispheric hypoxia-ischemia. Dev Brain Res 93:143-154.

Yamada K, Kinoshita A, Kohmura E, Sakaguchi T, Taguchi J, Kataoka K, Hayakawa T 1991 Basic fibroplast growth factor prevents thalamic degeneration after cortical infarction. J Cereb Blood Flow Metab 11:472-478.

Yeh M-N, Morishima HO, Niemann WH, James LS 1975 Myocardial conduction defects in association with compression of the umbilical cord. Am J Obstet Gynecol 121:951957.

Young BK 1995 A guest editorial: monitoring the fetal heart: a continuing controversy. Obstet Gynecol Surv 50:699-700.

Yue X, Mehmet H, Penrice J, Cooper C, Cady E, Wyatt JS, Reynolds EOR, Edwards AD, Squier MV 1997 Apoptosis and necrosis in the newborn piglet brain following transient cerebral hypoxia-ischaemia. Neuropathol Applied Neurobiol 13:16-25. 


\section{Chapter 3}

Absence of neuronal damage after umbilical cord occlusion of 10,15 and 20 minutes in midgestation fetal sheep

Han Keunen, MD . Carlos E. Blanco. MD. PhD .Jos L.H. van Reempts and Tom H.M. Hasaart MD. $\mathrm{PhD}$

(Am JObstet Gynccol 1997:176:515-520) 


\begin{abstract}
Title: Absence of neuronal damage after umbilical cord occlusion of 10,15 and 20 minutes in midgestation fetal sheep

Objectives: To determine whether neuronal damage results after total umbilical cord occlusion of increasing duration in midgestation fetal sheep.
\end{abstract}

Study design: We performed total umbilical cord occlusion during $10(n=11), 15(n=8)$ or 20 $(n=4)$ minutes in chronically instrumented midgestation fetal sheep. Nine fetuses served as sham controls. During the experiment, fetal blood pressure (MAP) and heart rate were continuously recorded. Fetal blood gas analyses were performed at regular intervals before, during and after the occlusion. Three days after the occlusion neuronal damage was evaluated histologically in three regions of the fetal brain.

Results: Total umbilical cord occlusion resulted in hypotension, bradycardia, severe mixed acidemia, hypoxia and hypercapnia. All fetuses survived the occlusion. No neuronal damage nor macroscopic intraventricular and/or germinal matrix hemorrhages were observed in either group.

Conclusion: Prolonging the duration of total umbilical cord occlusion in midgestation fetal sheep resulted in a progressive increase in the severity of asphyxia, not in neuronal damage. 


\section{Introduction}

Neurological sequelae of the newborn and infant, like cerebral palsy, are thought to be the consequence of antepartum rather than perinatal asphyxia. Antepartum asphyctic events, such as cord complications and uteroplacental insufficiency, may result in irreversible damage of the human fetal brain which becomes evident in the postpartum period $(1,2)$. In the immature neonate these events may result in periventricular leukomalacia, multifocal necrosis of white matter and intra-/ and periventricular hemorrhages (3).

Previous experimental studies described fetal brain damage after isolated cerebral and global asphyxia (4-9). Cerebral asphyxia, induced by transient isolated cerebral ischemia, almost invariably produced brain damage (9). Global fetal asphyxia, however, produced brain damage depending on the method of induction and the age of the fetus (4-8), for example, only mild neuronal damage was demonstrated in mature fetal sheep after reduction of the uterine perfusion (8), whereas severe neuronal damage could be observed in mature but not in immature fetal sheep after 10 minutes total umbilical cord occlusion $(4,5)$. Intrauterine asphyxia involves the whole fetus rather than the brain alone. During asphyxia, blood flow is centralized to priority organs (brain, heart, adrenal medulla) to maintain oxygen delivery $(10,11,12)$. When cerebral oxygen shortage develops as a result of failing compensatory mechanisms, brain damage may result as a consequence of immediate primary neuronal cell death or secondary neuronal loss some time after the insult $(13,14)$.

Mallard et al. (5) showed that global asphyxia, induced by total umbilical cord occlusion of 10 minutes, did not produce neuronal damage in immature fetal sheep. The question remains whether neuronal damage occurs in midgestation fetal sheep after total umbilical cord occlusion of longer duration. We tested the hypothesis that the occurrence of neuronal damage in immature fetuses is dependent on the duration of the umbilical cord occlusion. Therefore, we performed total umbilical cord occlusion of 10,15 or 20 minutes duration in chronically instrumented midgestation fetal sheep and evaluated several areas of the central nervous system for histological neuronal damage three days after the insult. 


\section{Material and Methods}

Surgery. Thirty-two fetal lambs of midgestational age ( 85 to 90 days) underwent surgery using sterile techniques under general anesthesia (sodium thiopentone $1 \mathrm{~g} / 70 \mathrm{~kg}$ iv for induction, 1\% halothane in a 2:1 nitrous oxide and oxygen mixture for maintenance). $\mathrm{A}$ midline abdominal incision was performed. The uterus was incised, and both fetal hindlimbs were exteriorized. Polyvinyl catheters $(0.6 \mathrm{~mm}$ inner diameter, $1.2 \mathrm{~mm}$ outer diameter $)$ were inserted in both femoral arteries and directed toward the heart to measure fetal arterial blood pressure, heart rate and to allow arterial blood sampling. A reversible cord occluder (model VO-4, Rhodes Medical Instruments, California, U.S.A.) was placed around the umbilical cord and tested for total occlusion volume by infusing sterile saline. Catheters were filled with heparin $(50,000 \mathrm{IE} / \mathrm{ml})$. All catheters were exteriorized through a small incision in the flank of the ewe. Ewes were housed in individual cages with free access to food and water. A recovery period of at least three days followed the operation before experiments were started. Guidelines for care and use of animals, as approved by the local Animal Medical Ethics Committee, were followed.

Measurements. Fetal blood pressure was determined with the zeropoint at the level of the estimated fetal position. Fetal heart rate was derived from the blood pressure wave form. Signals were collected on personal computer, using a customized hemodynamic data acquisition system, and stored on DAT recorder. Fetal blood gas values and $\mathrm{pH}$ were measured with an automated analyzer (AVL 993, Radiometer, Copenhagen) and corrected for fetal temperature. Fetal hemoglobin concentration $(\mathrm{mmol} / \mathrm{L})$ and hemoglobin oxygen saturation (\%) were measured with a hemoximeter (OSM2 hemoximeter, Radiometer, Copenhagen, Denmark). Arterial oxygen content (mmol/L) was calculated as follows: arterial oxygen content $(\mathrm{mmol} / \mathrm{L})=$ hemoglobin concentration $(\mathrm{mmol} / \mathrm{L}) \times$ hemoglobin oxygen saturation (\%).

Experiments. Fetal heart rate and blood pressure (MAP) were monitored continuously. Base line blood gas analyses were performed 30 minutes and 5 minutes before umbilical cord occlusion. Total umbilical cord occlusion was achieved by infusing sterile saline with the aforementioned total occlusion volume into the occluder. During total umbilical cord occlusion fetal arterial blood was sampled at a 2 minute interval. Occlusion lasted 10 minutes 
( $n=11$, group I), 15 min ( $n=8$, group II) or 20 minutes ( $n=4$, group III). Nine animals served as sham controls (group IV). Sham fetuses were identically instrumented, but not occluded. After release of the cord occluder, fetal arterial blood was sampled for analyses of blood gases and acid-base status at 30 minutes, 1 hour and 2 hours.

Fixation and histologic evaluation. Three days after the cord occlusion, a relaparotomy of the ewe was performed under general anesthesia. The fetal heart was approached by median thoracotomy. The fetus was completely heparinized with injection of $20,000 \mathrm{U}$ heparin into the left cardiac ventricle. A blunt steel catheter was inserted in the left cardiac ventricle. The right atrium was opened and both external jugular veins were dissected and cut. Five hundred $\mathrm{mL}$ of isotonic and isocolloidal fluid (Haemaccel, Hoechst Holland N.V.) was infused in the left ventricle followed by $750 \mathrm{~mL}$ Karnovsky's fixative ( $2 \%$ formaldehyde and $2.5 \%$ glutaraldehyde in phosphate buffer $0.1 \mathrm{~mol} / \mathrm{L}, \mathrm{pH} 7.40$ ). After decapitation the skull was opened, and the head was submerged into the same fixative for additional immersion fixation. After one day immersion fixation the fetal brain was removed from the skull for histologic evaluation. Vibratome sections $(200 \mu \mathrm{m})$ were cut from three areas (parietal cortex, hippocampus and cerebellum). Sections were postfixed in $2 \%$ osmium tetroxide, buffered with barbital acetate $(0.05 \mathrm{~mol} / \mathrm{L}, \mathrm{pH} 7.40)$, dehydrated in graded series of ethanol, and routinely imbedded in Epon. Light microscopic evaluation was performed on $2 \mu \mathrm{m}$ sections stained with toluidine blue by an observer blinded for the experimental situation. Neuronal damage was defined as the degree of coagulative cell changes per cell and per high power field, graded on a 9 point scale, whereby 0 is absence of coagulative changes and 4 is $100 \%$ of the tissue damaged (8).

Statistics. Data are presented as mean \pm SEM. Blood gas analyses and hemodynamic parameters between groups were compared by Mann-Whitney U Test. Histologic scores were compared by Fisher's exact test. A probability of less than 0.05 was considered significant.

\section{Results}

There were no significant differences in blood gases, $\mathrm{pH}$, heart rate and mean arterial blood pressure in group I, II and III compared to sham fetuses (group IV) before the occlusion. All fetuses survived the umbilical cord occlusion. Increasing duration of occlusion resulted in 


\section{0, 15 and 20 minutes umbilical cord occlusion}

severe mixed acidosis. Acidemia, hypoxia and hypercapnia resolved within 30 rain after the occlusion in all groups. Table I summarizes the results of the analyses of fetal arterial $\mathrm{pH}$, $\mathrm{paCO}_{2}(\mathrm{kPa})$, arterial oxygen content (mM) and base excess (mM) before, during and after the umbilical cord occlusion for all groups. At the end of occlusion $\mathrm{pH}$ decreased and $\mathrm{paCO}_{2}$ increased with increasing duration of the occlusion $(p<0.05)$. Arterial oxygen content and base excess decreased significantly after 15 and 20 minutes cord occlusion compared to 10 minutes cord occlusion $(p<0.05) . \mathrm{PaCO}_{2}$ and arterial oxygen content reached baseline values within 30 minutes after release of the cord occluder in all groups. Base excess and $\mathrm{pH}$ normalized within 2 hours after the occlusion in all groups.

The hemodynamic changes before during and after the occlusion are depicted in figure 1 and figure 2. Total umbilical cord occlusion resulted in an immediate rise in fetal MAP followed by a subsequent fall in MAP ending in hypotension at the end of occlusion (figure 1). Severe bradycardia developed immediately after the initiation of cord occlusion and lasted for the duration of the occlusion period (figure 2). After a temporary increase, fetal heart rate gradually decreased to a minimal value at the end of the occlusion. Bradycardia at the end of 15 and 20 minutes occlusion was more severe compared to 10 minutes umbilical cord occlusion ( $\mathrm{p}<0.05$ ); baseline heart rate (bpm): $196.90 \pm 4.09$ (group I), 200.98 \pm 4.06 (group II), $205.84 \pm 8.58$ (group III); delta \% heart rate: $-52.20 \pm 2.74$ (group I), $-62.85 \pm 2.64$ (group II) and $-63.31 \pm 0.72$ (group III). Hypotension after 15 and 20 minutes occlusion was more marked compared to 10 minutes occlusion $(\mathrm{p}<0.05)$; baseline MAP (mmHg): $39.29 \pm 1.81$ (group D), $38.48 \pm 0.98$ (group II), $41.31 \pm 1.50$ (group III); delta \% MAP: $-21.77 \pm 3.77$ (group I), $45.04 \pm 3.45$ (group II) and $-40.99 \pm 9.44$ (group III). Rebound tachycardia and hypertension started instantaneously after release of the cord occluder, reached their maximal values after \pm 4 minutes and resolved within 20 minutes. Rebound tachycardia showed no differences between groups; delta \% heart rate: $23.25 \pm 4.28$ (group I), $19.80 \pm 3.19$ (group II) and $19.57 \pm 6.67$ (group III). Rebound hypertension after 20 minutes occlusion was significantly lower compared to rebound hypertension after 10 minutes occlusion $(\mathrm{p}<0.05)$; delta \% MAP: $39.42 \pm 3.92$ (group I), $32.36 \pm 8.42$ (group II) and 22.67 \pm 4.86 (group III). 
Chapter 3

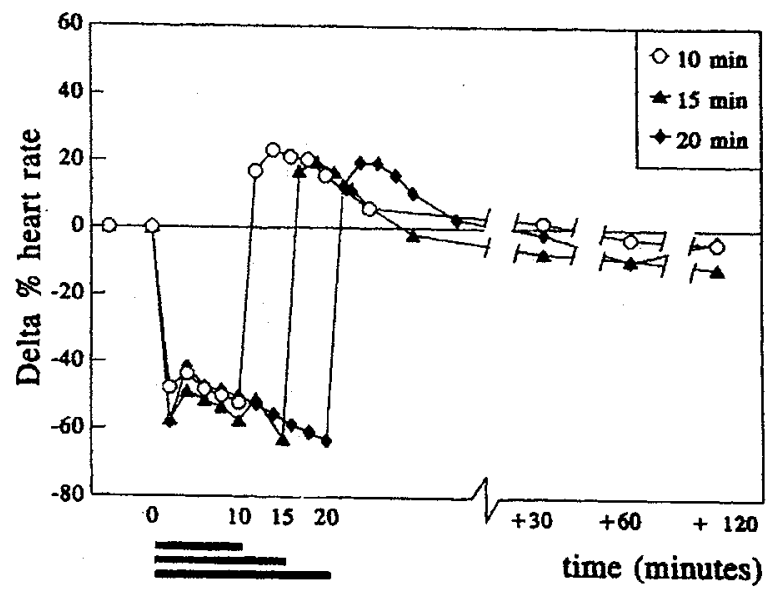

Figure 1. Delta \% fetal heart rate before, during and after 10 minutes (group I), 15 minutes (group II) and 20 minutes (group III) total umbilical cord occlusion. Values (mean) are at 30 minutes before, at the beginning of the occlusion, at a 2 minute regular interval during the occlusion, at 2,4,6,8,10,20,30,60 and 120 minutes after release of the umbilical cord occluder. Horizontal bars indicate the period of umbilical cord occlusion. 


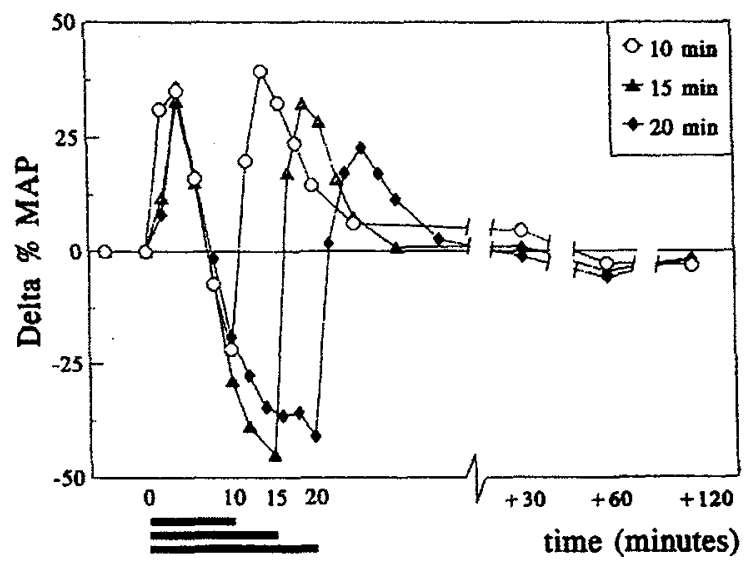

Figure 2. Delta \% fetal MAP before, during and after 10 minutes (group I), 15 minutes (group II) and 20 minutes (group III) total umbilical cord occlusion. Values (mean) are at 30 minutes before, at the beginning of the occlusion, at a 2 minute regular interval during the occlusion, at $2,4,6,8,10,20,30,60$ and 120 minutes after release of the umbilical cord occluder. Horizontal bars indicate the period of umbilical cord occlusion.

Macroscopic observation showed no evidence for intraventricular-germinal matrix hemorrhages (IVH-GMH). Good fixation quality was demonstrated by the absence of residual erythrocytes in open microvessels and the absence of disseminated cell swelling. Light microscopic evaluation did not demonstrate neuronal damage in any of the experimental groups in the parietal cortex, hippocampus and cerebellum (table II). 
Table I. Fetal arterial blood $\mathrm{pH}, \mathrm{paCO}_{2}$, oxygen content $\left(\mathrm{CaO}_{2}\right)$ and base excess (BE) before (baseline), after 5 minutes cord occlusion $(5 \mathrm{~min}$ ), at the end (end) and after the occlusion $(+30 \mathrm{~min},+120 \mathrm{~min}$ ) in the 10 minutes (group I, $\mathrm{n}=11$ ), 15 minutes (group II, $\mathrm{n}=7$ ) and 20 minutes (group $\mathrm{III}, \mathrm{n}=4$ ) total umbilical cord occlusion groups.

\begin{tabular}{|c|c|c|c|c|c|c|}
\hline & group & baseline & $5 \mathrm{~min}$ & end & $+30 \mathrm{~min}$ & $+120 \mathrm{~min}$ \\
\hline$\%$ & I & $7.35 \pm 0.01$ & $7.03 \pm 0.05$ & $6.92 \pm 0.01$ & $7.25 \pm 0.02$ & $7.34 \pm 0.01$ \\
\hline 2 . & II & $7.35 \pm 0.01$ & $7.01 \pm 0.02$ & $6.82 \pm 0.02 *$ & $7.26 \pm 0.01$ & $7.31 \pm 0.03$ \\
\hline 1.8 & III & $7.33 \pm 0.02$ & $6.98 \pm 0.04$ & $6.71 \pm 0.04 \#$ & $7.22 \pm 0.03$ & $7.33 \pm 0.02$ \\
\hline 8 & I & $5.73 \pm 0.10$ & $11.57 \pm 0.26$ & $13.11 \pm 0.37$ & $6.03 \pm 0.27$ & $5.93 \pm 0.11$ \\
\hline 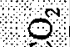 & II & $5.68 \pm 0.15$ & $10.71 \pm 1.16$ & $16.09 \pm 0.70 *$ & $5.91 \pm 0.29$ & $6.26 \pm 0.34$ \\
\hline$\approx$ & III & $6.70 \pm 0.12$ & $12.95 \pm 0.40$ & $19.69 \pm 0.72 \#$ & $6.60 \pm 0.20$ & $6.38 \pm 0.29$ \\
\hline$\Leftrightarrow$ & I & $2.58 \pm 0.14$ & $0.56 \pm 0.06$ & $1.25 \pm 0.07$ & $2.61 \pm 0.18$ & $2.94 \pm 0.21$ \\
\hline$\stackrel{8}{8}$ & $\Pi$ & $2.69 \pm 0.20$ & $0.39 \pm 0.04$ & $0.26 \pm 0.06 *$ & $2.79 \pm 0.16$ & $2.67 \pm 0.27$ \\
\hline 0 & III & $2.44 \pm 0.56$ & $0.40 \pm 0.09$ & $0.40 \pm 0.09 *$ & $2.69 \pm 0.53$ & $2.51 \pm 0.53$ \\
\hline$=$ & I & $-1.05 \pm 0.89$ & $-8.42 \pm 1.70$ & $-12.51 \pm 1.92$ & $-6.69 \pm 1.21$ & $-0.48 \pm 1.24$ \\
\hline$\frac{8}{4}$ & II & $-0.93 \pm 0.68$ & $-9.86 \pm 1.32$ & $-17.14 \pm 1.48 *$ & $-6.03 \pm 1.02$ & $-1.74 \pm 1.75$ \\
\hline $1 \%$ & III & $1.00 \pm 0.80$ & $-10.13 \pm 2.16$ & $-20.85 \pm 2.09 *$ & $-6.40 \pm 1.80$ & $-0.58 \pm 1.17$ \\
\hline
\end{tabular}

Values are mean \pm SEM. ${ }^{*} \mathrm{p}<0.05$ compared to group I ( 10 minutes occlusion). \# $\mathrm{p}<0.05$ compared to group II (15 minutes occlusion). Mann-Whitney U Test. 
Table II. Histological score of brain damage (presence of cell coagulation) on a 9 point scale ranging from 0 (no damage) to 4 ( $100 \%$ of the tissue damaged) in the hippocampus, cerebellum and parietal cortex of the sham, 10 minutes, 15 minutes and 20 minutes cord occlusion groups.

\begin{tabular}{cccc}
\hline group & hippocampus & cerebellum & parietal cortex \\
\hline sham & $0.06(0.06)^{*}$ & $0(0)$ & $0(0)$ \\
$10 \mathrm{~min}$ & $0(0)$ & $0(0)$ & $0(0)$ \\
$15 \mathrm{~min}$ & $0(0)$ & $0(0)$ & $0(0)$ \\
$20 \mathrm{~min}$ & $0(0)$ & $0(0)$ & $0(0)$ \\
\hline
\end{tabular}

Values are mean (SEM). ${ }^{*} \mathrm{p}>0.05$, Fisher's exact test.

\section{Comment}

Acute asphyxia, induced by total umbilical cord occlusion up to 20 minutes, did not result in neuronal damage and/or IVH-GMH in midgestation fetal sheep despite severe acidosis, hypercapnia and hypoxia associated with large hemodynamic changes. Although all fetuses survived, three fetuses of group III showed considerable general edema, indicating that cardiovascular decompensation was at hand. Hypotension is considered an important determinator in the pathogenesis of intrauterine brain damage (20). Prolonging the duration of the occlusion up to 20 minutes in the present study significantly increased the degree of hypotension at the end of the occlusion period. In the present study fetal MAP decreased to approximately $55 \%$ of control value at the end of the occlusion period. The level of hypotension reached during occlusion in the present study may have been insufficient to result in brain ischemia and therefore brain damage. In a comparative study, mature but not immature sheep fetuses developed neuronal damage after 10 minutes cord occlusion, with a decrease of fetal MAP to respectively $68 \%$ and $33 \%$ of control value (5).

Various factors as the developmental anatomic state of the brain and cerebral blood flow autoregulation, may have protected the fetus from neuronal damage in the present experiments. The immature brain has small and less branched neurons with fewer synapses and therefore low basal energy demands. Consequently, midgestation fetal sheep have a rather low cerebral metabolism (15). In combination with preservation of cerebral circulation, energy metabolism can be maintained for a long period during asphyxia (16). The preservation of 
cerebral circulation is secured by cerebral autoregulation. An intact autoregulation of cerebral blood flow has been described in midgestation sheep fetuses under non-asphyxial circumstances (17). During acute hypoxia, an impaired but sufficient cerebral autoregulatory response was reported (16). The ability to maintain membrane function during anoxia may further protect the immature brain $(5,18)$. Furthermore, a variety of maturational factors, such as the maturation of amino acid neurotransmitter systems, may influence the susceptibility and pattern of postasphyxial neuronal damage (19).

It is unlikely that the absence of neuronal damage was due to the timing of the histologic evaluation since neuronal damage was described in midgestation fetal sheep within 3 days after an asphyctic insult $(21,22)$. The histological evaluation used in the present study revealed detailed information at a high resolution level (23). Furthermore, the results of the histological evaluation are in concordance with another study using a similar experimental set up but different methodology of histological evaluation (5).

Macroscopic evaluation revealed no evidence for IVH-GMH. The combination of arterial hypotension-hypertension and impaired autoregulation is thought to induce IVH-GMH in the very premature infant (3). It is known that asphyxia can abolish the protective mechanism of autoregulation (24). Impaired autoregulation in midgestation fetal sheep has been described at reduced cerebral perfusion pressures (25). In the present study both asphyxia and hypotension-hypertension were observed. Rebound hypertension, however, decreased with longer duration of the occlusion. This combination of severe asphyxia with moderate hypertension proved insufficient to produce IVH-GMH. Accordingly, no IVH-GMHs were described in mid- and late gestation fetal sheep after 10 minutes total umbilical cord occlusion $(4,5)$, or after a combination of hypoxia and hypo- or hypervolemia (26). In contrast, IVHGMHs were produced in exteriorized immature fetal lambs following a combination of asphyxia and intermittent elevation of venous and arterial pressure, and intermittently raised arterial pressure alone (27). The occurence of IVH-GMH presumably depend on the combination of severity of the asphyctic insult, frequency and amplitude of fluctuations in vascular pressure and gestational age.

Total umbilical cord occlusion resulted in hypercapnia and hypoxia as a result of an interruption of the oxygen and carbon dioxide exchange between the maternal and fetal 


\section{15 and 20 minutes umbilical cord occlusion}

circulation. After sustained hypoxia, metabolic acidosis developed as a result of anaerobic metabolism in the fetus. Increase of the duration of the cord occlusion resulted in a more severe mixed acidemia, hypercapnia and hypoxia. Although severely acidotic, all blood gas parameters normalized in all fetuses within two hours after release of the cord occluder, demonstrating sufficient buffer capacity at this gestational age.

Total umbilical cord occlusion was immediately followed by an increase of fetal mean arterial blood pressure. This response is generated by an increase of vascular resistance in the umbilical circulation due to the cord occlusion. The rise in blood pressure and developing hypoxia result in bradycardia through a baroreceptor and chemoreceptor mediated vagal response. Hypoxia may lead to a further increase in peripheral vascular resistance caused by a peripheral chemoreceptor reflex, the release of cathecholamines and other humoral vasoconstrictors $(28,29)$. Approximately four minutes after the onset of the occlusion, fetal arterial blood pressure decreased as a result of myocardial depression induced by hypoxia, eventually leading to hypotension at the end of the occlusion period. After release of the cord occluder a rebound hypertension and tachycardia was observed, likely due to elevated plasma levels of cathecholamines. Rebound hypertension after 20 minutes cord occlusion compared to 10 or 15 minutes occlusion was significant lower. The mechanism behind this observation remains unclear. Possible explanations are a lower peripheral vascular resistance after release of the cord occluder as a result of circulatory decentralization (11) and/or the lower MAP from which the fetuses in group III had to recover.

The present study has shown that midgestation fetal sheep are resistant to histological neuronal damage and intracranial hemorrhage after total umbilical cord occlusion up to 20 minutes. So far the viability of neuronal cells has been used tor visualize and quantificate brain damage. However, other parameters must be studied to elucidate the long-term sequelae of a similar asphyctic event in the immature sheep fetus emphasizing neuronal function rather than form. Extrapolating the results of this study to the human situation should be done with great reserve. The immature human brain, being proportionally greater than immature sheep brain, has a higher metabolic rate and receives a greater percentage of the cardiac output. The influence of species difference on susceptibility for neuronal damage is not known. 


\section{References}

1. Bejar R, Wozniak P, Allard M, Bernischke K, Vaucher Y, Coen R, Berry C, Schragg $P$, Villegas I, Resnik R. Antenatal origin of neurologic damage in newborn infants. Am J Obstet Gynecol 1988;159:357-363.

2. Mann LI. Pregnancy events and brain damage. Am J Obstet Gynecol 1986;155:6-9.

3. Volpe JJ. Brain injury in the premature infant - current concepts of pathogenesis and prevention. Biol Neonate 1992;62:231-242.

4. Mallard EC, Gunn AJ, Williams CE, Johnston BM, Gluckman PD. Transient umbilical cord occlusion causes hippocampal damage in the fetal sheep. Am J Obstet Gynecol 1992;167:1423-1430.

5. Mallard EC, Gunn AJ, Williams CE, Johnston BM, Gluckman PD. Increased vulnerability to neuronal damage after umbilical cord occlusion in fetal sheep with advancing gestation. Am J Obstet Gynecol 1994;170:206-214.

6. Clapp III JF, Mann LI, Peress NS, Szeto HH. Neuropathology in the chronic fetal lamb preparation: Structure-function correlates under different environmental conditions. Am J Obstet Gynecol 1981;141:973-986.

7. Clapp III JF, Peress NS, Wesley M, Mann LI. Brain damage after intermittent partial cord occlusion in the chronically instrumented fetal lamb. Am J Obstet Gynecol 1988;159:504-509.

8. de Haan HH, Van Reempts JLH, Vles JSH, de Haan J, Hasaart THM. Effects of asphyxia on the fetal lamb brain. Am J Obstet Gynecol 1993;169:1493-1501.

9. Williams CE, Gunn AJ, Synek B, Gluckman PD. Delayed seizures occurring with hypoxic-ischemic encephalopathy in the fetal sheep. Pediatr Res 1990;27:561-565.

10. Jensen A, Hohmann M, Künzel W. Dynamic changes in organ blood flow and oxygen consumpiton during acute asphyxia in fetal sheep. J Dev Physiol 1987;9:543559 .

11. Jensen A, Berger R. Fetal circulatory responses to oxygen lack. J Dev Physiol 1991;16:181-207.

12. Peeters LLH, Sheldon RE, Jones MD, Makowski EL, Meschia G. Blood flow to fetal organs as a function of arterial oxygen content. Am J Obstet Gynecol 1979;159:14181424. 
13. de Haan HH, Hasaart THM. Neuronal death after perinatal asphyxia. Eur J Obstet Gynecol Reprod Biol 1995;61:123-127.

14. Gluckman PD, Williams CE. When and why do brain cells die? Dev Med Child Neurol 1992;34:1010-1014.

15. Gleason CA, Hamm C, Jones Jr. MD. Cerebral blood flow, oxygenation, and carbohydrate metabolism in immature fetal sheep in utero. Am J Physiol 1989;256:R1264-1268.

16. Gleason CA, Hamm C, Jones Jr. MD. Effect of acute hypoxemia on brain blood flow and oxygen metabolism in immature fetal sheep. Am J Physiol 1990;258:H10641069.

17. Papile L, Rudolph AM, Heyman MA. Autoregulation of cerebral blood flow in the preterm fetal lamb. Pediatr Res 1985;19:159-161.

18. Hansen A. Extracellular potassium concentration in juvenile and adult rat brain cortex during anoxia. Acta Physiol Scand 1977;99:412-420.

19. McDonald JW, Johnston MV. Physiological and pathophysiological roles of excitatory amino acids during central nervous system development. Brain Res Rev 1990;15:41-70.

20. Wagner KR, Ting P, Westfall MV, Yamaguchi S, Bacher JD, Myers RE. Brain metabolic correlates of hypoxic-ischemic cerebral necrosis in mid-gestational sheep fetuses: significance of hypotension. J Cereb Blood Flow Metab 1986;6:425-434.

21. Penning DH, Grafe MR, Hammond R, Matsuda Y, Patrick J, Richardson B.

Neuropathology of the near-term and midgestation ovine fetal sheep after sustained in utero hypovolemia. Am J Obstet Gynecol 1994;170:1425-32.

22. Ting P, Yamaguchi S, Bacher JD, Killens RH, Myers RE. Hypoxic-ischemic cerebral necrosis in midgestational sheep fetuses: physiopathologic correlations. Exp Neurol $1983 ; 80: 227-245$.

23. Brown AW, Brierley JB. Anoxic-ischaemic cell changes in rat brain. Light microscopic and fine-structural observations. J Neurol Sci 1972;16:59-84.

24. Lou HC. The "lost autoregulation hypothesis" and brain lesions in the newborn, an update. Brain Dev 1988;10:143-146.

25. Helou S, Koehler RC, Gleason CA, Jones MD, Traystman RJ. Cerebrovascular autoregulation during fetal development in sheep. Am J Physiol 1994;266:H10691074. 
26. Ting P, Yamaguchi S, Bacher JD, Killens RH, Myers RE. Failure to produce germinal matrix or intraventricular hemorrhage by hypoxia, hypo-, or hypervolemia. Exp Neurol 1984;83:449-460.

27. Reynolds ML, Evans CAN, Reynolds EOR, Sauders NR, Durbin GM, Wigglesworth JS. Intracranial haemorrhage in the preterm sheep fetus. Early Human Develop 1979;3:163-186.

28. Siassi B, Wu PYK, Blanco CE, Martin CB. Baroreceptor and chemoreceptor responses to umbilical cord occlusion in fetal lambs. Biol Neonate 1979;35:66-73.

29. Giussani DA, Spencer JAD, Moore PJ, Bennet L, Hanson MA. Afferent and efferent components of the cardiovascular reflex responses to acute hypoxia in term fetal sheep. J Physiol 1993;461:431-449. 


\section{Chapter 4}

Transient umbilical cord occlusion in late gestation fetal sheep

results in hippocampal damage but not in cerebral arterio-venous difference for nitrite, a stable end product of nitric oxide

Han Keunen ,MD , Nicolaas E.P. Deutz , MD, PhD. Jos L.H. Van Reempts and Tom H.M. Hasaart . $\mathrm{MD}, \mathrm{PhD}$

(J Soc Gynecol Iovest 1999:6:120-126) 
Nitric oxide and fetal asphyxia

\section{Abstract}

Objective: To investigate the effect of total umbilical cord occlusion on cerebral arteriovenous difference for nitrite (a stable end product of nitric oxide) and neuronal outcome.

Study design: The cord was totally occluded for 10 minutes in 14 late gestation (gestational age 113-120 days) chronically instrumented fetal sheep. Arterial (carotid artery) and venous (superior sagittal sinus) blood samples were taken at regular intervals for determination of acid-base status, glucose, lactate and nitrite plasma levels. Three days after the occlusion period the fetal brain was perfusion fixed and the parietal cortex, hippocampus and cerebellum were scored for neuronal damage.

Results: Three fetuses died shortly after the occlusion period. Total umbilical cord occlusion resulted in a combined respiratory and metabolic acidosis as observed in carotid arterial blood gas samples (pH: $6.96 \pm 0.02 ; \mathrm{CaO}_{2}(\mathrm{mM}): 0.43 \pm 0.9 ; \mathrm{PaCO}_{2}(\mathrm{kPa}): 13.46 \pm 0.38$; base excess $(\mathrm{mM}):-11.1 \pm 0.8 ;$ lactate $(\mathrm{mM}): 10.57 \pm 0.95)$, bradycardia $(75 \pm 9 \mathrm{bpm})$ and hypotension $(29.85 \pm 3.00 \mathrm{mmHg})(\mathrm{n}=14$, values are mean $\pm \mathrm{SEM})$. Selective brain damage was observed in the hippocampus in 10 of the 11 surviving fetal sheep. No changes in arterial, venous and cerebral arterio-venous difference for nitrite plasma levels were observed $(n=11)$.

Conclusion: Total umbilical cord occlusion of 10 minutes in preterm fetal sheep results in hippocampal damage but not in changes of cerebral arterio-venous difference for nitrite plasma levels, a stable end product of NO. 


\section{Introduction}

Since nitric oxide (NO) was discovered as a novel neurotransmitter, vasodilatator and cytotoxic agent (1), several investigators studied its potential pathophysiological role in perinatal neuronal damage $(2,3)$. Controversy exists on whether NO is friend or foe regarding brain damage after an hypoxic-ischemic incident. Recently, a beneficial role for endothelial nitric oxide synthase (eNOS) and a deleterious role for neuronal nitric oxide synthase (nNOS) was proposed (4). So far, most studies were conducted in neonatal rat pups, i.e. in an ex utero environment. In utero, a surge of citrulline (a by-product of NO synthesis) was measured by microdialysis in the parasagittal cortex after 30 minutes global cerebral ischemia in a chronic fetal sheep preparation (5). However, in clinical asphyxia, the whole fetus rather than the brain alone is compromized. Therefore, experiments were performed in models with better resemblance to the pathophysiological circumstances of human fetal asphyxia. For instance, total umbilical cord occlusion of 10 minutes results in severe acidosis, hypotension and hippocampal damage in late gestation sheep fetuses (6).

Direct measurement of NO in organs is cumbersome because of rapid reactions with hemoglobin and the short half life of NO. However, indirect measurement of NO is possible by assaying nitrite and nitrate, stable end products of NO. An increased production of NO may result in increased levels of by products and end products of NO synthesis. Methods of measurement might be microdialysis, analysis of the cerebrospinal fluid or cerebral arteriovenous differences from the carotid artery and superior sagittal sinus (7). In adult rats, an elevation in cephalic venous plasma NO end products, nitrate and nitrite, was observed during focal cerebral ischemia and subsequent reperfusion (8). The question remains if a similar surge of NO end products occurs in a fetal preparation during asphyxia rather than isolated cerebral ischemia. Therefore, we investigated the effect of 10 minutes total umbilical cord occlusion on cerebral arterio-venous difference for nitrite and neuronal outcome in the late gestation chronic fetal sheep preparation. 
Nitric oxide and fetal asphyxia

\section{Material and methods}

Surgery. Fourteen preterm fetal lambs (GA: mean 118.3 days; range 113 to 120 days) underwent surgery using sterile techniques under general anesthesia (sodium thiopentone 1 $\mathrm{g} / 70 \mathrm{~kg}$ iv for induction, $1 \%$ halothane in a 2:1 nitrous oxide and oxygen mixture for maintenance). A midline abdominal incision was performed. The uterus was incised, and the fetus was partly exteriorized to allow access to the umbilical cord. A reversible cord occluder (model VO-4, Rhodes Medical Instruments, California, U.S.A.) was placed around the umbilical cord and tested for total occlusion volume by infusing sterile saline. Electrodes, made of stranded silver plated copper wire isolated with extruded Teflon, were implanted subcutaneously at the level of the cardiac apex and both forelegs for recording of the fetal ECG. Polyvinyl catheters $(0.8 \mathrm{~mm} \mathrm{ID}, 1.6 \mathrm{~mm} \mathrm{OD})$ were inserted in the carotid artery and directed toward the heart to measure fetal arterial blood pressure, heart rate and to allow arterial blood sampling and in the superior sagittal sinus, to allow cerebral venous blood sampling. The catheters were filled with heparin $(50,000 \mathrm{IU} / \mathrm{ml})$. All catheters were exteriorized through a small incision in the flank of the ewe. Ewes were housed in individual cages with free access to food and water. A recovery period of at least three days followed the operation before experiments were started. Guidelines for care and use of animals, as approved by the local Animal Medical Ethics Committee, were followed.

Experiments. During experiments mean (range) gestational age was 121.3 (116-123) days. Total umbilical cord occlusion was performed during 10 minutes and achieved by infusing sterile saline with the aforementioned total occlusion volume into the occluder. Fetal heart rate and blood pressure (MAP) were monitored continuously. Fetal blood pressure was determined with the zeropoint at the level of the estimated fetal position and corrected for amniotic pressure. Fetal heart rate was derived from the blood pressure wave form. Signals were collected on personal computer, using a customized hemodynamic data acquisition system, custom built by the Instrumental Department of Maastricht University, and stored on DAT recorder. For measurement of fetal blood gases, acid-base status, lactate, glucose and nitrite, heparinized arterial $(1 \mathrm{~mL})$ and venous $(1 \mathrm{~mL})$ blood samples were taken simultaneously. Fetal blood samples were withdrawn 30 and 5 minutes before the occlusion, at 5 and 10 minutes during the occlusion and 15, 30 minutes, 1,2,24, 48 and 72 hours after release of the 
cord occluder. Whole blood was used to measure $\mathrm{pH}$ and blood gases with an automated analyzer (AVL 993, AVL Medical Instruments AG, Schaffhausen, Switzerland) and corrected for fetal temperature $\left(\mathrm{T}=39^{\circ} \mathrm{C}\right)$. Fetal hemoglobin concentration $(\mathrm{mmol} / \mathrm{L})$ and hemoglobin oxygen saturation (\%) were measured with a hemoximeter (OSM2 hemoximeter, Radiometer, Copenhagen, Denmark). Arterial oxygen content ( $\mathrm{mmol} / \mathrm{L}$ ) was calculated as follows: arterial oxygen content $(\mathrm{mmol} / \mathrm{L})=$ hemoglobin concentration $(\mathrm{mmol} / \mathrm{L}) \times$ hemoglobin oxygen saturation (\%). The remaining blood sample was collected on ice and centrifuged at $4{ }^{\circ} \mathrm{C}$ during 5 minutes at $10,000 \mathrm{~g}$. From each sample, $200 \mu \mathrm{L}$ plasma was stored at $-70^{\circ} \mathrm{C}$. Another $200 \mu \mathrm{L}$ of plasma was deproteinized with addition of $10 \%$ trichloroacetic acid (TCA) and subsequently stored at $-70^{\circ} \mathrm{C}$. Glucose and lactate plasma concentrations were determined enzymatically in the deproteinized samples (Cobas Mira, Roche, Mijdrecht, the Netherlands)(9).

HPLC determination of plasma nitrite. The HPLC system consisted of a Gilson 233 XL autosampler (Meyvis, Bergen op Zoom, The Netherlands), two Jasco PU 980 pumps, a Jasco RI 930 detector, a Jasco UV 975 UV absorption detector, a Jasco FP 920 fluorescence detector equipped with a xenon lamp (B\&L systems, Zoetermeer, The Netherlands) and a Mistral column oven (Spark Holland, Hendrik Ido Ambacht, The Netherlands). Data were collected and processed using Turbochrom software (version 3.2: Perkin-Elmer/ Nelson). Plasma nitrite was measured on an Inertsil ODS III column at $25^{\circ} \mathrm{C}\left(5 \mu \mathrm{m}\right.$ particles, $4.6^{*} 125$ mm (I.D.), Chrompack, Bergen op Zoom, The Netherlands). $100 \mu \mathrm{L}$ of the plasma sample was injected and the nitrite derivative was separated using a linear gradient $(0-60 \%$ in $10 \mathrm{~min}$, flow $1.5 \mathrm{~mL} / \mathrm{min}$, solvent $\mathrm{A}$ : sodium phosphate buffer, $12.5 \mathrm{mM}, \mathrm{pH} 8.0,20 \%$ acetonitrile, solvent B: sodium phosphate, $12.5 \mathrm{mM}, \mathrm{pH} 8.0,60 \%$ acetonitrile). The diaminonaphtalene (Aldrich Chem. Co., Milwaukee, WI) derivative was detected using a fluorescence detector (ex. w.1. 365 nm, em. w.1. $425 \mathrm{~nm}$ ) (10).

Fixation and histologic evaluation. Three days after the cord occlusion, a second laparotomy of the ewe was performed under general anesthesia (sodium thiopentone $1 \mathrm{~g} / 70 \mathrm{~kg}$ iv for induction, $1 \%$ halothane in a 2:1 nitrous oxide and oxygen mixture for maintenance). The fetal heart was approached by median thoracotomy. The fetus was heparinized with injection of 20,000 U heparin into the left cardiac ventricle. A blunt steel catheter was inserted in the 


\section{Nitric oxide and fetal asphyxia}

left cardiac ventricle. The right atrium was opened and both external jugular veins were dissected and cut. Five hundred $\mathrm{mL}$ of isotonic and isocolloidal fluid (Haemaccel, Hoechst Holland N.V.) was infused in the left ventricle followed by $750 \mathrm{~mL}$ Karnovsky's fixative ( $2 \%$ formaldehyde and $2.5 \%$ glutaraldehyde in phosphate buffer $0.1 \mathrm{~mol} / \mathrm{L}, \mathrm{pH} 7.40$ ). After decapitation the skull was opened, and the head was submerged into the same fixative for additional immersion fixation. After one day immersion fixation the fetal brain was removed from the skull for histologic evaluation. Vibratome sections $(200 \mu \mathrm{m})$ were cut from three areas (parietal cortex, hippocampus and cerebellum). Sections were postfixed in $2 \%$ osmium tetroxide, buffered with uranyl acetate $(0.05 \mathrm{~mol} / \mathrm{L}, \mathrm{pH} 7.40)$, dehydrated in graded series of ethanol, and routinely imbedded in Epon. Light microscopic evaluation was performed on 2 $\mu \mathrm{m}$ sections stained with toluidine blue by an observer (J.V.R) blinded for the experimental situation. Neuronal damage was defined as the degree of coagulative cell change per cell and per high power field, graded on a 9 point scale, whereby 0 is absence of coagulative changes and 4 is $100 \%$ of the tissue damaged (11).

Statistical Analysis. Values are mean \pm SEM. Results of blood gas and metabolic analysis were compared to baseline values (Wilcoxon Sign Rank test). Histologic scores were analyzed by Fisher's exact test. Spearman's rank correlation was used to analyze the relationship between blood gas parameters, metabolic analysis, nitrite analysis, minimal MAP during the occlusion and histological score. A probability of less than 0.05 was considered significant.

\section{Results}

Three fetuses demonstrated persistent bradycardia and hypotension which became fatal within 10 minutes after release of the cord occluder. Of the 11 surviving fetuses, 10 demonstrated neuronal damage predominantly located in the hippocampus. The distribution and degree of neuronal damage is depicted in table 1 . The results of the biochemical analyses of arterial and venous blood samples are shown in figure 1 and 2 . Ten minutes total umbilical cord occlusion resulted in severe mixed acidemia and hypoxemia: $\mathrm{pH}: 6.96 \pm 0.02 ; \mathrm{CaO}_{2}(\mathrm{mM}): 0.43 \pm 0.9$; $\mathrm{PaCO}_{2}(\mathrm{kPa}): 13.46 \pm 0.38$; base excess $(\mathrm{mM}):-11.1 \pm 0.8$; lactate $(\mathrm{mM}): 10.57 \pm 0.95$. Arterial

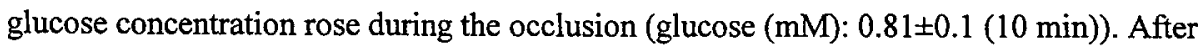
release of the cord occluder plasma glucose concentration reached its maximum level at 15 
minutes (glucose (mM): 1.14 \pm 0.14 ) and gradually declined during the following days and three days after the occlusion values within base line ranges were eventually reached (glucose (mM): $0.73 \pm 0.12(+72 \mathrm{hrs})$. During the recovery period hypoxemia and hypercapnia normalized within 15 minutes. Fetal acidemia resolved after 2 hours (pH: 7.35 0.02 ), although arterial lactate concentrations comparable to base line values were not observed until 24 hours after the occlusion (lactate (mM): $7.21 \pm 2.29(+2 \mathrm{hrs}) ; 2.27 \pm 0.98(+24 \mathrm{hrs})$ ).
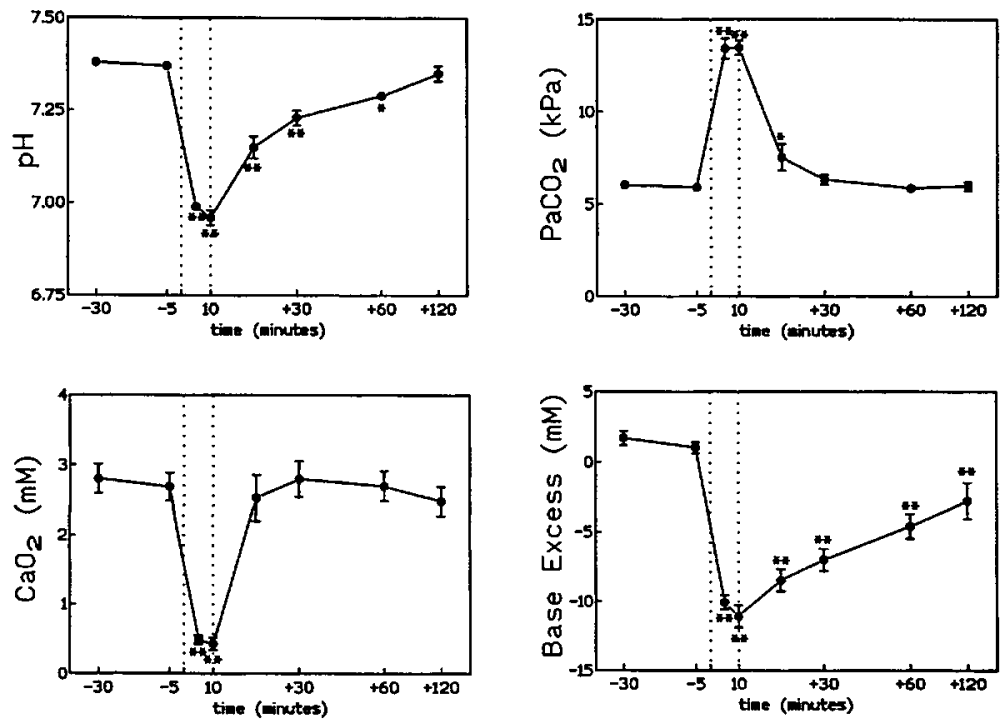

Figure 1. Acid - base status and blood gas analysis in arterial fetal blood before, during and after the total umbilical cord occlusion. One asterix: $p<0.05$; two asterices: $p<0.01$ (Wilcoxon Sign Rank Test, compared to sample taken 5 minutes before occlusion was commenced $(-5)$, values are mean $\pm \mathrm{SEM})$. The period of occlusion is indicated by the area between the dotted lines. 


\section{Nitric oxide and fetal asphyxia}

Arterio-venous differences for lactate and glucose are depicted in figure 2. Cord occlusion resulted in an increase in arterial-venous difference for lactate, reaching its mamimum value after 5 minutes of occlusion (lactate $(a-v): 1.83 \pm 0.31(m M) ; p<0.05)$. Measurements of arteriovenous differences for glucose showed a similar increase during the occlusion although it reached no statistical significance.
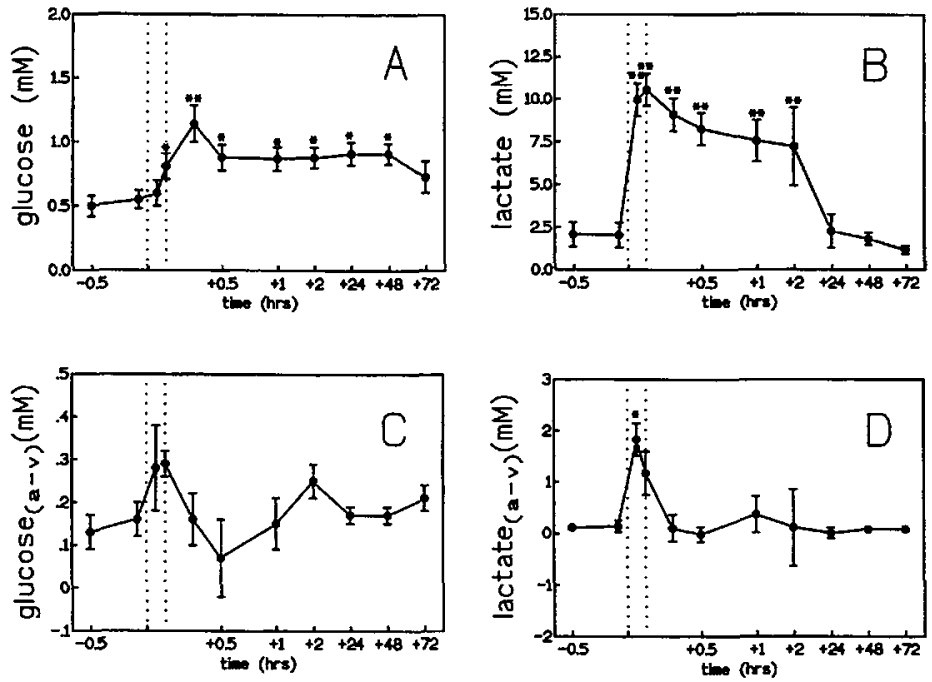

Figure 2. Arterial plasma concentrations $(A, B)$ and cerebral arterio-venous differences $(C, D)$ of metabolic parameters during the time course of the experiment until three days after release of the cord occluder. One asterix: $p<0.05$; two asterices: $p<0.01$ (Wilcoxon Sign Rank Test, compared to the sample taken 5 minutes before occlusion was commenced $(-5)$, values are mean \pm SEM). 
The hemodynamic changes before during and after the occlusion are depicted in figure 3. During the cord occlusion, fetal MAP demonstrated a biphasic response consisting of an initial increase followed by a subsequent fall in MAP ending in hypotension at the end of occlusion (MAP (mmHg): from 51.16 \pm 2.18 (baseline) to $29.85 \pm 3.00, \mathrm{p}<0.01$ ). The degree of hypotension correlated with the magnitude of the hippocarnpal damage (Spearman's correlation coefficient $(r):-0.88, \mathrm{p}<0.001$ ) (table 2 ). Severe bradycardia developed immediately after the cord was occluded (FHR (bpm): from $175 \pm 4$ to $81 \pm 13, p<0.01$ ). After a temporary increase, fetal heart rate gradually decreased to a minimum value at the end of the

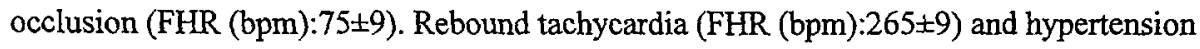
(MAP (mmHg): 77.35 \pm 2.66 ) started instantaneously after release of the cord occluder, and resolved within 20 minutes.

The results of the nitrite analyses are depicted in figure 4 . No changes in arterial plasma concentration nor arterio-venous difference for nitrite were demonstrated during the time course of the experiment ( $\mathrm{p}=0.42$ and 0.25 respectively, Friedman's one-way ANOVA). Correlations between hippocampal damage and results of the analysis of arterial and venous blood gas parameters, acid-base and metabolic status and plasma concentrations for nitrite did not reach statistical significance (table 2 and 3). 

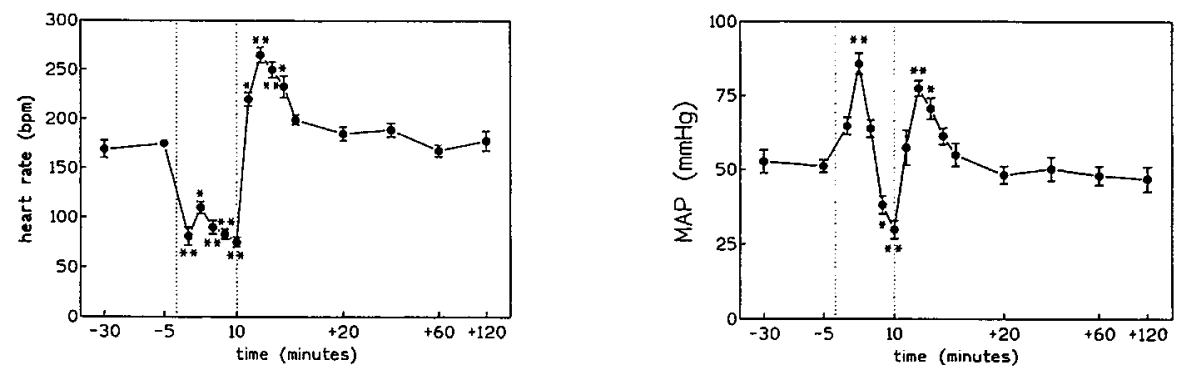

Figure 3. Changes in fetal heart rate and mean arterial pressure (MAP). Cord occlusion resulted in bradycardia and hypotension following a transient hypertensive phase in the beginning of the occlusion period. One asterix: $p<0.05$; two asterices: $p<0.01$ (Wilcoxon Sign Rank Test, compared to measurements 5 minutes before the occlusion was commenced $(-5)$, values are mean $\pm \mathrm{SEM}$ ).
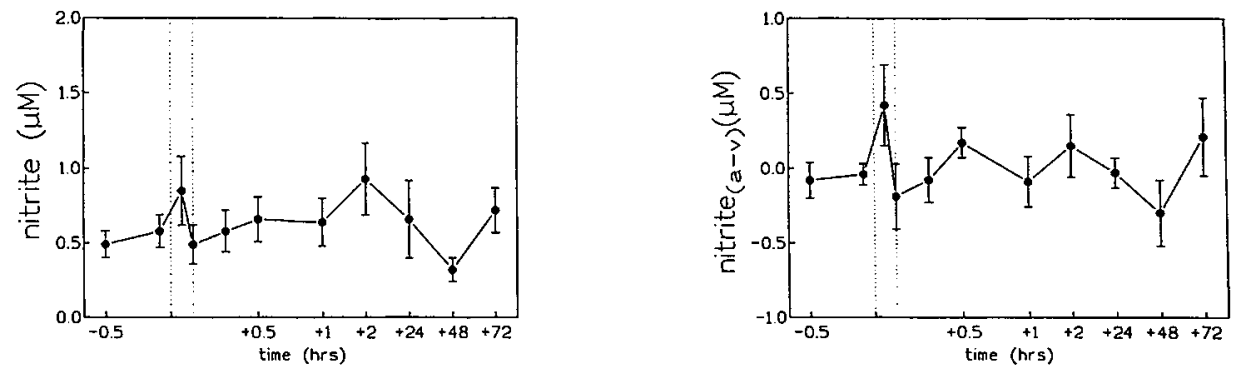

Figure 4. Arterial plasma concentrations (A) and cerebral arterio-venous differences (B) for nitrite before, during and after the occlusion until three days after release of the occluder. Changes were not observed during the occlusion nor after release of the cord occluder (Wilcoxon Sign Rank Test, compared to measurements 5 minutes before the occlusion was commenced $(-5)$, values are mean \pm SEM). 
Table 1. Distribution and degree of neuronal damage as expressed by number of fetuses with according neuronal damage score in the parietal cortex, hippocampus and cerebellum ( $0=$ no damage; $4=100 \%$ of the tissue damaged).

\begin{tabular}{cccccccccc}
\hline & \multicolumn{1}{c}{ score } \\
\cline { 2 - 10 } region & 0 & 0.5 & 1 & 1.5 & 2 & 2.5 & 3 & 3.5 & 4 \\
\hline parietal cortex & 10 & 1 & 0 & 0 & 0 & 0 & 0 & 0 & 0 \\
hippocampus & 1 & 3 & 0 & 2 & 1 & 0 & 1 & 0 & 3 \\
cerebellum & 10 & 1 & 0 & 0 & 0 & 0 & 0 & 0 & 0 \\
\hline
\end{tabular}

Table 2. Spearman's correlation coefficients $(r)$ between the degree of hippocampal damage and metabolic parameters, and fetal arterial blood pressure (MAP) at the nadir of asphyxia.

\begin{tabular}{cccc}
\hline pHa & $r$-value & & p-value \\
\cline { 2 - 2 } [lactate]a & 0.487 & & 0.268 \\
[lactate]a-v & 0.599 & & 0.155 \\
[glucose]a & 0.051 & & 0.935 \\
[glucose]a-v & -0.655 & & 0.11 \\
MAP & -0.359 & & 0.553 \\
\hline
\end{tabular}


Nitric oxide and fetal asphyxia

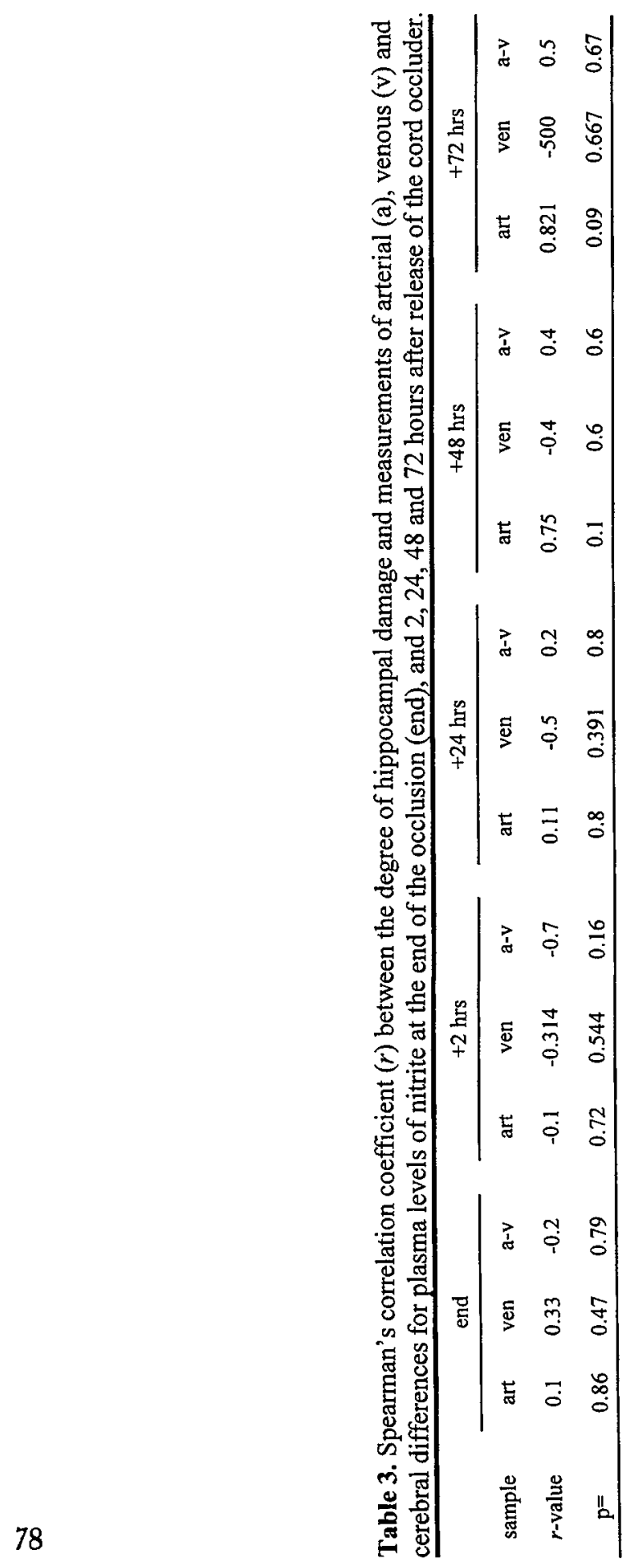




\section{Comment}

The selective hippocampal neuronal damage reported in our study is in concordance with the results of a previous study with a similar experimental setup (6). On the other hand, white matter lesions were observed following prolonged partial umbilical cord occlusion (11). Although confronted with a high mortality rate ( 3 out of 14), neuronal loss in the present study was relatively mild. Compared to immature fetuses subjected to a similar insult, the fetuses in the present study are more susceptible to neuronal damage and are less likely to survive $(12,13)$.The correlation between the degree of hippocampal damage and hypotension at the end of occlusion emphasizes once more the significance of hypotension in the occurrence of post asphyxial neuronal damage $(6,14)$. Hippocampal damage is described in various mammals both in fetal as in adult subjects and is predominantly the result of a single severe insult like cardiopulmonary arrest or transient forebrain ischemia and frequently manifests itself as memory defects and learning disorders.

In a previous study, cerebral oxygen uptake remained unchanged during partial umbilical cord occlusion, cerebral blood flow increases but heart and intestinal blood flow remained stable in contrast to uterine artery occlusion asphyxia (15). Likewise, cerebral oxidative metabolism appeared to be well maintained during repetitive severe umbilical cord occlusions (16). Metabolic factors proved to be of poor prognostic value for hippocampal damage (table 2). Much controversy exists on the role of lactic acidosis in determining the occurrence and degree of brain damage $(17,18)$. The increase in arterio-venous difference for lactate suggests an influx of lactate from the arterial blood into the fetal brain. This phenomenon could be explained by a greater blood to brain gradient for lactate than vice versa. The systemic production of lactate might thus exceed cerebral lactate production during the occlusion. Measurements of arterial plasma levels and arterio-venous difference for nitrite did not demonstrate any changes during and after the total umbilical cord occlusion until 3 days after release of the occluder. Various factors may explain this absence of a surge in this stable NO end product. When confronted with oxyhemoglobulin nitrite is transformed to nitrate (19). However, this reaction was described in vitro after 30 minutes incubation of nitrite with oxyhemoglobulin at $37^{\circ} \mathrm{C}$. Furthermore, Kader et al. reported stable nitrite concentrations in brain homogenates when incubated for 3 hours $(20)$. The short distance between the site of 
possible NO production and the sampling site (superior sagittal sinus), the rapia processing of blood sampling at low temperatures and separation of plasma of whole blood, makes a major transformation of nitrite to nitrate less probable.

Compared to the severe brain damage following global cerebral ischemia for a prolonged period of time (21), brain damage in the present study is mild and predominantly involves the hippocampus. Therefore, elevations of NO production in small selective proportions of the brain may not be reflected in the major venous drainage of the forebrain. During a 30 minutes period of global cerebral ischemia, a surge of NO production was indirectly measured in the microdialysate of the parasagittal cortex in late gestation fetal sheep. After reperfusion, a second, sustained surge of citrulline was observed which coincided with the development of seizures and brain edema (5). The type (asphyxia vs. cerebral ischemia) and duration (10 vs. 30 minutes) of the insult may be responsible for the difference in NO production measured. Furthermore, the site of sampling (venous plasma vs. interstitium of infarcted brain region) probably determines in part whether a accumulation of NO end products can be detected. NO end products are more likely to be detected at the parenchymal side of the brain blood barrier. Although hippocampal damage was highly reproducible, the range of the degree of damage varied from 0 to 4 (i.e. 0 to $100 \%$ of the pyramidal neurons damaged). Similarly, large variations between animals existed in nitrite levels measured during total umbilical cord occlusion and after release of the cord occluder. However, no correlation could be observed between the degree of hippocampal damage and arterial, venous and arterio-venous differences for nitrite plasma levels during the time course of the experiment.

Recently, the ontogenesis of nitric oxide synthase activity in fetal sheep brain was described (22). Already at 92 days of gestation, adult levels of NOS activity were reached in the hippocampus. These results are consistent with similar studies in neonatal rat pups where the expression of NOS in the hippocampus increased from P7 onwards (23). In the hippocampus NOS containing cells primarily appear in the pyramidal cell layer of the Ammon's horn (CA1CA3) and express predominantly the eNOS isoform. They are relatively resistant to ischemia (24), probably due to the enhanced regional blood flow as a result of an increased eNOS activity (4). However, the role of NO in the pathophysiology of post hypoxic-ischemic neuronal damage in immature subjects remains controversial as the detrimental effect of NO 
on hippocampal brain damage was described in neonatal rat pups $(2,3)$.

In conclusion, the present study demonstrated that after 10 minutes total umbilical cord occlusion in late gestation fetal sheep selective hippocampal damage strongly correlated with the degree of hypotension at the end of the occlusion. However, changes in arterial, venous or cerebral arterio-venous differences for plasma levels of nitrite were not observed and did not correlate with neuronal outcome. Therefore, we speculate that asphyxia induced in this experimental set up does not result in a cerebral overproduction of NO. 


\section{References}

1. Moncada S, Palmer RMJ, Higgs EA. Nitric oxide : physiology, pathophysiology, and pharmacology. Pharmacol Rev 1991;109-42.

2. Hamada $Y$, Hayakawa T, Hattori H, Mikawa H. Inhibitor of nitric oxide synthesis reduces hypoxic-ischemic brain damage in the neonatal rat. Pediatr Res 1993;35:104.

3. Trifiletti RR. Neuroprotective effects of $N^{G}$-nitro-L-arginine in focal stroke in the 7day old rat. Eur. J. Pharmacol 1992;218:197-198.

4. Huang ZH, Huang PL, Panahian N, Dalkara T, Fishman MC, Moskowitz MA. Effects of cerebral ischemia in mice deficient in neuronal nitric oxide synthase. Science 1994;265:1883-85.

5. Tan WKM, Williams CE, During MJ, Mallard EC, Gunning MI, Gunn AJ, Gluckman PD. Accumulation of cytotoxins during the development of seizures and edema after hypoxic-ischemic injury in the late gestation fetal sheep. Pediatr Res 1996;39:791-97.

6. Mallard EC, Gunn AJ, Williams CE, Johnston BM, Gluckman PD. Transient umbilical cord occlusion causes hippocampal damage in the fetal sheep. Am J Obstet Gynecol 1992;17:1423-30.

7. Beckman JS. The double-edged role of nitric oxide in brain function and superoxidemediated injury. J Dev Physiol 1991;53-59.

8. Kumura E, Kosaka H, Shiga T, Yoshimine T, Hayakawa T. Elevation of plasma nitric oxide end products during focal cerebral ischemia and reperfusion in the rat. J Cereb Blood Flow and Metab 1994;14:487-91.

9. de Blaauw I, Deutz NE, van der Hulst RR, von Meyenfeldt MF. Glutamine depletion and increased gut permeability in nonanorectic, non-weight-losing tumor-bearing rats. Gastroenterology 1997;112:118-126.

10. Misko, TP. A fluorometric assay for the measurement of nitrite in biological samples. Anal Biochem 1993; 214:11-16.

11. Ikeda T, Murata Y, Quilligan EJ, Choi BH, Parer JT, Doi S, Park SD. Physiologic and histologic changes in near-term fetal lambs exposed to asphyxia by partial umbilical cord occlusion. Am J Obstet Gynecol 1998;178:24-32.

12. Keunen $\mathrm{H}$, Blanco CE, Van Reempts JLH, Hasaart THM. Absence of neuronal damage after umbilical cord occlusion of 10,15 and 20 minutes in midgestation fetal sheep. Am J Obstet Gynecol 1997;176:515-20. 
13. Mallard EC, Gunn AJ, Williams CE, Johnston BM, Gluckman PD. Increased vulnerability to neuronal damage following umbilical cord occlusionin the fetal sheep with advancing gestation. Am J Obstet Gynecol 1994;170:206-14.

14. Wagner KR, Ting P, Westfall MV, Yamaguchi S, Bacher JD, Myers RE. Brain metabolic correlates of hypoxic-ischemic cerebral necrosis in mid-gestational sheep fetuses: Significance of hypotension. J Cereb Blood Flow Metab 1986;6:425-34.

15. Ball RH, Parer JT, Caldwell LE, Johnson J.Regional blood flow and metabolism in ovine fetuses during severe cord occlusion. Am J Obstet Gynecol 1994;171:1549-55.

16. Richhardson BS, Carmichael L, Homan J, Johnston L, Gagnon R. Fetal cerebral, circulatory, and metabolic responses during heart rate decelerations with umbilical cord compression. Am J Obstet Gynecol 1996;175:929-36.

17. Voorhies TE, Rawlinson D, Vannucci RC. Glucose and perinatal hypoxic-ischemic brain damage. Neurology 1986;36:1115-1118.

18. Pulsinelli WA, Waldman S, Rawlinson D, Plum F. Moderate hyperglycemia augments ischemic brain damage: a neuropathological study in the rat. Neurology $1982 ; 32: 1239-1246$.

19. Ignarro LJ, Fukuto JM, Grisc.avage JM, Rogers NE, Byrns RE. Oxidation of nitric oxide in aqueous solution to nitrite but not nitrate: Comaprison with enzymatically formed nitric oxide from L-arginine. Proc Natl Acad Sci 1993;90:8103-07.

20. Kader A, Frazzini VI, Solomon RA, Trifiletti RR. Nitric oxide production during focal cerebral ischemia in rats. Stroke 1993;24:1709-16.

21. Williams CE, Gunn AJ, Mallard EC, Gunning MI, Gluckman PD. Outcome after ischemia in the developing sheep brain: an electroencephalographic and histological study. Ann Neurol 1992;31:14-21.

22. Northington FJ, Tobin JR, Harris AP, Traystman RJ, Koehler RC. Developmental and regional differences in nitric oxide synthase activity and blood flow in the sheep brain. J Cereb Blood Flow Metab 1997;17:109-15.

23. Giuili G, Luzi A, Poyard M, Guellaën G. Expression of mouse brain soluble guanylyl cyclase and NO synthase during ontogeny. Dev Brain Res 1994;81:269-283.

24. Ferriero DM, Arcavi LJ, Sagar SM, McIntosh TK, Simon RP. Selective sparing of NAPDH-diaphorase neurons in neonatal hypoxia-ischemia. Ann Neurol 1988;24:670-76. 


\section{Chapter 5}

Fetal arterial pressure and heart rate changes in surviving and nonsurviving immature fetal sheep following brief repeated total umbilical cord occlusions

Han Keunen, MD and Tom H.M. Hasaart MD, PhD

(Eur ) Obstet Gynecol Reprod Biol 1999:87:151-157) 
Hemodynamic changes during repetitive umbilical cord occlusions

\begin{abstract}
Objectives: To describe the changes in fetal heart rate and mean arterial pressure during repetitive total umbilical cord occlusions in immature sheep fetuses, resulting in severe asphyxia or fetal death. To describe the relationship between these changes and concurrent changes in acid-base status.
\end{abstract}

Study Design: We performed brief repeated total umbilical cord occlusions, 2 out of every 5 minutes, in 14 immature sheep fetuses (at 90 days of gestation), until fetal mean arterial pressure dropped below $50 \%$ of baseline value during 2 successive occlusions. Fetal blood gas analyses were performed at regular intervals just before cord occlusions.

Results: Progressive acidemia and hypotension developed with ongoing occlusions. The degree of hypotension during occlusions increased with ongoing occlusions. The minimum fetal arterial blood pressure during occlusions correlated well with the progressive acidemia. Six fetuses died at the end of the repetitive occlusion period. In the non-survivors, acidemia was more severe and $\mathrm{paCO}_{2}$ gradually increased during the entire repetitive occlusion period. In the survivors group, a period of transient hypoxia and hypotension was observed with a nadir at +60 minutes following the final occlusion.

Conclusion: Repetitive umbilical cord occlusions in immature sheep fetuses resulted in repetitive periods of hypotension, bradycardia, progressive fetal acidemia and ultimately fetal demise. Minimum fetal arterial blood pressure during occlusions correlated well with the progressive fetal acidemia. 


\section{Introduction}

Various experimental studies have shown that hemodynamic, metabolic, endocrinologic and neuropathologic consequences of intrauterine asphyxia may change with the maturity of the fetus. Specifically, it was hypothesized that the immaturity of the parasympathetic, sympathetic and neurohormonal systems render the immature fetus rather vulnerable to asphyxia (1). In contrast, a remarkable resistance to neuronal damage and fetal demise was observed in immature fetuses when subjected to acute, severe asphyxia $(2,3)$. Fetal hypovolemia (4), maternal hypoxemia $(5,6)$, graded umbilical cord occlusion (7), and total umbilical cord occlusion up to 20 minutes $(2,3)$ were used to study the effect of intrauterine asphyxia on sheep fetuses around midgestation. Intrauterine asphyxia in these experimental protocols was characterized by a continuous, single period pattern. However, in clinical practice, peripartal asphyxia often follows a repetitive pattern, e.g. during recurrent uterine contractions. The detrimental effects of repeated periods of fetal compromise differ both in quality and quantity compared to a single period of fetal asphyxia (8-11). Repeated brief periods of asphyxia or ischemia result in more extensive brain damage (11) in different brain regions (9) when compared with a single period of asphyxia $(12,13)$. Furthermore, clinical (14) and experimental (15) studies suggest that fluctuations in arterial blood pressure combined with an insufficient autoregulation $(16,17)$ of cerebral blood flow can result in intracranial hemorrhages. Therefore, intermittent periods of fetal compromise as an experimental paradigm may further elucidate the pathophysiological mechanisms of asphyxia in the immature fetus.

Umbilical cord compressions, associated with uterine contractions, can repetitively challenge the fetus. Therefore, we chose repetitive total umbilical cord occlusions at rates consistent with established labor to induce asphyxia in immature fetal sheep. The purpose of the present study was to describe fetal arterial blood pressure and heart rate changes, changes in acid-base status and their interrelationship during the time course of repetitive total umbilical cord occlusions. 


\section{Material and methods}

Surgery. Fourteen immature fetal sheep (gestational age: mean 90.6 days; range 87 to 93 days) underwent surgery using sterile techniques under general anesthesia (sodium thiopentone $1 \mathrm{~g} / 70 \mathrm{~kg}$ iv for induction, $1 \%$ halothane in a 2:1 nitrous oxide and oxygen mixture for maintenance). A midline abdominal incision was performed. The uterus was incised, and the fetus was partly exteriorized to allow access to the umbilical cord. A reversible cord occluder (model VO-4, Rhodes Medical Instruments, California, U.S.A.) was placed around the umbilical cord and tested for total occlusion volume by infusing sterile saline. A polyvinyl catheter $(0.5 \mathrm{~mm} \mathrm{ID}, 1.0 \mathrm{~mm} \mathrm{OD})$ was inserted in the carotid artery and directed toward the heart to measure fetal arterial blood pressure (MAP), heart rate and to allow arterial blood sampling. The dead-volume space of the catheter was filled with heparin $(50,000 \mathrm{IU} / \mathrm{ml})$ which remained in situ and was removed at the day of the experiment. All catheters were exteriorized through a small incision in the flank of the ewe. Ewes were housed in individual cages with free access to food and water. The ewes were allowed a recovery period of at least three days following the operation before experiments were started. Guidelines for care and use of animals, as approved by the local Animal Medical Ethics Committee, were followed.

Measurements. Fetal blood pressure was determined with the zeropoint at the level of the estimated fetal position and corrected for amniotic pressure. Fetal heart rate was derived from the blood pressure wave form. Signals were collected on personal computer, using a hemodynamic data acquisition system, custom built by the Instrumental Department of the University of Maastricht, and stored on DAT recorder. Beat per beat measurements of fetal heart rate and mean arterial pressure were on-line displayed on a monitor. Fetal blood gas values and $\mathrm{pH}$ were measured with an automated analyzer (AVL 993, AVL Medical Instruments AG, Schaffhausen, Switzerland) and corrected for fetal temperature $\left(T=39.5^{\circ} \mathrm{C}\right)$. Fetal hemoglobin concentration $(\mathrm{mmol} / \mathrm{L}$ ) and hemoglobin oxygen saturation (\%) were measured with a hemoximeter (OSM2 hemoximeter, Radiometer, Copenhagen, Denmark). Arterial oxygen content $(\mathrm{mmol} / \mathrm{L})$ was calculated as follows: arterial oxygen content $(\mathrm{mmol} / \mathrm{L})$ $=$ hemoglobin concentration $(\mathrm{mmol} / \mathrm{L}) \times$ hemoglobin oxygen saturation $(\%)$. 
Experiments. Experiments were started at a mean gestational age of 93.6 (range 90-96) days. Fetal heart rate and blood pressure were monitored continuously. Base line fetal arterial blood gas analyses were performed 30 and 5 minutes before the first umbilical cord occlusion and immediately before every fourth occlusion. Total umbilical cord occlusion was achieved by infusing sterile saline with the predetermined occlusion volume into the occluder. The umbilical cord was repetitively occluded for 2 minutes out of every 5 minutes. Repetitive occlusions were maintained until the fetal mean arterial pressure decreased below $50 \%$ of base line value during two successive occlusions. To limit excessive blood sampling, the maximum time allowed to reach this degree of hypotension during the repetitive occlusion period was 4 hours.

Statistics. Data are presented as mean \pm SEM. Blood gas analyses and hemodynamic parameters were compared by Mann-Whitney U Test between groups, and by Friedman analysis and Wilcoxon test within groups. A probability of less than 0.05 was considered significant. The correlations between minimum fetal heart rate and minimum fetal MAP with fetal arterial $\mathrm{pH}$ were performed with the use of simple linear regression.

\section{Results}

Out of 14 fetuses ( 8 males , 6 females, mean weight $716 \mathrm{~g}$ (range 608-894g), 6 fetuses died at the end or shortly after the occlusion period. Non-surviving fetuses did not recover from fetal bradycardia following the last umbilical occlusion. Subsequently, fetal arterial pressure decreased gradually until fetal demise. The experimental group was subsequently subdivided depending on survival after the repetitive occlusion period: survivors (group $I, n=8$,) and nonsurvivors (group II, $\mathrm{n}=6$ ). The characteristics of the experimental group are depicted in table 1 . More occlusions were needed in the survivors compared with the non-survivors (mean (range) group I: 38.5 (27-48); group II: $27.2(21-39)$, p<0.05). Fetal survival after asphyxia was not related to fetal weight, gestational age or gender.

The acid-base status and blood gas analyses before and during the repetitive occlusion period are shown in figure 1 . In the baseline period no deterioration of the fetal condition was observed (group I: pH: $7.35 \pm 0.01 ; \mathrm{paCO}_{2}: 5.79 \pm 0.09 \mathrm{kPa} ; \mathrm{CaO}_{2}: 2.67 \pm 0.11 \mathrm{mM}$; base excess: $-1.18 \pm 0.55 \mathrm{mM}$; group II: $\mathrm{pH}: 7.33 \pm 0.01 ; \mathrm{paCO}_{2}: 5.69 \pm 0.19 \mathrm{kPa} ; \mathrm{CaO}_{2}: 2.21 \pm 0.23 \mathrm{mM}$; base 
excess: $-2.78 \pm 0.55 \mathrm{mM}$ ). Due to variation in survival and number of occlusions after 105 minutes of the repetitive occlusion period, data between 105 minutes and the last occlusion are not shown. During the time course of the repetitive occlusions, both groups showed a gradually developing acidosis. Group II demonstrated a significant increase in $\mathrm{paCO}_{2}$ during the occlusion period which was not observed in group I. At the end of the repetitive occlusion period a more severe acidosis was observed in group II compared to group I (pH: $7.13 \pm 0.02$ (I), 7.03 \pm 0.04 (II) ( $<<0.05) ; \mathrm{paCO}_{2}(\mathrm{kPa}): 6.34 \pm 0.16$ (I), 8.88 \pm 0.47 (II) $(\mathrm{p}<0.01) ; \mathrm{CaO}_{2}$ (mM): $2.08 \pm 0.26$ (I), $1.53 \pm 0.31$ (II); base excess (mM): $-12.6 \pm 1.0$ (I), $-13.9 \pm 1.6 \mathrm{mM}$ (II)) After release of the final occlusion all blood gas parameters recovered within 4 hours. In the survivors group, the arterial oxygen content decreased to a minimum value of $1.86 \pm 0.25,15$ minutes after the final occlusion, before returning to baseline levels within 4 hours.

Representative examples of fetal heart rate and mean arterial pressure changes during repetitive umbilical cord occlusions (first, halfway the entire repetitive occlusion period (middle) and last occlusion) are shown in figure 2.

Time course changes of mean arterial pressure and fetal heart rate are shown for group I and II (figure 3). Differences between groups were not observed at either point in time. During the first occlusions mean arterial pressure increased and remained elevated between occlusions resulting in a hypertensive period reaching its maximum value after 15 minutes. In subsequent occlusions mean arterial pressure slowly decreased with little blood pressure changes during the occlusions. Finally, a mean arterial pressure pattern developed characterized by a biphasic response with an initial increase and subsequent decrease in MAP, eventually resulting in repetitive periods of hypotension during the occlusions. The magnitude of hypotension during occlusions increased with ongoing occlusions. 


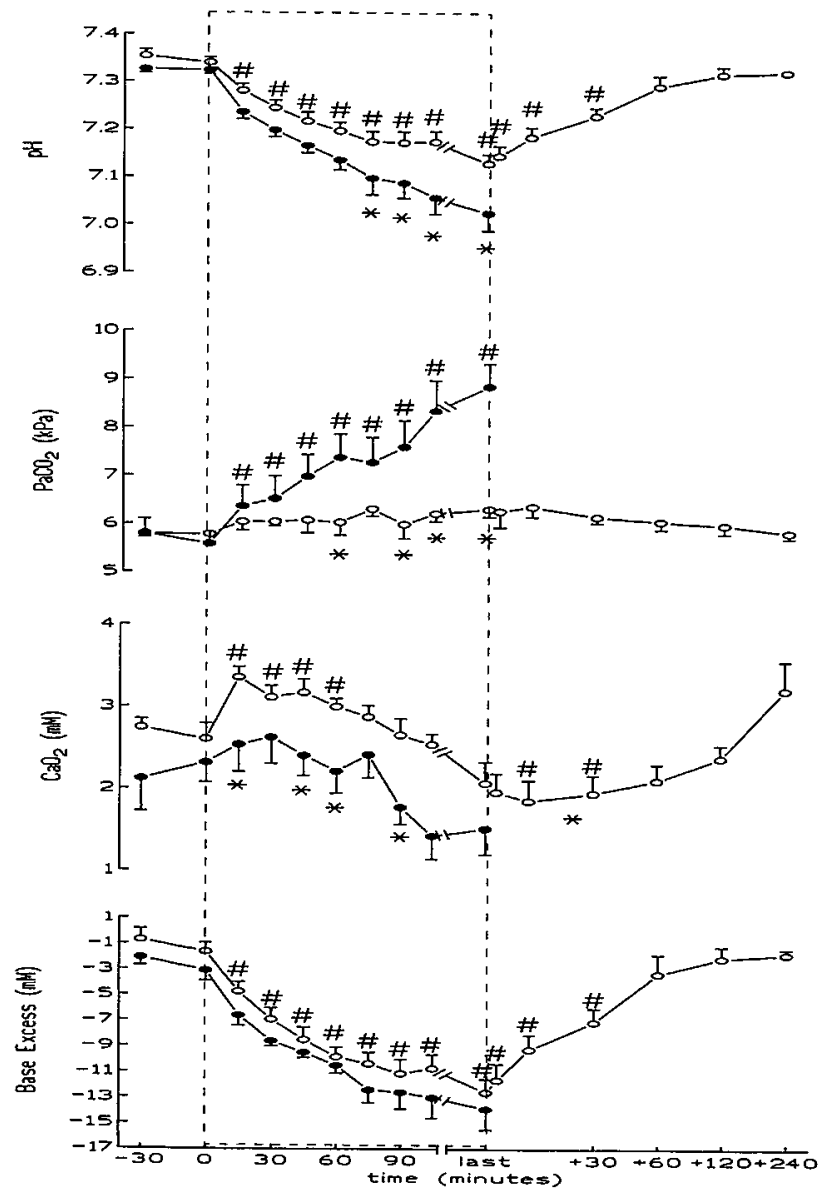

Figure 1. Time course of blood gas analyses and acid-base status for survivors (open circles, group I) and non-survivors (closed circles, group II). Values are mean \pm SEM. ${ }^{*}: \mathrm{p}<0.05$ (group I compared with group II, Mann Whitney $U$ test). \#: $\mathrm{p}<0.05$ (Wilcoxon, compared with baseline, Friedman $p<0.05$ ) The repetitive occlusion period is represented by the dotted box. 


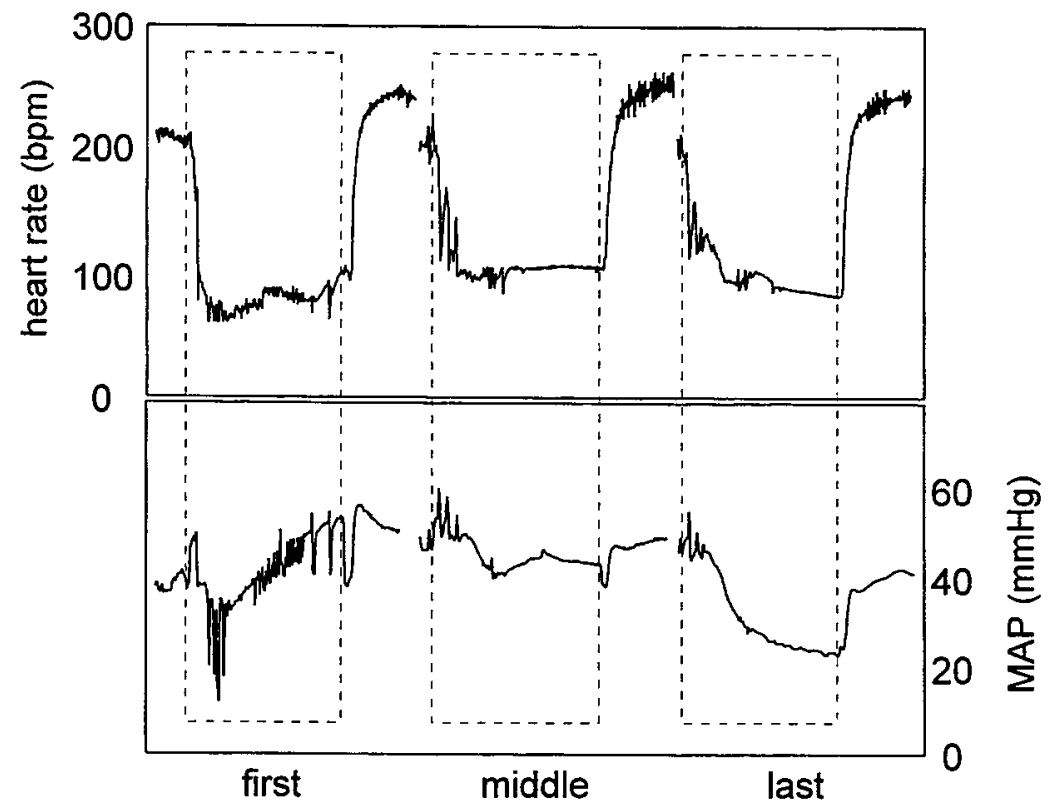

Figure 2. Example of characteristic changes in fetal heart rate (upper panel) and mean arterial pressure (lower panel) during the first occlusion (begin), halfway the occlusion sequence (middle), and last occlusion (end). The occlusions are represented by the dotted boxes.

Following the hypertensive period due to the first occlusions, fetal MAP between occlusions gradually decreased, however but not to a level below baseline value. After the final occlusion, the decrease in fetal MAP perpetuated resulting in a significant hypotension at +30 and +60 minutes, followed by a recovery to baseline values at +4 hours (Figure 3 ).

Fetal heart rate changes were characterized by a prompt decrease during the first occlusion, followed by a gradual increase during the occlusion. With ongoing occlusions, fetal heart rate decreased to a mild bradycardic level with little subsequent changes during the occlusion. Toward the end of the repetitive occlusion period fetal heart rate gradually decreased from mild to severe bradycardia during the occlusion. Time course changes of fetal heart rate are depicted in figure 3c. Fetal heart rate decreased maximally during the first occlusion. With 
ongoing occlusions, minimum heart rate during occlusions demonstrated a transient increase compared to the first occlusion. Throughout the time course of the repetitive occlusion period fetal heart rate showed a prompt recovery with a rebound tachycardia which resolved during the recovery phase after each occlusion. The fetal heart rate between occlusions was significantly higher compared to baseline after 3 to 7 occlusion, then decreased to levels comparable to baseline values when occlusions were continued. In the recovery period of the survivors fetal heart demonstrated a second rebound tachycardia which resolved within 30 minutes after the final occlusion.

The correlation coefficients between minimum fetal MAP, minimum fetal heart rate and arterial pH during occlusions of every individual fetus are depicted in table 2 . No differences between the groups could be observed. When compared to minimum fetal heart rate, minimum fetal MAP demonstrated a strong correlation with arterial $\mathrm{pH}$ in both groups (Mann Whitney $U$ test, $\mathrm{p}<0.05$ ). 


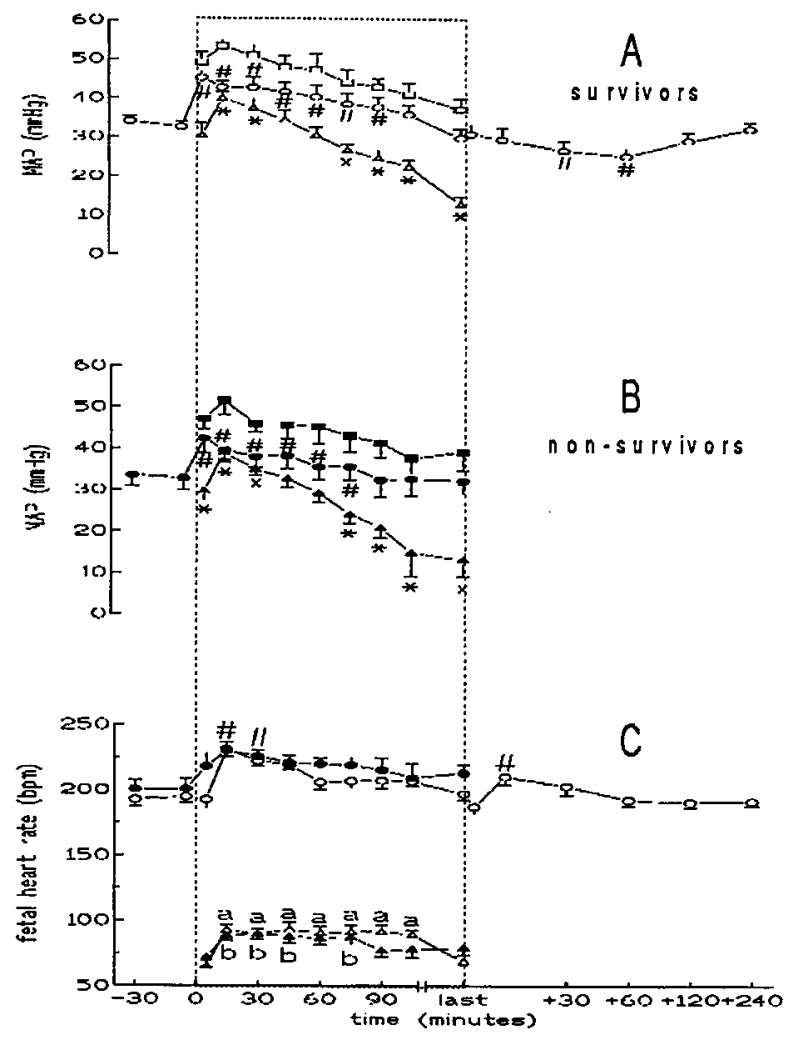

Figure 3. Time course of changes in fetal heart rate and fetal blood pressure. Figure $3 \mathrm{~A}$ and $3 \mathrm{~B}$ represent the maximum (square), minimum (triangle), and the blood pressure values between occlusions (circles) of group I (survivors) and group II (non-survivors) respectively. Figure $3 \mathrm{C}$ represents the time course of changes in fetal heart rate just before subsequent occlusions (circles) and minimum fetal heart rate during occlusions (triangles) for group I (open symbols) and group II (filled symbols).Values are mean \pm SEM. \#:p<0.05 (Wilcoxon, compared with baseline, Friedman $p<0.05$ ); a:p $<0.05$ (Wilcoxon, compared with first occlusion survivors, Friedman $\mathrm{p}<0.05$ ); $b$ :p $<0.05$ (Wilcoxon, compared with first occlusion non-survivors, Friedman $\mathrm{p}<0.05$ ). 
Table 1. Summary of results and characteristics of the experimental group

\begin{tabular}{|c|c|c|c|c|}
\hline group & $\begin{array}{c}\text { number of } \\
\text { fetuses }\end{array}$ & $\begin{array}{c}\text { occlusions (n) } \\
\text { mean (range) }\end{array}$ & $\begin{array}{c}\text { gestational age } \\
\text { mean (range) }\end{array}$ & $\begin{array}{c}\text { fetal weight } \\
\text { mean (range) }\end{array}$ \\
\hline $\begin{array}{c}\text { I } \\
\text { (survivors) }\end{array}$ & 8 & $\begin{array}{c}38.5 \\
(27-48)\end{array}$ & $\begin{array}{c}92.8 \text { days } \\
(90-96)\end{array}$ & $\begin{array}{c}692 \mathrm{~g} \\
(612-864)\end{array}$ \\
\hline II & 6 & 27.2 & $\begin{array}{c}93.8 \text { days } \\
(90-96)\end{array}$ & $\begin{array}{c}747 \mathrm{~g} \\
(608-894)\end{array}$ \\
\hline (non-survivors) & $(21-39)$ & $\begin{array}{c}93.2 \text { days } \\
(90-96)\end{array}$ & 716 \\
\hline TOTAL & 14 & $(21-48)$ & $(608-894)$ \\
\hline
\end{tabular}

Table 2. Correlation coefficient ( $\mathrm{r}$ ) between fetal arterial $\mathrm{pH}$ vs. minimum FHR and minimum fetal MAP during occlusions (from 4th occlusion to end of occlusion period) in individual fetuses of the survivor (A) and non-survivor group (B).

\begin{tabular}{c|cccc}
\hline \multicolumn{5}{c}{ survivors (A) } \\
\hline fetus & pH-MAP & $\mathrm{p}$ & $\mathrm{pH}-\mathrm{FHR}$ & $\mathrm{p}$ \\
\hline 1 & 0.97 & $<0.0001$ & 0.75 & 0.0030 \\
2 & 0.97 & $<0.0001$ & 0.74 & 0.0059 \\
3 & 0.93 & $<0.0001$ & 0.77 & 0.0036 \\
4 & 0.87 & $<0.0001$ & 0.55 & 0.0260 \\
5 & 0.93 & $<0.0001$ & 0.72 & 0.0023 \\
6 & 0.91 & $<0.0001$ & 0.88 & $<0.0001$ \\
7 & 0.72 & 0.0197 & -0.03 & 0.9453 \\
8 & 0.95 & 0.0036 & 0.64 & 0.1724 \\
\hline mean \pm SEM & $0.91 \pm 0.03$ & & $0.63 \pm 0.10$ & \\
\hline
\end{tabular}

non-survivors (B)

\begin{tabular}{c|cccc}
\hline fetus & pH-MAP & $\mathrm{p}$ & $\mathrm{pH}-\mathrm{FHR}$ & $\mathrm{p}$ \\
\hline 1 & 0.90 & 0.0036 & 0.91 & 0.0110 \\
2 & 0.86 & 0.0009 & 0.75 & 0.0334 \\
3 & 0.81 & 0.0010 & 0.91 & 0.0008 \\
4 & 0.87 & 0.0008 & 0.62 & 0.1003 \\
5 & 0.72 & 0.0711 & -0.91 & 0.0338 \\
6 & 0.94 & $<0.0001$ & 0.59 & 0.0978 \\
\hline mean \pm SEM & $0.92 \pm 0.02$ & & $0.48 \pm 0.28$ & \\
\hline
\end{tabular}




\section{Hemodynamic changes during repetitive umbilical cord occlusions}

\section{Comment}

This study describes the hemodynamic responses and changes in acid-base status following repetitive umbilical cord occlusions in immature sheep fetuses resulting in asphyxia and even fetal death. Acidosis developed gradually after initiation of repetitive cord occlusions. Just before the last occlusion, acidosis was more severe in the non-survivors compared to the survivors group. As fetal arterial blood samples were taken following a 3-minute recovery period, acidosis during the last occlusions may have been quite severe, with $\mathrm{pH}$ values well below 7.00. The most striking difference in acid-base status and blood gases between group I and II is the relatively constant $\mathrm{paCO}_{2}$ in group I and gradual increasing $\mathrm{paCO}_{2}$ in group II. As carbon dioxide is dependent on the flow in the umbilical-placental circulation, the rise in $\mathrm{paCO}_{2}$ may be related to a general reduction in combined ventricular output and a reduced clearance by the placental circulation. The latter could be explained by a damaged umbilical cord or a faulty or twisted cord occluder. However, during the post mortem examination of the deceased fetuses no evidence was found with respect to these causes.

After initiation of the occlusion fetal MAP rises as peripheral resistance is increased by occluding the low resistant umbilical circulation. As a result of developing bradycardia, both a baro- and chemoreceptor response $(18,19)$, fetal MAP decreases. After approximately 1 minute of occlusion, fetal MAP increases with fetal heart rate, probably due to an increased level of plasma catecholamines and chemoreceptor reflex as a result of developing hypoxia and acidosis. With ongoing cord occlusions this increase in fetal MAP and heart rate during the latter part of the occlusion is attenuated or does not even occur at all, resulting in a sustained decrease of fetal MAP and heart rate during the occlusion.

When assuming that MAP $=$ combined ventricular output $(\mathrm{CVO}) \times$ total peripheral resistance (TPR), the decrease of MAP during the latter part of the occlusion can be attributed to a decrease in CVO and/or TPR. In the fetus CVO is almost linearly related to heart rate (23). A decrease in heart rate therefore results in a decrease in CVO. To prevent the arterial blood pressure from falling, TPR has to increase. Several mechanisms are known to result in this increase of TPR. When acidosis and hypoxia develops, chemoreceptors induce vasoconstriction by stimulation of $\alpha$-adrenergic receptors of peripheral vessels. Furthermore, cathecholamines plasma concentration increases during asphyxia, although this response is 
blunted in immature fetuses $(4,20)$. These phenomena result in a centralization of blood flow to vital organs (21) by increasing the vascular resistance to the carcass, intestines, lungs and kidneys. However, when asphyxia persists, this compensatory mechanism fails, and blood flow decentralizes as a result of a decrease of TPR (22). A decrease of CVO during occlusions may be explained by the fall in heart rate and increase in afterload (23). Combined with the greater energy demand during anerobic metabolism, repetitive occlusions will progressively deplete cardiac energy resources, eventually leading to cardiac exhaustion and a further decrease in CVO. Furthermore, it is known that acidosis reduces myocardial contractility in vivo (24) and in vitro (25), thereby contributing to the decrease in CVO.

Surely, the fetal response to asphyxia is not solely dependent on the autonomic nervous system. Even a greater role is assumed for locally induced effects and humoral factors in the fetal cardiovascular responses to asphyxia (26). Following removal of the afferent or efferent limbs of the autonomic reflex pathway, fetal bradycardia still persists during asphyxia (27). Likewise, asphyxia has a direct effect on adrenal medulla in the release of norepinephrine and epinephrine (28). Humoral factors such as renin (29), vasopressin (30) and atrial natriuretic factor (31) have predominantly been studied in relation to hypoxemia. Their role in asphyxia, let alone in immature fetuses, has yet to be established.

The fetal deaths demonstrate that occlusions were continued until or beyond the borderline of fetal tolerance to asphyxia. The lower limit of fetal MAP, $50 \%$ of baseline value, was chosen with respect to identical values reached during our previous study in immature fetal lambs (3). In that study, fetal MAP decreased to a similar value following a single total umbilical cord occlusion of 15 to 20 minutes. The number of occlusions needed to reduce fetal MAP below $50 \%$ of baseline value varied between animals in both groups. Less occlusions were needed in the non-survivors group. A variety of factors are thought to determine survival after and tolerance to asphyxia. The higher cardiac tissue glycogen content favor immature versus mature subjects (32). During asphyxia, the autonomic nervous system protects the fetus by increasing or stabilizing the oxygen delivery to, and lowering the metabolic needs of essential organs (20-22). The relative immaturity of this stress response (1) to asphyxia in midgestation sheep fetuses may be responsible for fetal decompensation and even death as is described in this study. 
Recently, de Haan et al. (33) described a study in mature sheep fetuses using a similar experimental set-up. In 9 mature fetuses, the umbilical cord was repetitively occluded 2 out of every 5 minutes until fetal MAP decreased below $20 \mathrm{mmHg}$. At the nadir of asphyxia acidosis was more severe compared to the present study ( $\mathrm{pH}: 6.84 \pm 0.02$ vs. $7.09 \pm 0.02 ; \mathrm{p}<0.0001$ ). In part, this can be explained by the timing of the fetal arterial blood sampling: at the end of vs. just before an occlusion in the present study. The hemodynamic responses to repetitive cord occlusions, however, show an striking similarity between immature and mature fetuses. This similarity in responses of FHR and fetal MAP, in part dependent on the autonomic nervous system, may indicate a qualitive similarity of the autonomic nervous control of the fetal circulation at these different gestational ages. In the present study more occlusions were needed $(33.6 \pm 2.3$ vs. $24 \pm 2$ (mean $\pm S E M) ; p<0.01)$ to reach a similar degree of hypotension as in mature fetuses. This is in concordance with observations in mid- and late gestation sheep fetuses where mature compared with immature fetuses became more hypotensive during a single umbilical cord occlusion of 10 minutes (2).

In conclusion, repetitive umbilical cord occlusion resulted in progressive asphyxia and even fetal death in immature sheep fetuses. In the non-survivors, acidosis was more severe and $\mathrm{paCO}_{2}$ gradually increased between occlusions. Distinctive changes in the fetal MAP pattern could be observed with ongoing occlusions. After a transient hypertensive period during and between the first occlusions, a biphasic response developed during successive occlusions, characterized by an initial increase and subsequent decrease in fetal MAP resulting in hypotension during an occlusion. The degree of hypotension during occlusions increased with ongoing occlusions. The fetal MAP pattern succesfully reflected fetal deterioration, underlining the significance of hypotension during fetal compromise $(34,13)$. Therefore, an estimation of changes in fetal blood pressure may be potentially useful to identify fetal compromise during peripartal asphyxia at an early gestational age (35). 


\section{References}

1 Nuwayhid B, Brinkman III CR, Su C, Bevan JA, Assali NS. evelopment of autonomic control of fetal circulation. Am J Physiol 1975;228:337-344.

2. Mallard EC, Gunn AJ, Williams CE, Johnston BM, Gluckman PD. Increased vulnerability to neuronal damage after umbilical cord occlusion in fetal sheep with advancing gestation. Am J Obstet Gynecol 1994;170:206-214.

3. Keunen H, Blanco CE, Van Reempts JLH, Hasaart THM. Absence of neuronal damage after totoal umbilical cord occlusion of 10,15 and 20 minutes in midgestation fetal sheep. Am J Obstet Gynecol 1997;176:515-20.

4. Penning DH, Grafe MR, Hammond R, Matsuda Y, Patrick J, Richardson B. Neuropathology of the near-term and midgestation ovine fetal sheep after sustained in utero hypovolemia. Am J Obstet Gynecol 1994;170:1425-32.

5. Iwamoto HS, Kaufman T, Keil LC, Rudolph AM. Responses to acute hypoxemia in fetal sheep at 0.6-0.7 gestation. Am J Physiol 1989;256: H613-20.

6. Matsuda Y, Patrick J, Carmichael L, Challis J, Richardson B. Effects of sustained hypoxemia on the sheep fetus at midgestation: Endocrine, cardiovascular, and biophysical responses. Am J Obstet Gynecol 1992;167:531-40.

7. Iwamoto HS, Stucky E, Roman CM. Effect of graded umbilical cord compression in fetal sheep at 0.6-0.7 gestation. Am J Physiol 1991;261:H1268-1274.

8. Mallard EC, Williams CE, Gunn AJ, Gunning MI, Gluckman PD. Frequent episodes of brief ischemia sensitize the fetal sheep brain to neuronal loss and induce striatal injury. Pediatr Res 1993;33:61-65.

9. Mallard EC, Williams CE, Johnston BM, Gunning MI, Davis S, Gluckman PD. Repeated episodes of umbilical cord occlusion in fetal sheep lead to preferential damage to the striatum and sensitize the heart to further insults. Pediatr Res 1995;37:707-713.

10. Clapp JF III, Peress NS, Wesley M, Mann LI. Brain damage after intermittent partial cord occlusion in the chronically instrumented fetal lamb. Am J Obstet Gynecol 1988; 159:504-509.

11. Lin B, Globus MYT, Dietrich WD, Busto, Martinez E, Ginsberg MD. Differing neurochemical and morphological sequelae of global ischemia: comparison of singleand multiple-insult paradigms. J Neurochem 1992;59:2213-2223. 
12. de Haan HH, Van Reempts JLH, Vles JSH, de Haan J, Hasaart THM. Effects of asphyxia on the fetal lamb brain. Am J Obstet Gynecol 1993;169:1493-501.

13. Mallard EC, Gunn AJ, William CE, Johnston BM, Gluckman PD. Transient umbilical cord occlusion causes hippocampal damage in the fetal sheep. Am J Obstet Gynecol 1992;167:1423-30.

14. Perlman JM, Goodman S, Kreusser KL, Volpe JJ. Reduction in intraventricular hemorrhage by elimination of fluctuating cerebral blood flow velocity in preterm infants with respiratory distress syndrome. N Eng J Med 1985; 313:1353-1357.

15. de Haan HH, Gunn AJ, Williams CE, Gluckman PD. Brief repeated umbilical cord occlusions cause sustained cytotoxic cerebral edema and focal infarcts in near-term fetal lambs. Pediatr Res 1997;41:96-104.

16. Helou S, Koehler RC, Gleason CA, Jones JR. MD, Traystman RJ. Cerebrovascular autoregulation during fetal development in sheep. Am J Physiol 1994;266:H1069$\mathrm{H} 1074$.

17. Gleason CA. Effect of acute hypoxemia on brain blood flow and oxygen metabolism in immature fetal sheep. Am J Physiol 1990;258:H1064-H1069.

18. Giussani DA, Spencer JAD, Moore PJ, Bennet L, Hanson MA. Afferent and efferent components of the cardiovascular reflex responses to acute hypoxia in term fetal sheep. J Physiol 1993;461:431-449.

19. Siassi B, Wu PYK, Blanco CE, Martin CB. Baroreceptor and chemoreceptor responses to umbilical cord occlusion in fetal lambs. Biol Neonate 1979;35:66-73.

20. Jensen A, Berger R. Fetal circulatory responses to oxygen lack. J Dev Physiol $1991 ; 16: 181-207$.

21. Peeters LLH, Sheldon RE, Jones MD, Makowski EL, Meschia G. Blood flow to fetal organs as a function of arterial oxygen content. Am J Obstet Gynecol 1979;159:14181424.

22. Jensen A, Hohmann M, Künzel W. Dynamic changes in organ blood flow and oxygen consumption during acute asphyxia in fetal sheep. J Devel Physiol 1987;9: 543-559.

23. Rudolph AM, Heymann MA. Cardiac output in the fetal lamb: the effects of spontaneous and induced changes of heart rate on right and left ventricular output. Am J Obstet Gynecol 1976;124:183-192. 
24. Fisher DJ. Acidemia reduces cardiac output and left ventricular contractility in conscious lambs. J Dev Physiol 1986;8:23-31.

25. Friedman WF, Kirckpatrick SE. Fetal cardiovascular adaptation to asphyxia. In: Gluck L ed.: Intrauterine asphyxia and the developing fetal brain. Chicago: Year Book Medical Publisher, Inc., 1977: 155.

26. Jensen A, Hanson MA. Circulatory responses to acute asphyxia in intact and chemodenervated fetal sheep near term. Reprod Fertil Dev 1995;7:1351-9.

27. Barcroft J. Researches on Pre-natal Life. Blackwell Scientific: Oxford 1946.

28. Jones CT, Robinson C. Plasma catecholamines in fetal and adult sheep. J Physiol 1975;248:15-33.

29. Robillard JE, Weitzman RE, Burmeister L, Smith FG. Developmental aspects of the renal response to hypoxemia in the lamb fetus. Circulation Res 1981;48, 128-38.

30. Rurak DW. Plasma vasopressin levels during hypoxaemia and the cardiovascular effects of exogenous vasopressin in foetal and adult sheep. J Physiol 1978;277:34157.

31. Cheung CY, Brace RA. Fetal hypoxia elevates plasma atrial natriuretic factor concentration. Am J Obstet Gynecol 1988;160:926-32.

32. Dawes GS, Mott JC, Shelley HJ. The importance of cardiac glycogen for the maintenance of life in fetal lambs and newborn animals during anoxia. J Physiol 1959;146:516.

33. de Haan HH, Gunn AJ, Gluckman PD. Fetal heart rate changes do not reflect cardiovascular deterioration during brief repeated umbilical cord occlusions in nearterm fetal lambs. Am J Obstet Gynecol 1997;176:8-17.

34. Wagner KR, Ting P, Westfall MV, Yamaguchi S, Bacher JD, Myers RE. Brain metabolic correlates of hypoxic-ischemic cerebral necrosis in mid-gestational sheep fetuses: significance of hypotension. J Cereb Blood Flow Metab 1986;6:425-434.

35. Hoeks APG, Brands PJ, Reneman RS. Assessment of the arterial distension waveform using Doppler signal processing. J Hypertens 1992;6:S19-S22. 


\section{Chapter 6}

The effect of repetitive umbilical cord occlusions on neuronal brain activity measured by the Cerebral Function Analysing Monitor and histological outcome in immature fetal sheep

Han Keunen ,MD, Johannes S.H. Vles, MD, PbD. Jos L.H. Van Reempts, Danilo Gavilanes, MD, and Tom H.M. Hasaart . MD. PbD

(ISoc Gynecol Investig 2000:7:218-223) 


\section{Abstract}

Objectives: To examine the effect of repetitive total umbilical cord occlusions on electrocortical brain activity as measured by cerebral function analysing monitoring (CAFM) and the histological outcome in immature sheep fetuses.

Study Design: We performed brief repeated total umbilical cord occlusions, 2 out of every 5 minutes, in 12 immature sheep fetuses (at 90 days of gestation, term 147 days), until fetal mean arterial pressure dropped below $50 \%$ of baseline value during 2 successive occlusions. A pair of electrodes was inserted on the parietal dura for recording of electrocortical brain activity $(\mathrm{ECOG})$. Off-line ECoG signal processing consisted of amplitude integrated analysis (CFAM) and spectral analysis. Fetal blood gas analyses were performed at regular intervals just before subsequent umbilical cord occlusions. Three days after the occlusion neuronal damage was evaluated histologically in three regions of the fetal brain.

Results: CFAM amplitide parameters decreased significantly during the first occlusion and remained so during the entire repetitive occlusion period (Friedman, $\mathrm{p}<0.05$ ). Spectral analysis of the ECOG signal demonstrated no changes in the distribution of frequency bands. Progressive acidemia and hypotension developed with ongoing occlusions. Five fetuses died at the end or shortly after the entire repetitive occlusion period. No neuronal damage nor macroscopic intraventricular and/or germinal matrix hemorrhages were observed.

Conclusion: Repetitive umbilical cord occlusions in immature sheep fetuses resulted in functional not in structural changes of the fetal brain. At this gestational age, amplitude analysis is more sensitive than spectral analysis of the ECoG signal to functional changes of the compromised fetal brain. 


\section{Introduction}

Recently, we reported the absence of neuronal damage in immature fetal sheep following a single period of total umbilical cord occlusion up to 20 minutes (1). In clinical practice, asphyxia during labor is often characterized by short repetitive periods of fetal compromise. The question remains whether neuronal damage can be observed when immature sheep fetuses are subjected to repetitive periods of umbilical cord occlusions rather than a single transient occlusion.

Several methods have been used to monitor the effect of asphyxia on the fetal sheep brain. These methods include the registration of raw electrocorticogram signals (ECoG), cortical impedance and sensory and auditory evoked potentials. Another possible method is the cerebral function analysing monitor (CFAM). CFAM was first introduced by Maynard et al (3). The CFAM offers a one-channel registration of cerebral activity from two biparietal electrodes and it is represented as a band. The CFAM is a system of amplitude integrated electroencephalogram which can be used to predict gestational age and neurological outcome of the asphyxiated newborn. The use of CFAM as an on-line monitor might offer the possibility to monitor cortical brain activity during periods of umbilical cord occlusion. In this study we subjected immature sheep fetuses to asphyxia induced by repetitive umbilical cord occlusions to examine the neuronal outcome three days after the insult, the changes in electrocortical activitity during the occlusions and their possible interrelationships.

\section{Material and methods}

Surgery. Twelve immature fetal sheep (gestational age: mean 90.6 days; range 87 to 93 days) underwent surgery using sterile techniques under general anesthesia (sodium thiopentone 1 $\mathrm{g} / 70 \mathrm{~kg}$ iv for induction, $1 \%$ halothane in a $2: 1$ nitrous oxide and oxygen mixture for maintenance). A midline abdominal incision was performed. The uterus was incised, and the fetus was partly exteriorized to allow access to the umbilical cord. A reversible cord occluder (model VO-4, Rhodes Medical Instruments, California, U.S.A.) was placed around the umbilical cord and then tested for total occlusion volume by infusing sterile saline. A polyvinyl catheter $(0.5 \mathrm{~mm} \mathrm{ID}, 1.0 \mathrm{~mm}$ OD) was inserted in the carotid artery and directed toward the heart to measure fetal arterial blood pressure (MAP), heart rate and to allow 
arterial blood sampling. The dead-volume space of the catheter was filled with lieparin (5000 $\mathrm{IU} / \mathrm{ml}$ ) which remained in situ and was removed at the day of the experiment. For registration of electrical cortical activity (ECoG) a pair of shielded stainless steel electrodes were inserted through biparietal drilled burr holes on the parietal dura. A reference electrode was sewn subcutaneously into the scalp. All catheters and electrodes were exteriorized through a small incision in the flank of the ewe. Ewes were housed in individual cages with free access to food and water. The ewes were allowed a recovery period of at least three days following the operation before experiments were started. Guidelines for care and use of animals, as approved by the local Animal Medical Ethics Committee, were followed.

Measurements. Fetal blood pressure was determined with the zeropoint at the level of the estimated fetal position and corrected for amniotic pressure. Fetal heart rate was derived from the blood pressure wave form. Signals were collected on a personal computer, using a hemodynamic data acquisition system, custom built by the Instrumental Department of the University of Maastricht. Beat by beat measurements of fetal heart rate and mean arterial pressure were on-line displayed on a monitor. Fetal blood gas values and $\mathrm{pH}$ were measured with an automated analyzer (AVL 993, AVL Medical Instruments AG, Schaffhausen, Switzerland) and corrected for fetal temperature $\left(T=39.5^{\circ} \mathrm{C}\right)$. Fetal hemoglobin concentration (mmol/L) and hemoglobin oxygen saturation (\%) were measured with a hemoximeter (OSM2 hemoximeter, Radiometer, Copenhagen, Denmark). Arterial oxygen content ( $\mathrm{mmol} / \mathrm{L}$ ) was calculated as follows: arterial oxygen content $(\mathrm{mmol} / \mathrm{L})=$ hemoglobin concentration $(\mathrm{mmol} / \mathrm{L}) \mathrm{x}$ hemoglobin oxygen saturation (\%).

Experiments. Experiments were started at a mean gestational age of 93.6 (range 90-96) days. Fetal heart rate and blood pressure were monitored continuously. Base line fetal arterial blood gas analyses were performed 30 and 5 minutes before the first umbilical cord occlusion and immediately before every fourth occlusion. Total umbilical cord occlusion was achieved by infusing sterile saline with the predetermined occlusion volume into the occluder. The umbilical cord was repetitively occluded for 2 minutes out of every 5 minutes. Repetitive occlusions were maintained until the fetal mean arterial pressure decreased below $50 \%$ of base line value during two successive occlusions. To limit excessive blood sampling, the maximum time allowed to reach this degree of hypotension during the repetitive occlusion period was 4 
hours.

Off-line ECoG signal processing. Off-line processing of the raw ECoG signal included: weighted digital band filtering between 2 and $15 \mathrm{~Hz}$, rectification, logarithmic amplitude compression and smoothing of the signal. For further analysis epochs of the CFM-signal lasting 3.6 seconds were selected. CFM parameters (mean amplitude distribution and bandwith in microvolts) were calculated by the computer using the software program Poly (Inspector Research System BV, Amsterdam, The Netherlands), modified by the Department of Clinical Neurophysiology, University Hospital Maastricht. Two epochs of 10 minutes were used to calculate baseline CFM values. CFM parameters during occlusions were obtained at the first and last occlusion, and at the occlusion halfway the entire repetitive occlusion period (e.g. at the 12 th occlusion when a total of 24 occlusions were administered). At every time point one epoch of 3 minutes before and after an occlusion and an epoch during the 2-minute occlusion were calculated. In addition, the ECoG of the similar epochs was subjected to spectral analysis by means of Fourier transformation resulting in a percentage distribution of the raw EcoG signal over the following frequency bands: delta $(1-4 \mathrm{~Hz})$, theta $(4-8 \mathrm{~Hz})$, alpha $(8-14 \mathrm{~Hz})$ and beta $(14-30 \mathrm{~Hz})$.

Fixation and histologic evaluation. Three days after the cord occlusion, a second laparotomy of the ewe was performed under general anesthesia (sodium thiopentone $1 \mathrm{~g} / 70 \mathrm{~kg}$ iv for induction, $1 \%$ halothane in a 2:1 nitrous oxide and oxygen mixture for maintenance). The fetal heart was approached by median thoracotomy. The fetus was heparinized with injection of 20,000 U heparin into the left cardiac ventricle. A blunt steel catheter was inserted in the left cardiac ventricle. The right atrium was opened and both external jugular veins were dissected and cut. Five hundred $\mathrm{mL}$ of isotonic and isocolloidal fluid (Haemaccel, Hoechst Holland N.V.) was infused in the left ventricle followed by $750 \mathrm{~mL}$ Karnovsky's fixative (2\% formaldehyde and $2.5 \%$ glutaraldehyde in phosphate buffer $0.1 \mathrm{~mol} / \mathrm{L}, \mathrm{pH} 7.40$ ). After decapitation the skull was opened, and the head was submerged into the same fixative for additional immersion fixation. After one day immersion fixation the fetal brain was removed from the skull for histologic evaluation. Vibratome sections $(200 \mu \mathrm{m})$ were cut from three areas (parietal cortex, hippocampus and cerebellum). Sections were postfixed in $2 \%$ osmium tetroxide, buffered with uranyl acetate $(0.05 \mathrm{~mol} / \mathrm{L}, \mathrm{pH} 7.40)$, dehydrated in graded series of 
ethanol, and routinely imbedded in Epon. Light microscopic evaluation was performed on 2 $\mu \mathrm{m}$ sections stained with toluidine blue by an observer (J.V.R) blinded for the experimental situation . Neuronal damage was defined as the degree of coagulative cell change per cell and per high power field, graded on a 9 point scale, whereby 0 is absence of coagulative changes and 4 is $100 \%$ of the tissue damaged (1).

Statistics. Data are presented as mean \pm SEM. Blood gas and acid base status analyses, hemodynamic parameters, CFAM amplitude parameters and the results of spectral analysis were compared by Friedman analysis and Wilcoxon test. A probability of less than 0.05 was considered significant.

\section{Results}

The experimental group consisted of 12 fetal lambs with a mean gestational age of 93.2 days (range 90-96) and weight of 716 grams (range 608-894). The fetuses were subjected to a total of 33.6 occlusions (range 21-48). Out of 12 fetuses, 5 fetuses died at the end or shortly after the occlusion period. Table 1 describes the results of the blood gas and acid-base status analyses at baseline, just before the first, middle and final occlusion, and 2 hours after the final occlusion. Repetitive umbilical cord occlusions resulted in moderate to severe acidosis, mild hypercapnia and moderate hypoxia. In the surviving fetuses all parameters returned to baseline values 2 hours after the final occlusion.

Table 1. Time course of the blood gas and acid-base status analysis. Fetal arterial blood samples were taken at baseline, just before the first, middle and last occlusion (all fetuses, $\mathrm{n}=12$ ), and 2 hours following the entire repetitive occlusion period (surviving fetuses, $\mathrm{n}=7$ ).

\begin{tabular}{lcccc}
\hline & $\mathrm{pH}$ & $\begin{array}{c}\mathrm{PaCO}_{2} \\
(\mathrm{kPa})\end{array}$ & $\begin{array}{c}\mathrm{CaO}_{2} \\
(\mathrm{mmol} / \mathrm{l})\end{array}$ & $\begin{array}{c}\text { Base Excess } \\
(\mathrm{mmol} / \mathrm{l})\end{array}$ \\
\hline baseline & $7.34 \pm 0.01$ & $5.79 \pm 0.13$ & $2.48 \pm 0.19$ & $-1.48 \pm 0.59$ \\
occl first & $7.33 \pm 0.01$ & $5.70 \pm 0.14$ & $2.49 \pm 0.15$ & $-2.26 \pm 0.54$ \\
occl middle & $7.17 \pm 0.02 \S$ & $6.55 \pm 0.22^{\S}$ & $2.50 \pm 0.13$ & $-10.64 \pm 0.67 \S$ \\
occl last & $7.09 \pm 0.02 \S$ & $7.43 \pm 0.41 \S$ & $1.84 \pm 0.21 \S$ & $-13.15 \pm 0.90^{\S}$ \\
post 2 hrs & $7.32 \pm 0.02$ & $6.01 \pm 0.17$ & $2.39 \pm 0.16$ & $-2.09 \pm 0.91$ \\
\hline
\end{tabular}

$\S: \mathrm{p}<0.05$, Wilcoxon, compared to baseline. 
The results of the fetal mean arterial pressure and heart rate measurements at similar time points are depicted in table 2. Repetitive umbilical cord occlusions resulted in repetitive periods of bradycardia. During occlusions, fetal MAP demonstrated a biphasic response which consisted of an initial increase followed by a subsequent decrease resulting in severe hypotension during the final occlusions. Likewise, between occlusions fetal MAP first increased and then decreased to values below but not significantly different from baseline values. Non-surviving fetuses failed to recover after release of the last occlusion. They remained bradycardic and hypotensive until they finally succumbed.

Table 2. Time course of the mean fetal heart rate during baseline and 2 hours following the entire repetitive occlusion period, and minimum fetal heart rate during the first, middle and last occlusion (beats per minute). Time course of the maximum (MAP max) and minimum (MAP min) fetal mean arterial pressure during the first, middle and last occlusion. Time course of the fetal mean arterial pressure during baseline and 2 hours following the entire repetitive, and between occlusion following the first and middle and just before the last occlusion (MAP int) ( $\mathrm{mmHg}$ ).

\begin{tabular}{lcccc}
\hline & FHR & MAP max & MAP min & MAP int \\
\hline baseline & $197.33 \pm 4.23$ & & & $32.73 \pm 1.40$ \\
occl first & $68.11 \pm 3.15^{\S}$ & $48.41 \pm 1.84 \S$ & $30.21 \pm 1.94$ & $44.04 \pm 1.72 \S$ \\
occl middle & $86.76 \pm 3.08 \S$ & $45.27 \pm 2.49 \S$ & $28.83 \pm 1.51$ & $38.33 \pm 2.02 \S$ \\
occl last & $72.95 \pm 3.13^{\S}$ & $38.21 \pm 2.37 \S$ & $13.08 \pm 1.90 \S$ & $30.92 \pm 1.87$ \\
post 2 hrs & $191.11 \pm 3.82$ & & & $29.54 \pm 2.23$ \\
\hline
\end{tabular}

$\S: \mathrm{p}<0.05$, Wilcoxon, compared to baseline. 
The results of the off-line CFAM amplitude and spectral analysis of the ECoG are depicted in figure 1.
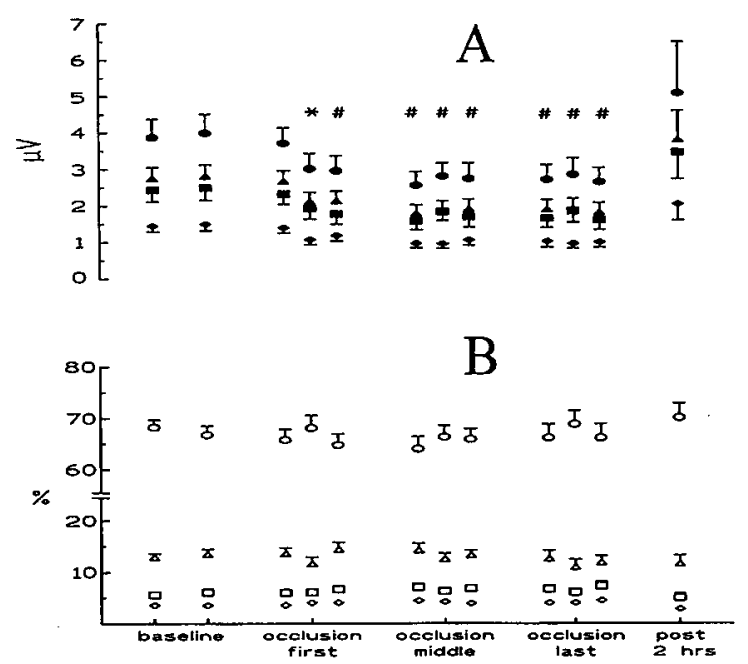

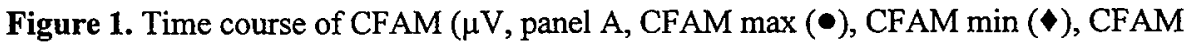
width $(\mathbf{\square})$, CFAM mean $(\Delta))$ and spectral analysis of the ECoG signal $(\%$, panel B, delta band $(0)$, theta band $(\Delta)$, alpha band $(\square)$, beta band $(\diamond)$ ) during baseline (two epochs of ten minutes), first, middle and last occlusion (three epochs: one epoch of three minutes before and after, and one epoch during the occlusion, all fetuses, $n=12$ ), and two hours following the entire repetitive occlusion period (one epoch of ten minutes, post $2 \mathrm{hrs}$, only surviving fetuses, $\mathrm{n}=7$ ). \#: $\mathrm{p}<0.05$, Wilcoxon, compared to baseline, all CFAM parameters. *: $\mathrm{p}<0.05$, Wilcoxon, compared to baseline, all CFAM parameters except CFAM width. Values are mean \pm SEM. 
All CFAM amplitude parameters demonstrated a significant decrease during the entire repetitive occlusion period compared to baseline (Friedman, $p<0.05$ ). Decrease of all CFAM amplitude parameters except CFM width started during the first occlusion and remained depressed throughout the entire repetitive occlusion period. Of the surviving fetuses, all CFAM amplitude parameters recovered to baseline values at 2 hours after the final occlusion. Spectral analysis of the ECoG signal demonstrated no differences between the baseline and entire repetitive occlusion period.

Macro- and microscopic evaluation of brain damage was performed only on surviving fetuses. Macroscopic inspection showed no evidence for intraventricular-germinal matrix hemorrhage (IVH-GMH). Good fixation quality was demonstrated by the absence of residual erythrocytes in open microvessels and the absence of disseminated cell swelling. Light microscopic evaluation of the surviving fetuses did not demonstrate neuronal damage in the parietal cortex, hippocampus and cerebellum.

\section{Comment}

Repetitive umbilical cord occlusions in immature fetal sheep in this experimental set up resulted in repetitive periods of hyper- and hypotension, bradycardia and sustained mixed acidosis. The degree of hypotension was comparable to the changes in MAP observed in our previous study where immature fetuses were subjected to a single total umbilical cord occlusion up to 20 minutes (1). In concordance with repetitive umbilical cord occlusions in mature fetal lambs, changes in fetal MAP demonstrated a biphasic response which consisted of an initial rise in MAP followed by a subsequent decrease resulting in severe hypotension (4). As arterial blood pressure is the result of the product of cardiac output times peripheral vascular resistance, hypotension at the end of the repetitive occlusion period may result in a decrease of one of or both these parameters. Severe hypoxia and depletion of myocardial glycogen stores may decrease cardiac output. Furthermore, during severe asphyxia a decrease in total peripheral vascular resistance was observed in fetal lambs (5). Whether a decrease in cardiac output or peripheral vascular resistance was responsible for the repetitive periods of hypotension observed in this study remains unsolved.

The absence of neuronal damage and IVH-GMHs agrees with our previous observations in 


\section{CFAM and repetitive umbilical cord occlusions}

immature fetal lambs following a single umbilical cord occlusion up to 20 minutes (1). The degree of hypotension at the end of the final occlusions in this study was comparable to the changes of MAP observed in the transient total umbilical cord occlusion. However, acidosis in the single transient occlusion group was more severe. In part this could be explained by the timing of the fetal blood gas analysis, which was just before an occlusion in the present study compared to fetal blood gas analysis at the end of the single umbilical occlusion period in the former experiments (1). On the other hand, repetitive umbilical cord occlusions in mature sheep fetuses resulted in cerebral damage ranging from mild selective neuronal loss to focal infarcts in the parasagittal cortex, thalamus and cerebellum (2). This ontogenetic difference in neuronal damage was also observed in a comparative study in mature and immature fetal lambs subjected to 10 minutes total umbilical cord occlusion (6). Considering the mortality rate in the present study, fetal demise probably occurred before neuronal damage could develop. IVH-GMHs were absent although asphyxia and arterial pressure fluctuations were present. So far, one study succeeded to produce IVH-GMHs in fetal lambs, be it under acute experimental circumstances (7). In the chronic fetal sheep preparations several experimental set ups studying fetal asphyxia and brain damage failed to demonstrate similar results. Intact cerebral autoregulation was described in immature fetal lambs (8). It is known that asphyxia can abolish the protective mechanism of autoregulation (9). Likely, in the present study hypertensive periods during the first occlusions were not coincidental with severe asphyxia while hypotension during the final occlusions was not severe enough to decrease below the lower limit of cerebral vascular autoregulation.

To date this is the first report on the use of CFAM in the chronic fetal sheep preparation. As a simplified one-channel EEG registration the CFAM allows non invasive long-term recording of cortical activity and similtaneous rejection of artifacts. At present it is used in neonatal intensive care units for the monitoring of seizures. Furthermore, it is suggested that CFAM can be used as a prognostic tool following severe peripartal asphyxia $(10,11,12)$. Currently , a newly designed computerized cerebral function monitor is in use at our neonatal intensive care unit (13). Electronic intrapartum fetal monitoring has been associated with a significant reduction in fetal mortality due to asphyxia and postasphyxial seizures $(14,15)$. Nevertheless, much controversy exists on its ability to predict cerebral palsy (16). Whether CFM may be 
useful to improve the positive predictive value of changes in the fetal heart rate pattern is unknown.

Fetal CFAM amplitude parameters decreased during the repetitive occlusion period. However, this decrease already occurred during the first occlusion and remained so throughout the entire repetitive occlusion period. Evidently, an umbilical occlusion of 2 minutes resulted in an impairment of cortical activity which remained depressed throughout the following 3-minute recovery period and subsequent occlusions. No futher decrease in CFAM amplitude parameters was observed during the time course of repetitive cord occlusions. At 2 hours after the final occlusion, CFAM amplitude parameters recovered to baseline recordings in the surviving fetuses.

Evidence of seizure activity, periodic increases in CFAM amplitude parameters and fetal MAP, was not observed in the recovery period. The rapid decrease in ECoG activity was also observed in intermittent umbilical cord occlusions in mature fetal lambs (2). However, in that study epileptiform ECoG changes were observed in the recovery period which were coincidental with subsequent neuronal damage in the parasaggital cortex. The rapid decrease in CFAM amplitude parameters is not in concert with previous observations in an acute experimental set up in newborn piglets (17). In that study, a decrease in CFAM amplitude parameters was only observed when the piglets were subjected to isolated hypovolemic hypotension or a combination of hypotension and hypoxemia. Isolated hypoxemia did not result in a decrease of the CFAM amplitude parameters. In the present study, early occlusions may result in hypoxemia, not in hypotension. Furthermore, final occlusions resulted in a combination of hypoxemia and hypotension. Therefore, a gradual decrease in CFAM amplitude parameters toward the final occlusions was expected in the present investigation. Apparantly, repetitive occlusions did result in impairment of neuronal activity based on hypoxemia in early occlusions and a combination of hypoxemia and hypotension during final occlusions. However, although neuronal quiescence occurred neuronal damage was not observed. The latter may be the result of the former as cortical metabolic rate decreases during an impaired cortical activity.

In conclusion, repetitive umbilical cord occlusion resulted in severe asphyxia and repetitive periods of hypotension. In comparison to mature fetuses subjected to a similar insult, neuronal 
damage was not observed. CFAM in the fetal preparation is feasible. CFAM amplitude parameters decreased already during the first occlusions and remained so throughout the entire repetitive occlusion period. Although a decrease in CFAM amplitude parameters occurred, these changes in CFAM amplitude parameters were not predictive for neuronal damage nor the severity of fetal compromise. Further investigations are warranted to study the relationship between CFAM amplitude parameters and hemodynamical and histological changes during and following fetal compromise at various gestational ages. 


\section{References}

1) Keunen $\mathrm{H}$, Blanco CE, Van Reempts $Л \mathrm{LH}$, Hasaart THM. Absence of neuronal damage after total umbilical cord occlusion of 10,15 and 20 minutes in midgestation fetal sheep. Am J Obstet Gynecol 1997;176:515-20.

2) de Haan $\mathrm{HH}$, Gunn AJ, Williams CE, Gluckman PD. Brief repeated umbilical cord occlusions cause sustained cytotoxic cerebral edema and focal infarcts in near-term fetal lambs. Pediatr Res 1997;41:96-104.

3) Maynard DE, Development of the CFM: the cerebral function analysing monitor. Ann Anesth Franc 1979;3:253.

4) de Haan $\mathrm{HH}$, Gunn AJ, Gluckman PD. Fetal heart rate changes do not reflect cardiovascular deterioration during brief repeated umbilical cord occlusions in nearterm fetal lambs. Am J Obstet Gynecol 1997;176:8-17.

5) Jensen A, Gips H, Hohmann M, Künzel W. Adrenal endocrine and circulatory responses to acute prolonged asphyxia in surviving and non-surviving fetal sheep near term. In: Künzel W and Jensen A eds. The Endocrine Control of the Fetus. Berlin-Heidelberg: Springer Verlag, 1988: 64-79.

6) Mallard EC, Gunn AJ, Williams CE, Johnston BM, Gluckman PD. Increased vulnerability to neuronal damage after umbilical cord occlusion in fetal sheep with advancing gestation. Am J Obstet Gynecol 1994;170:206-214.

7) Reynolds ML, Evans CAN, Reynolds EOR, Sauders NR, Durbin GM, Wigglesworth JS. Intracranial haemorrhage in the preterm sheep fetus. Early Human Develop $1979 ; 3: 163-186$.

8) Helou S, Koehler RC, Gleason CA, Jones MD, Traystman RJ. Cerebrovascular autoregulation during fetal development in sheep. Am J Physiol 1994;266:H10691074.

9) Lou HC. The "lost autoregulation hypothesis" and brain lesions $\mathbf{n}$ the newborn, an update. Brain Dev 1988;10:143-146.

10) Archbald F, Verma UL, Tejani NA, Handwerker SM. Cerebral function monitor in the neonate. II: Birth asphyxia. Dev Med Child Neurol 1984; 26:162-168.

11) Bjerre I, Hellstrom-Westas L, Rosen I, Svenningsen NW. Monitoring of cerebral function after severe asphyxia in infancy. Arch Dis Child 1983: 58:997-1002. 
12) Hellstrom-Westas L, Rosen I, Svenningsen NW. Predictive value of early continuous amplitude integrated EEG recordings on outcome after severe birth asphyxia in full term infants. Arch Dis Child 1995;72:F34-38.

13) Reulen JPH, Gavilanes AW, van Mierlo D, Blanco C, Spaans F, Vles JS. The Maastricht Cerebral Monitor (MCM) for the neonatal intensive care unit. J Med Eng Technol 1999;23:29-37.

14) Vintzileos AM, Nochimson DJ, Guzman ER, Knuppel RA, Lake M, Schifrin BS. Intrapartum electronic fetal monitoring versus intermittent auscultation: a metaanalysis. Obstet Gynecol 1995;85:149-155.

15) Thacker SB, Stroup DF, Peterson HB. Efficacy and safety of intrapartum electronic fetal monitoring: an update. Obstet Gyncol 1995;86:613-620.

16) Nelson KB, Dambrosia JM, Ting TY, Grether JK. Uncertain value of electronic fetal monitoring in predicting cerebral palsy. N Engl J Med 1996;334:613-618.

17) Bunt JEH, Gavilanes AWD, Reulen JPH, Blanco CE, Vles JSH. The influence of acute hypoxemia and hypovolemic hypotension of neuronal brain activity measured by the cerebral function monitor in newborn piglets. Neuropediatr 1996;27:260-264. 


\section{Chapter 7}

The PR interval - fetal heart rate relationship during repetitive umbilical cord occlusions in immature fetal sheep

Han Keunen, MD . Willem J. van Wijngaarden, DM . Daljit S. Sahota PhD , and Tom H.M. Hasaart MD, PhD

(Eur J Obstet Gynccol Reprod Biol 2000;89:69-74) 


\begin{abstract}
Objective: To evaluate the relationship of the PR interval and fetal heart rate during repetitive umbilical cord occlusions in immature sheep fetuses.

Study design: In 7 chronically cannulated immature sheep fetuses (gestational age 90.6 days (mean)), we analyzed continuous fetal electrocardiogram recordings during repetitive cord occlusions for 2 out of every 5 minutes until fetal mean arterial pressure dropped to $50 \%$ of baseline value. PR interval-fetal heart rate correlation coefficients (Pearson) was measured on consecutive blocks of 2.5 minutes. R-values of the baseline and the repetitive occlusion period were compared by Fisher's exact test.

Results: Repetitive cord occlusions resulted in acidosis and hypotension. Two fetuses died at the end of the repetitive occlusion period. Four out of 7 fetuses showed a significant change from a negative relationship between the PR interval and fetal heart rate during baseline to a predominantly positive relationship during the repetitive occlusion period.

Conclusion: In immature fetal sheep, a change from a negative relationship between the PR interval and fetal heart rate to a predominantly positive relationship between the PR interval and fetal heart rate was observed in 4 out of 7 fetuses following the initiation of repetitive umbilical cord occlusions.
\end{abstract}




\section{Introduction}

Neurodevelopmental disorders contribute largely to morbidity and mortality of prematurely born infants. Although these disorders are thought to originate predominantly in the prenatal period, peripartal asphyxia remains a well known cause of brain damage of the premature newborn (1-3). More than thirty years, intrapartum fetal surveillance techniques including electronic fetal monitoring have been used to detect fetal asphyxia. Nevertheless, no benefit was shown compared to intermittent fetal heart rate auscultation during labor in long-term neurologic morbidity $(4,5)$.

Consequently, new methods of intrapartum fetal surveillance have been proposed to improve perinatal outcome. The analysis of time constants (PR interval) of the fetal electrocardiogram (FECG) waveform may be useful for the detection fetal compromise during labor (6). Changes in PR interval-fetal heart rate relationship during fetal compromise are reported both in clinical and experimental studies $(6,7-10,11)$. Recently, we described changes in PR interval and FHR during prolonged fetal compromise in mature sheep fetuses (7). It has been suggested that fetal maturity significantly influences the FECG waveform morphology changes during acute hypoxia (10). It is not known whether fetal maturity influences the changes in the PR interval- fetal heart rate relationship during fetal compromise.

The objective of the present investigation was to describe the changes in the relationship between PR interval and FHR during fetal compromise at an early gestational age. To mimic human fetal compromise during labor, we repetitively occluded the umbilical cord until fetal acidemia developed and fetal mean arterial pressure dropped $50 \%$ or more below baseline value. The lower limit of fetal MAP, $50 \%$ of baseline value, was chosen with respect to our previous study in immature fetal lambs (12). In that study, fetal MAP decreased to a similar value following a single total umbilical cord occlusion of 15 to 20 minutes.

\section{Material and methods}

Surgery. Seven immature sheep fetuses (mean 90.6 days; range 87 to 93 days) underwent surgery using sterile techniques under general anesthesia (sodium thiopentone $1 \mathrm{~g} / 70 \mathrm{~kg}$ iv for induction, $1 \%$ halothane in a 2:1 nitrous oxide and oxygen mixture for maintenance). A midline abdominal incision was performed. The uterus was incised, and the fetus was partly 


\section{PR interval - FHR relationship during asphyxia}

exteriorized to allow access to the umbilical cord. A reversible cord occluder (model VO-4, Rhodes Medical Instruments, California, U.S.A.) was placed around the umbilical cord and tested for total occlusion volume by infusing sterile saline. Electrodes, made of stranded silver plated copper wire isolated with extruded Teflon, were implanted subcutaneously at the level of the cardiac apex and both forelegs to record the fetal ECG. A polyvinyl catheter $(0.5 \mathrm{~mm}$ $\mathrm{ID}, 1.0 \mathrm{~mm} \mathrm{OD}$ ) was inserted in the carotid artery and directed toward the heart to measure fetal arterial blood pressure, heart rate and to allow arterial blood sampling. The catheter was filled with heparin $(50,000 \mathrm{IE} / \mathrm{ml})$. All catheters were exteriorized through a small incision in the flank of the ewe. Ewes were housed in individual cages with free access to food and water. A recovery period of at least three days followed the operation before experiments were started. Guidelines for care and use of animals, as approved by the local Animal Medical Ethics Committee, were followed.

Measurements. The fetal ECG was recorded continuously and stored on a multichannel FM tape (Hewlett-Packard 8800 series, Andover, Mass.). The fetal ECG signal was filtered to an overall bandwidth of 0.05 to $100 \mathrm{~Hz}$. Fetal blood pressure was determined and corrected for amniotic pressure. Fetal heart rate was derived from the blood pressure wave form. The signals were collected on personal computer, using a customized hemodynamic data acquisition system, and stored on a DAT recorder. Fetal blood gas values and $\mathrm{pH}$ were measured with an automated analyzer (AVL 993, AVL Medical Instruments AG,

Schaffhausen, Switzerland) and corrected for fetal temperature $\left(T=39^{\circ} \mathrm{C}\right)$. Fetal hemoglobin concentration ( $\mathrm{mmol} / \mathrm{L})$ and hemoglobin oxygen saturation (\%) were measured with a hemoximeter (OSM2 hemoximeter, Radiometer, Copenhagen, Denmark). Arterial oxygen content $(\mathrm{mmol} / \mathrm{L})$ was calculated as follows: arterial oxygen content $(\mathrm{mmol} / \mathrm{L})=$ hemoglobin concentration (mmol/L) $x$ hemoglobin oxygen saturation (\%).

Experiments. Experiments were started at a mean gestational age of 93.6 days (range: 90-96). Fetal heart rate and blood pressure were monitored continuously. Fetal arterial blood gas analyses were performed 30 and 5 minutes before the first umbilical cord occlusion and immediately before every third occlusion. Total umbilical cord occlusion was achieved by infusing a predetermined volume of sterile normal saline into the occluder. The umbilical cord was repetitively occluded for 2 minutes out of every 5 minutes. Occlusions were continued 
until fetal mean arterial pressure decreased to $50 \%$ of baseline value during two successive occlusions.

Data analysis. ECG recordings were replayed by a RACAL (Racal-Thermionic, Southampton, United Kingdom) Store 4 FM recorder and fed into a Nottingham fetal ECG analyzer as described in detail elsewhere $(6,10)$. In short, the analogue fetal ECG signal is digitized at a sampling rate of $500 \mathrm{~Hz}$., R-peaks are identified with a suitably matched software filter, and RR-interval is calculated. A window of 256 sample points is taken about the R-peak and presented for enhancement with a time-coherent filter. The enhanced waveform is updated by every new beat with a signal-to-noise ratio $>3: 1$. This enhanced waveform is measured at 2-second intervals with a linear line-fitting software routine and saved on hard disk for analysis.

Analysis of time interval features were restricted to $P R$ and $R R$ interval measurements. To enable the Nottingham fetal ECG analyzer to cope with the higher normal heart rate of fetal sheep, the replay speed was halved and the linear line-fitting routine adjusted to match the resultant fetal ECG waveforms. The stored 1 -second PR interval and FHR measurements were correlated with Pearson's correlation coefficient (Lotus 1-2-3 for Windows, version 5.0), on discrete consecutive blocks of 150 data points representing a total of 2.5 minutes.

The $r$-values of the baseline and occlusion period were subjected to statistical analysis. $r$ values with a significance of $p<0.01$, calculated with the critical value for a $99 \%$ confidence interval of the correlation coefficient for the degrees of freedom (150 data points: \pm 0.244$)(13)$, were classed as either positive or negative according to the vector regardless the strength of the correlation. A Fisher's exact test was performed on each case comparing the baseline period with the entire repetitive occlusion period.

Data representing blood gas analyses and hemodynamic parameters are presented as mean \pm SEM. Blood gas analyses and hemodynamic parameters between groups were compared by Mann-Whitney U Test and Friedman analysis within groups. A $p<0.05$ was considered statistically significant. 


\section{$P R$ interval - FHR relationship during asphyxia}

\section{Results}

Out of 7 fetuses, 2 died 5 to 10 minutes after the repetitive occlusion period ended (fetuses $A$ and B) following persistent bradycardia and hypotension. The results of the fetal blood gas analyses, measurement of fetal mean arterial pressure (MAP) during the baseline period and at the end of the occlusion period are depicted in table 1. The arterial blood sample at the end of the occlusion period was taken just before the last occlusion. The MAP at the end of the occlusion period represents the minimal MAP measured during the last occlusion. Repetitive umbilical cord occlusions resulted in mild to severe acidosis (median (range): pH: 7.07 (6.847.18); base deficit (mM): 11.9 (10.3-17.9)) and hypercapnia in three fetuses ( $A, B$ and $C$ ). The number of occlusions used varied between fetuses. Repetitive cord occlusion in fetuses $B$ and $\mathrm{C}$ were discontinued after 6 occlusions because of rapid fetal deterioration.

Table 1. Fetal blood gas analysis $\left(\mathrm{CaO}_{2}\right.$ : oxygen content $\left.(\mathrm{mM}) ; \mathrm{paCO}_{2}(\mathrm{kPa})\right)$, acid-base status ( $\mathrm{pH}$; BE: base excess (mM)) and mean arterial pressure (MAP(mmHg)) before (baseline), and at the end of the repetitive occlusion period for each individual fetus.

\begin{tabular}{|c|c|c|c|c|c|c|c|c|c|c|c|}
\hline \multirow[b]{2}{*}{ fetus } & \multicolumn{5}{|c|}{ baseline } & \multicolumn{5}{|c|}{ end of occlusion period } & \multirow[b]{2}{*}{ occlusions(n) } \\
\hline & $\mathrm{pH}$ & $\mathrm{paCO}_{2}$ & $\mathrm{CaO}_{2}$ & $\mathrm{BE}$ & MAP & $\mathrm{pH}$ & $\mathrm{paCO}_{2}$ & $\mathrm{CaO}_{2}$ & $\mathrm{BE}$ & MAP & \\
\hline$A$ & 7.35 & 6.02 & 1.55 & 0.1 & 34.28 & 7.03 & 9.63 & 0.39 & -11.9 & 10.48 & 18 \\
\hline B & 7.28 & 7.10 & 1.57 & -1.5 & 30.30 & 6.84 & 16.09 & 0.59 & -16.6 & 31.01 & 6 \\
\hline $\mathrm{C}$ & 7.29 & 5.78 & 3.59 & -4.6 & 34.60 & 7.10 & 8.28 & 2.82 & -11.3 & 39.93 & 6 \\
\hline $\mathrm{D}$ & 7.37 & 6.47 & 2.71 & 2.0 & 37.33 & 7.17 & 6.42 & 1.39 & -10.3 & 11.89 & 36 \\
\hline $\mathrm{E}$ & 7.33 & 5.83 & 2.86 & -2.1 & 28.68 & 7.07 & 6.93 & 2.42 & -15.1 & 10.88 & 42 \\
\hline $\mathbf{F}$ & 7.36 & 5.10 & 1.75 & -2.2 & 34.64 & 7.18 & 5.78 & 2.31 & -11.2 & 19.86 & 48 \\
\hline G & 7.35 & 5.97 & 2.09 & -0.3 & 31.65 & 7.08 & 5.95 & 1.49 & -17.9 & 8.85 & 38 \\
\hline
\end{tabular}

Repetitive cord occlusions resulted in prompt bradycardia which was sustained during the period of occlusion. After release of the cord occluder a rebound tachycardia occurred which resolved within the 3 minute recovery period. Fetal heart rate responses did not change over the umbilical cord occlusion period. The time course changes of the fetal mean arterial pressure during the repetitive occlusion period are depicted in figure 1 . Initially, fetal mean arterial pressure increased and remained elevated between occlusions resulting in sustained 


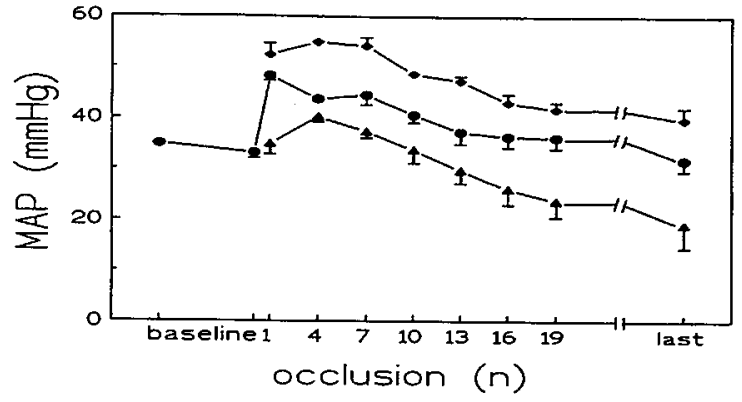

Figure 1. Time course of changes in maximal (diamonds) and minimal (triangles) MAP during occlusions, and MAP between occlusions (circles). Values are mean \pm SEM.
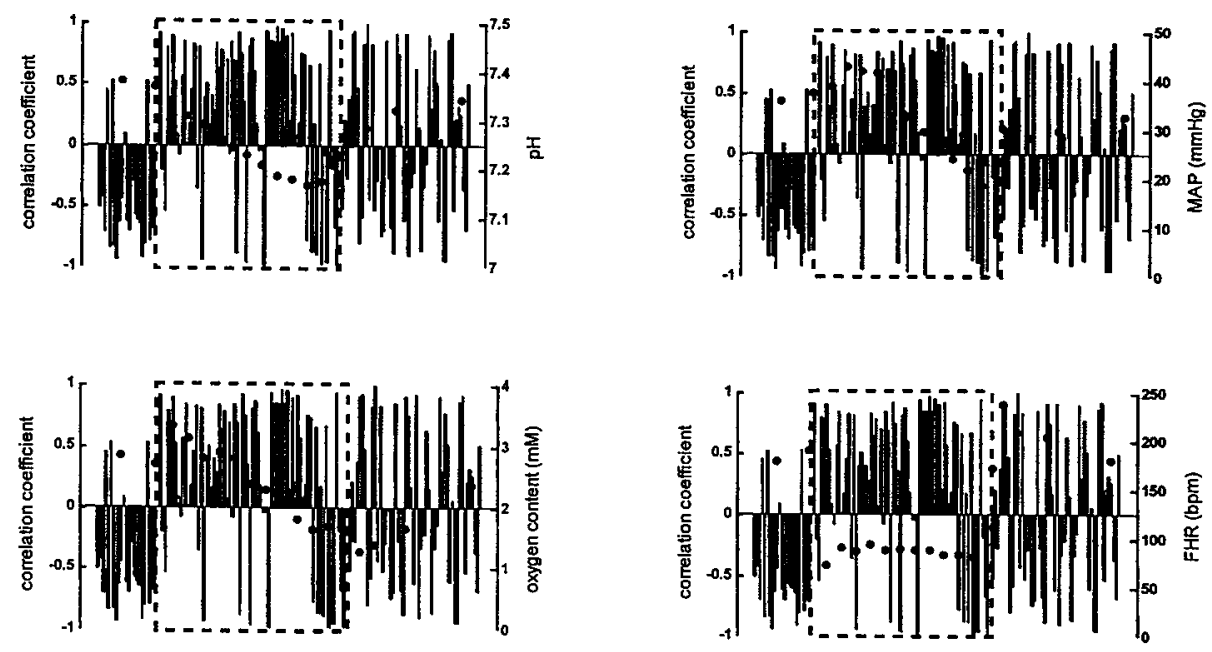

Figure 2. Characteristic example in which a statistically significant transition to a predominant positive PR interval-FHR relationship was seen. Graphs illustrate time course changes of 2.5 minute PR interval-FHR correlation coefficients (represented by bars) in relation to time course changes of respectively $\mathrm{pH}$, oxygen content, minimal fetal mean arterial pressure and minimal fetal heart rate during occlusions (represented by filled circles). The repetitive occlusion period is represented by the hatched box. 


\section{PR interva - FHR relationship during asphyxia}

hypertension. Gradually, a biphasic response developed with an initial increase and subsequent decrease in MAP during an occlusion, eventually resulting in repetitive periods of hypotension. Four fetuses showed a significant change from a negative PR-FHR correlation to a predominantly positive correlation between PR interval and FHR (fetus A-D). A typical example of temporal changes of the PR interval-FHR correlation coefficient in relation to changes in acid-base status, fetal blood pressure and heart rate is shown in figure 2 (fetus D). Initially, one fetus showed a similar shift to a positive PR interval-FHR correlation, which occurred immediately after the initiation of the repetitive cord occlusions (fetus E). However, after approximately 15 minutes, PR interval-FHR correlation returned negative and remained so throughout the repetitive occlusion period. One fetus demonstrated a positive PR intervalFHR correlation in the baseline period, which changed into a non-consistent PR interval-FHR correlation during the repetitive occlusion period (fetus F). In one fetus (fetus $\mathrm{G}$ ) no consistent PR interval-FHR correlation could be observed either during the baseline or repetitive occlusion period (fetus $\mathrm{G}$ ). In all fetuses with a predominant positive PR interval-FHR correlation after initiation of the repetitive cord occlusions (fetus A-E), PR interval-FHR correlation became positive within 7.5 minutes after the start of the occlusion period. After repetitive cord occlusions were discontinued, two fetuses ( $A$ and $C$ ) showed a persistence of positive $r$-values. In the remaining surviving fetuses $(D, E, F, G)$, no consistent $P R$ intervalFHR correlation was present in the post-occlusion recovery period.

\section{Comment}

The PR interval-FHR relationship, as a measure of cardiac conduction, is influenced by the autonomic nervous system. Both the vagal and sympathetic limb of this system have (in)direct influences on the sinoatrial and atrioventricular nodes. An increase in sympathetic activity has a positive chronotropic and dromotropic effect and increases atrioventricular conduction. An increase in vagal activity has the opposite effect. Atrioventricular conduction appears to be particularly sensitive to changes in sympathetic activity, whereas the sinus node is more responsive to vagal influences $(14,15)$. In addition, intracellular free calcium and adenosine are recognized as potent modulators of atrioventricular conduction under hypoxic conditions $(16,17)$. 
Under normoxic conditions a negative PR interval-FHR relationship is observed in the fetal subject. However, several experimental and clinical studies have shown that under hypoxemic circumstances PR interval and FHR may become positively related $(18,19)$. An explanation for this changing PR interval-FHR relationship is the oxygen-sensitive pacemaker cells in the sinoatrial node and the relative oxygen-insensitive cells in the atrio-ventricular node. Under hypoxemic conditions, the action potential of the sinoatrial pacemaker cells increases slowly, resulting in a decreased heart rate. The propagation of the action potential in the atrioventricular node, however, is less affected. Combined with an increase of sympathetic tone, as a result of an increased epinephrine plasma level, PR interval shortens and is now positively related with the decreasing FHR (20).

The change into a predominantly positive PR interval-FHR relationship in 4 out of 7 fetuses after initiation of the repetitive umbilical cord occlusion is consistent with our observations in mature fetuses (7). Morphological evidence of a well-developed cardiac conduction system at this early gestational age may further implicate a comparable response to prolonged asphyxia observed in older fetuses (21).

Although the hypoxemic conditions were induced repetitively, the PR interval-FHR relationship remained almost continuously positive during the repetitive occlusion period. The persistence of a positive PR interval-FHR relationship between occlusions is in agreement with the results of an experimental study which induced fetal hypoxia by occlusion of the maternal aorta for 1 minute (8). In that study, the PR interval-FHR relationship remained positive for approximately 3 minutes after release of the occluder. Furthermore, in mature fetuses a persistence of a positive PR interval-FHR relationship was observed during the recovery period after prolonged partial asphyxia (7). Apparently, disturbances in metabolic and hormonal conditions and changes in activity of the autonomic nervous system perpetuate their influence on the cardiac conduction system into the recovery phase. During repetitive cord occlusions, changes in fetal blood pressure and oxygenation of the fetus may have resulted in a potent vagal stimulation of the cardiac conduction system due to baro- and chemoreceptor activity respectively. However, it is unlikely that the reversal of the PR interval-FHR relationship is predominantly vagally mediated. An increased vagal input during occlusions would rather lengthen PR interval and decrease FHR, resulting in an inverse PR 
interval-FHR relationship. Moreover, chemically vagotomized mature fetuses persisted in their reversal of the normally negative PR interval-FHR relationship under hypoxic conditions (19).

On the other hand, the sympathetic limb of the autonomic nervous system seems to play an essential role in the reversal of the PR interval-FHR relationship. Especially the atrioventricular node appears to be sensitive to modulations in sympathetic activity (14). During hypoxia, immature fetuses respond with a less pronounced but significant increase in cathecholamines when compared to fetuses at late gestation $(10,22,23)$. An increase in plasma cathecholamines during occlusions will shorten the PR interval by decreasing the conduction time over the atrioventricular node. The persistence of the positive PR interval-FHR relationship between occlusions and after the repetitive occlusion period may be caused by sympathetic stimulation, evoked during the occlusions (24).

All fetuses demonstrating a transition to a positive PR interval-FHR relationship after initiation of repetitive cord occlusions showed a negative PR interval-FHR relationship during baseline, comparable with our observations in mature fetuses (7). Of the 2 remaining fetuses (fetus $F$ and $G$ ), one fetus demonstrated a predominant positive, the other no consistent $P R$ interval-FHR relationship during baseline recordings. Theoretically, this might indicate that fetal compromise was preexistent. Fetal blood gas analysis and cardiovascular parameters, however, did not show any sign of fetal compromise (table 1). During and after the repetitive occlusion period, a mixed relationship between PR interval and FHR was observed in both fetuses. Non-reversal to a predominantly negative PR interval-FHR relationship after cessation of the repetitive occlusions was also observed in the fetuses who showed a transition to a positive $\mathrm{PR}$ interval-FHR relationship during the repetitive occlusion period. In addition to the described metabolic deterioration and sympathetic activity, damage to the cardiac conduction system or abnormal cardiac performance may be responsible for this phenomenon. In the present study some, but not all immature fetuses showed a transition to a positive PRFHR relationship during fetal compromise. The exact reason why some fetuses do and others do not show this transition is not known. Therefore, with respect to the development of the autonomic control of the fetal circulation (25) and the paucity of knowledge of other mechanisms responsible for disturbances on fetal cardiac conduction, more experimental 
studies at this gestational age are needed to elucidate the pathophysiological mechanisms involved in the changing relationship of the PR interval and FHR during prolonged and intermittent fetal compromise. 


\section{References}

1. Bejar R, Wozniak P, Allard M, Bernischke K, Vaucher Y, Coen R, Berry C, Schragg $P$, Villegas I, Resnik R. Antenatal origin of neurologic damage in newborn infants. Am J Obstet Gynecol 1988;159:357-363.

2. Mann LI. Pregnancy events and brain damage. Am J Obstet Gynecol 1986;155:6-9.

3. Volpe $\mathrm{JJ}$. Brain injury in the premature infant - current concepts of pathogenesis and prevention. Biol Neonate 1992;62:231-242.

4. Macdonald D, Grant AM, Sheridan-Pereira M, Boylan P, Chalmers I. The Dublin randomized controlled trial of intrapartum fetal heart rate monitoring. Am J Obstet Gynecol 1985;152:524-39.

5. Grant AM, O'Brien N, Joy M-T, Hennesy E, MacDonald D. Cerebral palsy among children born during the Dublin randomised trial of intrapartum monitoring. Lancet $1989 ; 2: 1233-6$.

6. van Wijngaarden WJ, Sahota DS, James DK, Farrel T, Mires GJ, Wilcox M, et al. Improved intrapartum surveillance with PR interval analysis of the fetal electrocardiogram: a randomized trial showing a reduction in fetal blood sampling. Am J Obstet Gynecol 1996;174:1295-9.

7. van Wijngaarden WJ, de Haan HH, Sahota DS, James DK, Symonds EM, Hasaart THM. Changes in the PR interval-fetal heart rate relationship of the electrocardiogram during fetal compromise in chronically instrumented sheep. Am J Obstet Gynecol 1996;175:548-54.

8. Widmark C, Lindecrantz K, Murray H, Rosén K-G. Changes in the PR, RR intervals and ST waveform of the fetal lamb electrocardiogram with acute hypoxemia. J Dev Physiol 1992;18:99-103.

9. Widmark C, Hökegård K-H, Lagerkrantz H, Lilja H, Rosén K-G. Electrocardiographic waveform changes and cathecholamine responses during acute hypoxia in the immature and mature fetal lamb. Am J Obstet Gynecol 1989;160:1245-50.

10. Mohajer MP, Sahota DS, Reed NN, Chang A, Symonds EM, James DK. Cumulative changes in the fetal electrocardiogram and biochemical indices of fetal hypoxaemia. Eur J Obstet Gynecol Reproduc Biol 1994;55:63-70.

11. Westgate JA, Gunn AJ, Bennet L, Gunning MI, de Haan HH, Gluckman PD. Do fetal electrocardiogram PR-RR changes reflect progressive asphyxia after repeated umbilical cord occlusion in fetal sheep? Pediatr Res 1998;44:297-303. 
12. Keunen H, Blanco CE, Van Reempts JLH, Hasaart THM. Absence of neuronal damage after totoal umbilical cord occlusion of 10,15 and 20 minutes in midgestation fetal sheep. Am J Obstet Gynecol 1997;176:515-20.

13. Rohlf FJ, Sokal RR. Critical values for correlation coefficients. In: Rohlf FJ, editor. Statistical tables. 2nd ed. San Francisco: Freeman, 1981:166-8.

14. Urthaler F, Neely BH, Hageman GR, Smith LR. Differential sympatheticparasympathetic interactions in sinus node and AV junction. Am J Physiol 1986; $250: \mathrm{H} 43-51$.

15. Martin $P$. The influence of the parasympathetic nervous system on atrioventricular conduction. Circ Res 1977;41:593-599.

16. Clemo HF, Belardinelli L. Effect of adenosine on atrioventricular conduction. II: Modulation of atrioventricular node transmission by adenosine in hypoxic isolated guinea pig hearts. Circ Res 1986;59:437-446.

17. Anno T, Kodama I, Shibata S, Toyama J, Yamada K. Effects of calcium, calcium entry blockers and calmodulin inhibitors on atrioventricular conduction disturbances induced by hypoxia. Br J Pharmacol 1986;88:277-284.

18. Murray HG. The fetal electrocardiogram: current clinical developments in Nottingham. J Perinat Med 1986;14:399-404.

19. Murray HG. Evaluation of the fetal electrocardiogram (ECG) (thesis). Nottingham: University of Nottingham, 1992.

20. Noble D. The surprising heart: a review of recent progress in cardiac electrophysiology. J Physiol 1984;353:1-50.

21. Canale E, Smolich JJ, Campbell GR. Differentiation and innervation of the atrioventricular bundle and ventricular Purkinje system in sheep heart. Development 1987;100: 641-651.

22. Iwamoto HS, Stucky E, Roman CM. Effect of graded umbilical cord compression in fetal sheep at 0.6-0.7 gestation. Am J Physiol 1991;261:H1268-H1274.

23. Matsuda Y, Patrick J, Carmichael L, Challis J, Richardson B. Effects of sustained hypoxemia on the sheep fetus at midgestation: Endocrine, cardiovascular, and biophysical responses. Am J Obstet Gynecol 1992;167:531-40.

24. Salata JJ, Douglas PZ. Autonomic nervous system control of heart rate and atrioventricular nodal conduction. In: Zucker IH, Gilmore JP, eds. Reflex control of the circulation. Boston: CRC Press, Inc., 1991:68. 
$P R$ interval - FHR relationship during asphyxia

25. Nuwayhid B, Brinkman III CR, Su C, Bevan JA, Assali NS. Development of autonomic control of fetal circulation. Am J Physiol 1975;228:337-344. 


\section{Chapter 8}

Summary and discussion 


\section{Summasy and discussion}

The assumption that asphyxia during the perinatal period is the major cause of nonprogressive neurologic impairment such as cerebral palsy has recently been challenged. Epidemiological studies have shown that cerebral palsy, long thought to result mainly from intrapartum asphyxia, can be ascribed to such an event in only 8-10\% of cases. Therefore, the causative event must occur during fetal life at an earlier gestational age.

In chapter 1 asphyxia and cerebral palsy are defined in their clinical context. Several parameters of asphyxia are described and their individual and combined ability to predict cerebral palsy are discussed. Evidently, individually these parameters fail even to predict asphyxia, let alone the neurological outcome of the compromised fetus. The objectives of the present study is to seek new parameters of fetal asphyxia and brain damage in particular. This study comprises experimental setups in the chronically instrumented sheep fetus. The fetal sheep model proved in the past to be a useful experimental model to clarify several aspects of fetal pathophysiology during asphyxia. Regarding the high incidence of non-progressive neurologic impairment in immature human neonates, the objectives concern predominantly immature sheep fetuses.

In chapter 2 the pathophysiology of fetal asphyxia in general and the effect of asphyxia on the fetal brain and heart in particular is discussed. Compensatory mechanisms of the compromised fetus are outlined when subjected to obstruction of the umbilical circulation. Mechanisms by which hypoxic-ischemia results in fetal brain damage are summarized. Furthermore, the effect of fetal age on subsequent brain damage and specific factors of brain damage in the immature fetus are discussed.

The present study was conducted to study the effect of asphyxia, induced by umbilical cord occlusion, on the fetal heart and brain of immature fetuses in particular. Therefore, we used the chronic instrumented fetal sheep preparation in immature (chapters 3, 5,6 and 7) and mature sheep fetuses (chapter 4). Subsequently, fetuses were subjected to either a single total umbilical cord occlusion lasting to a maximum of 20 minutes (chapters 3 and 4 ) or short repetitive total umbilical cord occlusions (chapters 5,6 and 7). We studied the effects of asphyxia on cardiovascular parameters (chapters 3 and 5), histological outcome (chapters 3,4 and 6), production of nitric oxide (chapter 4), the fetal EEG (chapter 6) and ECG (chapter 7). For this purpose, surgery was performed on immature and mature fetuses. Under general 
anesthesia a midline abdominal incision was performed. The uterus was incised, and the fetus was partly exteriorized to allow access to the umbilical cord. A reversible cord occluder was placed around the umbilical cord. Further fetal instrumentation involved, depending on the effects to be studied, placement of catheters in the femoral and carotid artery, superior sagittal sinus, and amniotic cavity. Electrodes were placed bilaterally on the parietal cortex to measure fetal electrocorticogram, and implanted subcutaneously at the level of the cardiac apex and both forelimbs to record fetal electrocardiogram. All catheters were exteriorized through a small incision in the flank of the ewe. Following a recovery period of approximately three days, fetal asphyxia was induced by inflation of the balloon occluder around the umbilical cord. After a hypoxic-ischemic event it may take three days before histological brain damage becomes evident. Therefore, three days after the insult a relaparotomy was performed under general anesthesia. Subsequently, the fetal brain was preserved for histological examination through in situ perfusion fixation via the fetal heart and additional immersion fixation following removal of the fetal brain. Light microscopic examination was performed on three brain regions: parietal cortex, hippocampus and cerebellum.

In contrast to mature sheep fetuses, no neuronal damage was described following total umbilical cord occlusion of 10 minutes in immature fetal sheep. The question remained whether prolonging the duration of the occlusion would result in neuronal damage in immature fetal sheep. Therefore, we performed total umbilical cord occlusion of 10,15 or 20 minutes duration in chronically instrumented midgestation fetal sheep and evaluated histological neuronal damage three days after the insult (chapter 3). During the experiment, fetal blood.pressure (MAP) and heart rate were continuously recorded. Fetal blood gas analyses were performed at regular intervals before, during and after the occlusion. Total umbilical cord occlusion resulted in hypotension, bradycardia, severe mixed acidemia, hypoxia and hypercapnia. All fetuses survived the occlusion. No neuronal damage nor macroscopic intraventricular and/or germinal matrix hemorrhages were observed in either group. Prolonging the duration of total umbilical cord occlusion in midgestation fetal sheep resulted in an increase in the severity of asphyxia, not in neuronal damage.

Since nitric oxide (NO) was discovered as a novel neurotransmitter, vasodilatator and cytotoxic agent, several investigators studied its potential pathophysiological role in perinatal 


\section{Summary and discussion}

neuronal damage. So far, most studies were conducted in neonatal rat pups, i.e. in an ex utero environment. In utero, a surge of citrulline (a by-product of NO synthesis) was measured by microdialysis in the parasagittal cortex after 30 minutes global cerebral ischemia in a chronic fetal sheep preparation. However, in clinical asphyxia, the whole fetus rather than the brain alone is compromized. Therefore, experimental models with better resemblance to the pathophysiological circumstances of human fetal asphyxia are needed. For instance, in contrast to immature sheep fetuses, total umbilical cord occlusion is known to produce selective neuronal damage in the hippocampus in mature fetuses. To investigate the effect of total umbilical cord occlusion on cerebral arterio-venous difference for nitrite (a stable end product of nitric oxide) and neuronal outcome we occluded the umbilical cord totally for 10 minutes in 14 late gestation (gestational age 113-120 days) sheep fetuses. Arterial (carotid artery) and venous (superior sagittal sinus) blood samples were taken at regular intervals for determination of acid-base status, glucose, lactate and nitrite plasma levels. Three days after the occlusion period the fetal brain was perfusion fixed and the parietal cortex, hippocampus and cerebellum were scored for neuronal damage. Three fetuses died shortly after the occlusion period. Total umbilical cord occlusion resulted in a combined respiratory and metabolic acidosis as observed in carotid arterial blood gas samples, bradycardia and hypotension. Selective brain damage was observed in the hippocampus in 10 of the 11 surviving fetal sheep. No changes in arterial, venous and cerebral arterio-venous difference for nitrite plasma levels were observed. Total umbilical cord occlusion of 10 minutes in mature fetal sheep results in hippocampal damage but not in changes of cerebral arterio-venous difference for nitrite plasma levels, a stable end product of NO.

In clinical practice, peripartal asphyxic periods are often repetitive, e.g. during recurrent uterine contractions. The detrimental effects of repeated periods of fetal compromise differ both in quality and quantity compared to a single period of fetal asphyxia. Repeated brief periods of asphyxia or ischemia result in more extensive brain damage in different brain regions when compared with a single period of asphyxia. Furthermore, clinical and experimental studies suggest that fluctuations in arterial blood pressure combined with an insufficient autoregulation of cerebral blood flow can result in intracranial hemorrhages. Various experimental studies have shown that hemodynamic, metabolic, endocrinologic and 
neuropathologic consequences of intrauterine asphyxia may change with the maturity of the fetus. Therefore, we described the hemodynamic (chapter 5), electrocadiographic (chapter 7 ) electroencephalographic and neuropathologic (chapter 6) consequences of brief repeated umbilical cord occlusions in immature sheep fetuses.

We performed brief repeated total umbilical cord occlusions, 2 out of every 5 minutes, in 14 immature sheep fetuses (at 90 days of gestation), until fetal mean arterial pressure dropped below $50 \%$ of baseline value during 2 successive occlusions. Fetal blood gas analyses were performed at regular intervals just before cord occlusions. Progressive acidemia and hypotension developed with ongoing occlusions. After a transient hypertensive period during and between the first occlusions, a biphasic response developed during successive occlusions, characterized by an initial increase and subsequent decrease in fetal MAP eventually resulting in hypotension during an occlusion. The degree of hypotension during occlusions increased with ongoing occlusions. The minimum fetal arterial blood pressure during occlusions correlated well with the progressive acidemia. Six fetuses died at the end of the repetitive occlusion period. In the non-survivors, acidemia was more severe and $\mathrm{paCO}_{2}$ gradually increased during the entire repetitive occlusion period. In the survivors group, a period of transient hypoxia and hypotension was observed with a nadir 60 minutes following the final occlusion.

The CFAM is a system of integrated electroencephalogram which has been shown to be predictive of gestational age and the neurological status of the asphyxiated newborn. The use of CFAM as an on-line monitor might offer the possibility to detect critical changes in fetal cortical activity during asphyxia. CFAM parameters (mean amplitude distribution and bandwith in microvolts) were calculated by the computer. Two epochs of 10 minutes were used to calculate baseline CFAM values. CFAM parameters during occlusions were obtained at the first and last occlusion, and at the occlusion halfway the entire repetitive occlusion period (e.g. at the 12th occlusion when a total of 24 occlusions was used). At every time point one epoch of 3 minutes before and after an occlusion and an epoch during the 2-minute occlusion were processed. All CFAM parameters demonstrated a significant decrease during the entire repetitive occlusion period compared to baseline. Decrease of all CFAM parameters except CFAM width started during the first occlusion and remained depressed throughout the 


\section{Summary and discussion}

entire repetitive occlusion period. Of the surviving fetuses, all CFAM parameters recovered to baseline values at 2 hours after the final occlusion. Repetitive umbilical cord occlusion resulted in severe asphyxia and repetitive periods of hypotension. In comparison to mature fetuses subjected to a similar insult, neuronal damage was not observed. Furthermore, macroscopic inspection showed no evidence for intraventricular-germinal matrix hemorrhages (IVH-GMH). Although a decrease in CFAM parameters occurred, these changes in CFAM parameters were not predictive for neuronal damage nor the severity of fetal compromise in this experimental set-up.

The analysis of time constants (PR interval) of the fetal electrocardiogram (FECG) waveform may be useful for the detection fetal compromise during labor. Changes in PR interval-fetal heart rate relationship during fetal compromise are reported both in clinical and experimental studies. It has been suggested that fetal maturity significantly influences the FECG waveform morphology changes during acute hypoxia. It is not known whether fetal maturity influences the changes in the PR interval- fetal heart rate relationship during fetal compromise.To evaluate the relationship of the PR interval and fetal heart rate during repetitive umbilical cord occlusions in immature sheep fetuses. We analyzed continuous fetal electrocardiogram recordings during repetitive cord occlusions for 2 out of every 5 minutes in seven immature sheep fetuses until fetal mean arterial pressure dropped to $50 \%$ of baseline value. PR intervalfetal heart rate correlation coefficients (R-values) were measured on consecutive blocks of 2.5 minutes. Repetitive cord occlusions resulted in acidosis and hypotension. Two fetuses died at the end of the repetitive occlusion period. Four out of 7 fetuses showed a significant change from a negative relationship between the PR interval and fetal heart rate during baseline to a predominantly positive relationship during the repetitive occlusion period.

In summary, prolonging the duration of total umbilical cord occlusion in immature fetal sheep resulted in an increase in the severity of asphyxia, not in neuronal damage. In contrast, total umbilical cord occlusion of 10 minutes in mature sheep fetuses results in hippocampal damage but not in changes of cerebral arterio-venous difference for nitrite plasma levels, a stable end product of NO. Repetitive umbilical cord occlusions in immature sheep fetuses resulted in a transient hypertensive period during and between the first occlusions, followed by a biphasic response during successive occlusions, characterized by an initial increase and 
subsequent decrease in fetal MAP resulting in hypotension during an occlusion. The degree of hypotension during occlusions increased with ongoing occlusions. The minimum fetal arterial blood pressure during occlusions correlated well with the progressive acidemia. CFAM used as fetal electrocorticogram analysis demonstrated a significant decrease of CFAM parameters during the first occlusion which remained depressed throughout the entire repetitive occlusion period. In comparison to mature fetuses subjected to a similar insult, neuronal damage was not observed. Furthermore, macroscopic inspection showed no evidence for intraventriculargerminal matrix hemorrhages (IVH-GMH). Although a decrease in CFAM parameters occurred, these changes in CFAM parameters were not predictive for neuronal damage nor for the severity of fetal compromise. Fetal ECG analysis by means of measurements of the PRFHR interrelationship was inconclusive regarding the relation between the PR-FHR correlation coefficient, the onset of fetal compromise and subsequent degree of fetal asphyxia. The studies in this thesis failed to result in fetal brain damage in immature sheep fetuses despite severe fetal asphyxia induced by single or repetitive umbilical cord occlusions. The ontogenetic difference in the observed brain damage is probably multifactorial. The distribution of excitotoxic amino acids receptors, dependency on growth factors, susceptibility to free radical damage and apoptosis, metabolic demands, the acquisition of aerobic metabolism and the vascular responses all change during development. The focus of these studies was directed to short-term histological evidence of neuronal damage three days after the insult. When immature fetal sheep were subjected to a reduction of fetal arterial oxygen content by approximately $50 \%$ for 6 to 12 hours, histological analysis revealed retarded neuronal migration and the growth of neural processes in the hippocampus one week after the insult. However the effect of the asphyxic events implied in this thesis on the development and differentiation of the immature brain is not known. Recently, it has been proposed that hypoxia-ischemia is $a$, not the pathophysiological mechanism of non-progressive neurological impairment. Specifically, epidemiologic studies have demonstrated an association between infection, preterm labor and periventricular leucomalacia. In addition, experimental studies propose a prominent role of cytokines such as TNF- $\alpha$ and interleukins as mediators of brain injury. Future research should be directed upon the pathophysiological mechanisms by which these cytokines may act. Combined with more classic paradigms measuring the hemodynamic 


\section{Summary and discussion}

responses, these scientific endeavours may lead us to a higher level of understanding why some brains of premature infants become injured and others do not. 


\section{Hoofdstuk 8}

Samenvatting en discussie 


\section{Sameavatting ea discussie}

De veronderstelling dat asfyxie tijdens de bevalling de voornaamste oorzaak is van cerebrale parese is sedert kort aan discussie onderhevig. Recente epidemiologische studies wijten cerebrale parese slechts in $8-10 \%$ van de gevallen aan asfyxie tijdens de bevalling. Een asfyctische periode eerder in de zwangerschap lijkt daarom een plausibel alternatief voor de pathogenese van cerebrale parese.

In hoofdstuk 1 worden de begrippen asfyxie en cerebrale parese gedefiniëerd in hun klinische context. Meerdere asfyxie parameters worden beschreven met de nadruk op hun individuele en gezamelijk voorspellend vermogen t.a.v. het optreden van cerebrale parese. Hieruit blijkt dat deze parameters tekort schieten in hun vermogen om zowel het optreden van asfyxie als cerebrale parese te voorspellen.

Het doel van dit proefschrift is nieuwe parameters van asfyxie en de daaruit resulterende hersenschade te onderzoeken. Hiertoe werd gebruik gemaakt van chronisch geïnstrumenteerde foetale lammeren. Het chronisch foetaal schaapmodel is een internationaal bekend en gangbaar model waarmee in het verleden meerdere experimentele studies betreffende de foetale (patho)fysiologie zijn beschreven. Gezien de hoge incidentie van cerebrale parese bij immature/premature humane pasgeborenen, richt deze studie zich voornamelijk op immature foetale lammeren.

In hoofdstuk 2 wordt de pathofysiologie van foetale asfyxie in het algemeen, en het effect van asfyxie op het foetale hart en brein besproken. Vervolgens worden de compensatiemechanismen van de foetus in reactie op een obstructie van de umbilicale circulatie beschreven. Tot slot volgen de pathofysiologische mechanismen waarmee een hypoxisch-ischaemisch event resulteert in foetale hersenschade, het effect van de maturiteit van de foetus hierop en de specifieke factoren welke hierbij een rol spelen bij de immature foetus.

Deze studie werd verricht om de effecten van asfyxie, teweeggebracht door middel van complete navelstrengcompressies, op het foetale brein en hart bij met name immature foetale lammeren te bestuderen. Derhalve maakten we gebruik van het chronisch foetale schaapmodel met immature (hoofdstukken 3,5,6 en 7) en mature (hoofdstuk 4) foetale lammeren. De foetus werd blootgesteld aan een éénmalige complete navelstrengocclusie van 10 tot maximaal 20 minuten (hoofdstukken 3 en 4), of aan korte, repetitieve complete navelstrengocclusies met 
ieder een duur van 2 minuten (hoofdstukken 5,6 en 7). We bestudeerden het effect van asfyxie op cardiovasculaire parameters (hoofdstukken 3 en 5), histologische aanwijzingen voor foetale hersenschade (hoofdstukken 3,4 en 6), de vorming van stikstofmonoxide (hoofdstuk 4), het foetale EEG (hoofdstuk 6) en ECG (hoofdstuk 7). Hiertoe werden zwangere schapen bij een zwangerschapsduur van 90 dagen (voldragen bij een zwangerschapsduur van 145 dagen) op de volgende wijze geïnstrumenteerd.

Onder algehele anaesthesie werd in de mediaanlijn de onderbuik geïncideerd. De baarmoeder werd geopend en vervolgens werd de foetus ten dele geëxtraheerd. Een opblaasbare ringballon werd om de navelstreng geplaatst. Afhankelijk van de studie werden de volgende instrumentaties hieraan toegevoegd. Catheters werden geplaatst in de beenslagader, beenader, halsslagader, sinus saggitalis superior, en amnionholte. Electroden werden bilateraal geplaatst ter hoogte van de parietale cortex voor de registratie van het electrocorticogram, en tevens subcutaan geïmplanteerd ter hoogte van de hartpunt en beide voorpoten voor de registratie van het foetale electrocardiogram (FECG). De foetus werd vervolgens teruggeplaatst in de uterus, de uterus werd gesloten waarna alle catheters en electroden, via een opening in de flank van het moederdier, naar buiten werden geleid. Na het sluiten van de maternale buikwand volgde een herstelperiode van drie dagen. Hierna werd het experiment gestart waarin de foetus werd blootgesteld aan asfyxie door middel van het vullen van de ringballon met een tijdens de operatie vastgestelde hoeveelheid fysiologische zoutoplossing om dusdanig een complete occlusie van de navelstreng te bewerkstelligen. $\mathrm{Na}$ de asfyctische periode volgde wederom een herstelperiode van drie dagen. Uit voorgaande studies bij foetale lammeren bleek een herstelperiode van drie dagen na een hypoxisch-ischaemisch event noodzakelijk om histologisch aantoonbare hersenschade te detecteren. Na de herstelperiode van drie dagen werd onder algehele anaesthesie nogmaals de foetus geëxtraheerd en via de linker hartkamer het foetale brein in situ gefixeerd. Na aanvullende immersiefixatie werd het foetale brein aangeboden voor histologisch onderzoek. Histologisch onderzoek werd verricht op drie hersengebieden: de pariëtale cortex, de hippocampus en de kleine hersenen.

Uit recent onderzoek blijkt dat in tegenstelling tot mature foetale lammeren er geen hersenschade optreedt bij immature foetale lammeren na tien minuten navelstrengocclusie. Onbekend bleef of, en zo ja wanneer er hersenschade optreedt bij immature foetale lammeren 


\section{Samenvatting en discussie}

indien de duur van de navelstrengocclusie wordt verlengd. Daarom occludeerdeu wij de navelstreng bij immature foetale lammeren gedurende 10,15 en 20 minuten en verrichtten drie dagen na het asfyctisch event histologisch onderzoek van de foetale hersenen (hoofdstuk 3). Tijdens het experiment werden de foetale bloeddruk en hartfrequentie continu gemeten. Met regelmatige tijdsintervallen werd zowel vóór, tijjens als na de navelstrengocclusie een foetale bloedgasanalyse verricht. Complete navelstrengocclusie resulteerde in hypotensie, bradycardie, ernstige acidemie, hypoxie en hypercapnie. Alle foetale lammeren overleefden de navelstrengocclusie. De occlusies resulteerden niet in hersenschade of intra-/periventriculaire bloedingen hetzij na 10, 15 of 20 minuten complete navelstrengocclusie. Samengevat resulteerde de verlenging van de duur van de occlusie wel in een toename van de ernst van de asfyxie echter niet in het optreden van hersenschade.

Recent werd stikstofmonoxide (NO) ontdekt als zijnde een endotheel afhankelijke vaatverwijder, neurotransmitter en cytotoxische stof. Sindsdien hebben meerdere onderzoekers de mogelijke rol van NO in de pathofysiologie van perinatale hersenschade onderzocht. Tot dusver werden de meeste van deze experimenten verricht met rattenpups, dat wil zeggen in een ex utero omgeving. In utero werd in het verleden bij mature foetale lammeren met behulp van microdialyse electroden in de pariëtale hersenschors een toename van citrulline (een bijproduct van NO synthese) gemeten na 30 minuten cerebrale ischaemie. Echter, in geval van asfyxie beperkt de hypoxie-ischaemie zich niet alleen tot de hersenen. Reeds eerder werd een selectieve hersenschade van de hippocampus beschreven na asfyxie in de vorm van 10 minuten complete navelstrengocclusie bij mature foetale lammeren. Wij onderzochten het effect van een gelijksoortige navelstrengocclusie op het cerebrale arterioveneuze verschil in nitrietconcentratie (een stabiel eindproduct van $\mathrm{NO}$ ) en histologische hersenschade bij 14 mature foetale lammeren (zwangerschapsduur 113-120 dagen, voldragen bij 145 dagen).

Hiertoe werden met regelmatige tussenpozen bloedmonsters afgenomen uit de halsslagader (arterieel) en de sinus sagittalis superior (veneuze afvloed van de hersenen). Naast nitriet werden hierin ook de concentraties bepaalt van glucose en lactaat.Tevens werd het zuur-base evenwicht onderzocht. Drie dagen na de navelstrengocclusie werden de foetale hersenen gefixeerd waarna histologisch onderzoek werd verricht naar het voorkomen van schade van de 
zenuwcellen in de hersenschors, hippocampus en de kleine hersenen. Drie foetale lammeren overleden kort na de navelstrengocclusie. De complete navelstrengocclusie resulteerde in een gemengde respiratoire en metabole acidose, bradycardie en hypotensie. In 10 van de 11 overlevende foetale lammeren werd een selectieve hersenschade in de hippocampus vastgesteld. Er konden echter geen cerebrale arterio-veneuze verschillen in nitrietconcentratie worden gemeten.

In de klinische praktijk treedt asphyxie vaak op in de vorm van korte, repeterende episoden van foetale nood gedurende de contracties van de baarmoeder. De schadelijke gevolgen van korte, repeterende perioden in vergelijking tot een éénmalige lange periode van foetale nood verschillen zowel in kwantitatiet als kwaliteit. Korte, repetitieve perioden van cerebrale ischaemie resulteert bijvoorbeeld in meer hersenschade in andere hersengebieden. De hierbij beschreven bloeddrukfluctuaties kunnen, gevoegd bij een insufficiënte autoregulatie van de bloeddoorstroming naar de hersenen, leiden tot hersenbloedingen. Voorts hebben experimentele studies ons getoond dat de hemodynamische, metabole, endocrinologische en neuropathologische gevolgen van intrauteriene asfyxie onder andere afhangen van de maturiteit van de foetus tijdens de asfyctische periode.

Derhalve beschrijven wij in dit proefschrift de hemodynamische (hoofdstuk 5), electrocardiografische (hoofdstuk 7) en electroencefalografische cq. neuropathologische (hoofdstuk 6) gevolgen van korte, repetitieve occlusies van de navelstreng bij immature foetale lammeren.

Wij verrichtten bij 14 immature foetale lammeren (zwangerschapsduur 90 dagen, voldragen bij 145 dagen) korte, repetitieve navelstrengocclusies van 2 minuten gevolgd door 3 minuten rust. De repetitieve navelstrengocclusies werden gecontinueerd totdat de gemiddelde foetale bloeddruk daalde tot minder dan 50\% van de uitgangswaarde gedurende minimaal twee opeenvolgende navelstrengocclusies. Met regelmatige tussenpozen werden metingen verricht van de foetale bloedgassen en het zuur-base evenwicht. Met het voortschrijden van de navelstrengocclusies werden de foetale lammeren in toenemende mate acidaemisch en hypotensief. $\mathrm{Na}$ een initiële hypertensieve periode tijdens en tussen de eerste navelstrengocclusies ontstond een bifasische respons in de daaropvolgende occlusies. Deze respons bestond uit een aanvankelijke stijging gevolgd door een daling van de gemiddelde 


\section{Sameavatting ea discussie}

foetale bloeddruk tijdens een navelstrengocclusie, uiteindelijk resulterend in hypotensie. De mate van hypotensie tijdens de occlusie nam toe met de voorschrijdende navelstrengocclusies en correleerde goed met de mate van acidaemie. Zes foetale lammeren overleden aan of kort na het einde van de gehele repetitieve occlusieperiode. In deze overleden foetale lammeren bleek de acidaemie ernstiger en werd een gestage toename van de $\mathrm{p}_{\mathrm{a}} \mathrm{CO}_{2}$ gedurende de gehele repetitieve occlusieperiode gemeten. In de overlevenden foetale lammeren werd een voorbijgaande periode van hypotensie en hypoxie waargenomen in de herstelperiode na de laatste navelstreng occlusie. De mate van hypotensie en hypoxie bereikte z'n dieptepunt 1 uur na de laatste occlusie.

De Cerebral Function Analysing Monitor (CFAM) is een systeem van een geïntegreerd electroencefalogram. In de klinische praktijk blijkt dat de metingen die met dit systeem worden verricht een goede weergave zijn van de neurologische toestand van een pasgeborene in geval van asfyxie. Het toepassen van CFAM tijdens de bevalling zou een mogelijkheid kunnen zijn om kritieke veranderingen van de hersenschorsactiviteit reeds bij de asfyctische foetus te detecteren. Hiertoe werden immature foetale lammeren blootgesteld aan repetitieve navelstrengocclusies zoals reeds eerder beschreven. Voorts werden de lammeren uitgerust met electroden welke geplaatst werden op de pariëtale hersenschors. Het dusdanig verkregen electrocorticografisch signaal werd off-line omgezet naar een CFAM signaal waaruit de volgende CFAM parameters werden gedestilleerd: amplitude verdeling en bandbreedte in microvolts.

Twee episoden van 10 minuten werden gebruikt om CFAM uitgangswaarden te meten. Verder werden CFAM parameters tijdens de eerste, laatste en middeiste (bijvoorbeeld de twaalfde occlusie bij in totaal 24 occlusies) navelstrengocclusie gemeten. Voor CFAM metingen tijdens occlusies werden CFAM parameters berekend gedurende de twee minuten durende occlusie en tevens gedurende een tijdsperiode van drie minuten zowel juist voor als na de desbetreffende occlusie. Alle CFAM parameters toonde een significante daling ten opzichte van de uitgangswaarden. De daling van de CFAM parameters trad reeds op tijdens de eerste occlusie. Een verdere daling van de CFAM parameters tijdens de gehele occlusieperiode werd niet waargenomen. Alle CFAM parameters herstelden tot het niveau van de uitgangswaarden binnen twee uur na de laatste occlusie in de overlevende foetale lammeren. Drie dagen na de 
repetitieve occlusieperiode werden geen aanwijzingen voor schade aan zenuwcellen of hersenbloedingen gevonden met behulp van histologisch onderzoek.

De analyse van de tijdconstanten (PR interval) van het foetale electrocardiogram signaal (FECG, bestaande uit P Q R S en T-toppen) is mogelijk nuttig voor het opsporen van foetale nood tijdens de bevalling. Zowel klinische als experimentele studies wijzen op veranderingen in de verhouding tussen het PR interval van de foetale hartfrequentie (FHR). Voorts wordt in experimentele studies gesuggereerd dat de mate van maturiteit van de foetus de veranderingen van het FECG signaal tijdens foetale hypoxie beïnvloedt. Het is onbekend welke de invloed is van de maturiteit van de foetus op de verhouding tussen PR interval en de foetale hartfrequentie tijdens asfyxie. Hiertoe werden zeven immature foetale lammmeren uitgerust met onderhuids geplaatste FECG electroden en vervolgens blootgesteld aan het hierboven beschreven repetitieve navelstrengocclusie regime. PR interval-FHR correlatiecoëfficiënten werden gemeten over aanéénsluitende tijdsperioden van 2,5 minuten gedurende het gehele experiment. Twee foetus overleden aan het eind van de gehele repetitieve occlusieperiode. Bij vier van de zeven foetale lammeren veranderde de negatieve correlatie tussen $P R$ interval en FHR gemeten vóór de repetitieve navelstrengocclusieperiode in een positieve correlatie tijdens de gehele occlusieperiode.

Samenvattend resulteerde het verlengen van de navelstrengocclusieperiode van tien naar twintig minuten bij immature foetale lammeren in een toename van de asfyxie echter niet in schade van de zenuwcellen. Tien minuten navelstrengocclusie bij mature foetale lammeren resulteerde nochtans in selectieve schade in de hippocampus maar niet in cerebrale arterioveneuze verschillen in nitrietconcentratie, een stabiel eindproduct van stikstofmonoxide (NO). Repetitieve navelstrengocclusies bij immature foetale lammeren leidden tot een voorbijgaande hypertensieve periode tijdens en tussen de eerste occlusies, gevolgd door een bifasische respons in de daaropvolgende occlusies bestaande uit een initiële stijging gevolgd door een daling van de gemiddelde foetale bloeddruk tijdens een navelstrengocclusie, resulterend in repetitief hypotensieve perioden. De mate van hypotensie tijdens de occlusie nam toe met de voortschrijdende navelstrengocclusies en correleerde goed met de mate van acidaemie. Analyse van het foetale electroencefalogram door middel van CFAM toonde een daling van de CFAM parameters tijdens de eerste occlusie. Een verdere daling van de CFAM parameters 


\section{Samenvatting en discussie}

tijdens de gehele occlusieperiode werd niet waargenomen. Na histologisch onderzoek werden noch neuronale schade noch hersenbloedingen waargenomen. Analyse van het FECG door middel van de PR interval-FHR correlatiecoëfficiënt bracht geen verband aan het licht tussen veranderingen in de PR interval-FHR correlatiecoëfficiënt en het optreden van en mate van foetale nood.

De experimentele studies in dit proefschrift verricht bij immature foetale lammeren slaagden er niet in hersenschade te induceren ondanks ernstige asfyxie na een langdurige éénmalige of korte repetitieve navelstrengocclusies. Het ontogenetisch verschil ten opzichte van de mature foetale lammeren is waarschijnlijk van meerdere factoren afhankelijk. De distributie van excitotoxische aminozuurreceptoren, afhankelijkheid van groeifactoren, vatbaarheid voor schade ten gevolge van zuurstofradicalen en apoptose, metabole behoefte en de autonome regulatie van het cardiovasculair systeem veranderen tijdens de ontwikkeling van de foetus.

De experimentele studies in dit proefschrift waren gericht op korte termijn histologische veranderingen na een asfyctische periode, drie dagen na de navelstrengocclusie(s). Andere studies onderwierpen immature foetale lammere aan chronische hypoxie hetgeen resulteerde in een vertraagde neuronale migratie en groei van neurale processen in de hippocampus één week na de hypoxische periode. De effecten van de navelstrengocclusies in dit proefschrift op de ontwikkeling en differentiatie van het foetale brein is niet bekend.

Recent is geopperd dat hypoxie-ischaemie slechts één maar niet hét pathofysiologisch mechanisme is welke ten grondslag ligt aan het fenomeen cerebrale parese. Met name epidemiologische studies brengen een verband aan het licht tussen het optreden van een intrauterien infect, vroeggeboorte en periventriculaire leucomalacie. Bovendien wijzen in vitro en in vivo experimentele studies op de prominente rol van cytokines als mediatoren van hersenschade. Geïmplementeerd in een klassieke experimentele opstelling zoals beschreven in dit proefschrift kan deze nieuwe kennis ons inzicht en begrip vergroten ten aanzien van de vraag waarom sommige te vroeg geboren pasgeborenen hersenschade hebben opgelopen en andere niet. 


\section{Curriculum Vitae}

27 december 1965

$1972-1978$

$1978-1979$

$1979-1984$

$1984-1985$

$1985-1993$

1989

$1989-1990$

1993

$1993-1997$
Geboren te Tegelen

Lagere school te Rheindahlen (D.) en Maasbree

Brugklas Bouwens van der Boye College Panningen

VWO-B St.Thomas College Venlo

Propaedeuse Voeding Landbouw Hogeschool Wageningen, Medische Biologie Rijksuniversiteit Utrecht

Studie Geneeskunde Rijksuniversiteit Limburg Maastricht

Doctoraal examen

Full-time researchmedewerker afdeling Neonatologie, Academisch Ziekenhuis Maastricht

Artsexamen, Rijksuniversiteit Limburg Maastricht Assistent Geneeskundige Niet in Opleiding Kindergeneeskunde, Academisch Ziekenhuis Maastricht

Arts-onderzoeker afdeling Gynaecologie \& Obstetrie, Academisch Ziekenhuis Maastricht 
Research Fellow Onderzoekscentrum voor

Ontwikkelingsgeneeskunde \& Biologie,

Universiteit van Auckland, Nieuw-Zeeland

$1998-1999$

Assistent Geneeskundige Niet in Opleiding

Gynaecologie \& Obstetrie, Elkerliek Ziekenhuis Helmond

2000 - heden

Assistent Geneeskundige in Opleiding

Gynaecologie \& Obstetrie, Academisch Ziekenhuis Maastricht, opleider Prof. dr. J.L.H. Evers 


\section{Dankwoord}

Het is eindelijk zo ver. Vele wegen leiden naar Rome en dit proefschrift heeft ze vrijwel allemaal bewandeld. Op deze lange tocht hebben velen een stukje meegelopen en anderen hebben de hele rit uitgezeten. Enkele van mijn reisgenoten wil ik met name noemen. Als eerste dr.T.H.M. Hasaart, beste Tom. Als co-promotor plukte je me bijna van het vliegtuig naar Curaçao. Zo'n dromer als promovendus zal niet altijd gemakkelijk geweest zijn. Gelukkig leidde je me weer naar het recht pad als ik weer voor de zoveelste keer een zijweg insloeg. Intussen is onze samenwerking ook op het klinische vlak een feit. Ik leer er iedere dag weer bij.

Prof. dr. Jelte de Haan, promotor. Dankzij U promoveren er nog bijna jaarlijks artsassistenten gynaecologie in Maastricht. Onder Uw toeziend oog liet $U$ mij m'n eigen weg en waarheid zoeken, een onvergetelijke les waarvoor dank.

Prof. dr. C.E. Blanco, beste Carlos. Inspirator van het eerste uur. Je introduceerde me tijdens mijn studie aan het chronisch foetaal schaapmodel. De literatuurbesprekingen met klassieke klanken op de achtergrond waren onvergetelijk. Irene Kuijpers, het is inderdaad fantastisch, bedankt. Dr. L.L.H. Peeters, beste Louis. Ik was dan wel niet je AIO maar je enthousiasme tijdens de researchbesprekingen en daarbuiten hebben me geïnspireerd.

Alle operaties en experimenten werden uitgevoerd onder deskundige begeleiding en fijne samenwerking binnen de Centrale Proefdier Voorziening van de Universiteit Maastricht. Meer dan tien jaar geleden maakte ik als pril studentje reeds kennis met Joyce Suyck en May Bost. Voor het eerst steriel staan en een buik sluiten. Schapen opereren bleek een hele kunst. Bedankt voor de leerschool en vriendschap. De goede verzorging van 'mijn dames' werd gegeven door Frans Slangen en Huub Simons. Inger Simons was mijn steun en toeverlaat bij operaties en experimenten in de eerste jaren.

In België, Jos Van Reempts en Marc Haseldonckx. De autoritten naar Beerse waren niet voor niets. Bedankt voor het nauwgezette verwerking en beoordeling van de foetale hersenen, het corrigeren van de artikelen en de altijd hartelijke ontvangst. 
Jan Geilen zorgde dat de electronen, bits en bytes de goede kant opstroomden. Peter Willems repareerde voor de zoveelste keer de bloedgasmachine.

In Engeland, dr. Willem van Wijngaarden en Daljit Sahota. Die paar weken in Nottingham bleken productief. Zonder jullie waren de PR-FHR metingen niet van de grond gekomen. Het PERIM: Brigitte Slangen, kamergenote sinds mensenheugenis, na onderzoeksmaatje nu ook AGIO-collega. Bedankt voor je vriendschap en begrip als ik de computer weer eens molesteerde. Carla Verkeste, PERIM-moeder en het luisterend oor als het niet mee zat. Jolanda, Marc, Eric, Tryphon bedankt voor de gezelligheid, discussies en de plezierige congresbezoeken. Harm de Haan ging mij voor en droeg door zijn morele en bemoedigende ondersteuning veel bij aan de totstandkoming van dit proefschrift.

Dr. Nicolaas Deutz van de vakgroep Algemene Heelkunde Universiteit Maastricht en diens medewerkers in zijn laboratorium. Bedankt voor de nauwgezette nitriet analyses en het actief meedenken. Prof. dr. H. Vles van de afdeling Neurologie, Jos Reulen en Diane van Mierlo van de afdeling klinische Neurofysiologie inroduceerden mij in de CFAM technologie. De medewerkers van de vakgroep Neuropsychologie. Het 'intermezzo' belandde uiteindelijk niet in dit proefschrift. Desalniettemin bedankt voor de inspiratie om steeds weer nieuwe vragen te bedenken.

De gynaecologen Joke Haartsen, Jan van der Avoort, Antoine van Vijfeijken en Arthur van de Walle, alle verpleegkundigen, secretariaat en medewerksters op de polikliniek in het Elkerliek ziekenhuis te Helmond/Deurne. Ik draag jullie allen een zeer warm hart toe. Bedankt voor de onvergetelijke ervaring bij mijn herintroductie in de kliniek. Alle medewerkers van de afdeling Gynaecologie en Obstetrie in het Academisch Ziekenhuis te Maastricht. Weer terug op het nest en ik voelde me meteen thuis, mijn dank hiervoor.

Mijn paranymfen, Ralph Hermans en Marc Senden. Ralph, misschien over enkele jaren mijn baas maar vooraleerst mijn vriend. Al vijftien jaar geef je mij op gezette tijden een zetje in de goede richting. Ik ben er trots op dat juist jij nu achter me staat. Marc, samen in de eerste onderwijsgroep en sindsdien onafscheidelijk. Jij mag dan ook op deze dag niet ontbreken.

Tenslotte mijn ouders Door en Pierre en zus Lon. Ik kom uit een warm nest en jullie zorgden daarvoor. Jullie onvoorwaardelijke liefde en steun hielpen me de zoveelste hindernis te overwinnen. Ik hou van jullie. 